\title{
Innovation strategies and their implications for technological change and market outcomes
}

Citation for published version (APA):

Cevikarslan, S. (2019). Innovation strategies and their implications for technological change and market outcomes: an evolutionary multi-agent based modelling approach. [Doctoral Thesis, Maastricht University]. Boekenplan. https://doi.org/10.26481/dis.20190313sc

Document status and date:

Published: 01/01/2019

DOI:

10.26481/dis.20190313sc

Document Version:

Publisher's PDF, also known as Version of record

\section{Please check the document version of this publication:}

- A submitted manuscript is the version of the article upon submission and before peer-review. There can be important differences between the submitted version and the official published version of record.

People interested in the research are advised to contact the author for the final version of the publication, or visit the DOI to the publisher's website.

- The final author version and the galley proof are versions of the publication after peer review.

- The final published version features the final layout of the paper including the volume, issue and page numbers.

Link to publication

\footnotetext{
General rights rights.

- You may freely distribute the URL identifying the publication in the public portal. please follow below link for the End User Agreement:

www.umlib.nl/taverne-license

Take down policy

If you believe that this document breaches copyright please contact us at:

repository@maastrichtuniversity.nl

providing details and we will investigate your claim.
}

Copyright and moral rights for the publications made accessible in the public portal are retained by the authors and/or other copyright owners and it is a condition of accessing publications that users recognise and abide by the legal requirements associated with these

- Users may download and print one copy of any publication from the public portal for the purpose of private study or research.

- You may not further distribute the material or use it for any profit-making activity or commercial gain

If the publication is distributed under the terms of Article $25 \mathrm{fa}$ of the Dutch Copyright Act, indicated by the "Taverne" license above, 
Innovation Strategies and Their Implications for Technological Change and Market Outcomes:

An Evolutionary Multi-Agent Based Modelling Approach 
(c) Salih Çevikarslan, 2019

\title{
ISBN 9789086664740
}

Publisher: Boekenplan, Maastricht

\section{Cover photo: Nazlıhan Uğur}

\begin{abstract}
All rights reserved. No part of this dissertation may be reproduced, stored in a retrieval system or transmitted in any form, or by any means, electronic, mechanical, photocopying, recording, or otherwise, without the prior permission in writing from the author.
\end{abstract}




\section{Innovation Strategies and Their Implications for Technological Change and Market Outcomes: An Evolutionary Multi-Agent Based Modelling Approach}

\section{DISSERTATION}

to obtain the degree of Doctor at Maastricht University, on the authority of the Rector Magnificus, Prof. Dr. Rianne

M. Letschert

in accordance with the decision of the Board of Deans, to be defended in public

on Wednesday 13 March 2019, at 12:00 hours

by

Salih Çevikarslan 
Supervisor

Prof. Dr. Bart Verspagen

\author{
Assessment Committee \\ Prof. Dr. Robin Cowan (chair) \\ Prof. Dr. Murat Yıldızoğlu, Bordeaux University, France \\ Dr. Marco Valente, University of L'Aquila, Italy \\ Dr. Tania G. Treibich
}




\section{Acknowledgements}

I lived my PhD years in Tilburg with the Turkish PhD community: Ata Can Bertay, Ayşe Gül Mermer, Bilge Çelik, Bilge Karataş, Boran Ekin Aydın, Burak Uras, Erdal Aydın, Fatih Cemil Özbuğday, Haki Pamuk, Korhan Nazlıben, Sami Umut Can, Serhan Sadıkoğlu, Suphi Şen, and Tunga Kantarcı. Our house was the main hub for many gatherings of dinners, parties, festive days, basketball game watching and several others for all these years. I collected lots of fond memories with my friends that I will always remember.

My thesis supervisor Bart Verspagen has been an idealization of a professor for me. I had the exclusive opportunity to observe his openmindedness, humility, patience and scientific curiosity among many other humanitarian merits first-hand during our hour long discussions. $\mathrm{He}$ generously shared his time, immense knowledge and experience with me. I feel privileged and heavily indebted to him for the opportunity to work under his guidance and benefit from his wisdom in writing this dissertation.

I would like to thank the assessment committee members Robin Cowan, Murat Yıldızoğlu, Marco Valente and Tania G. Treibich who gave me some fruitful comments to finalize the thesis.

I want to thank Marco Valente once again, the creator of Laboratory for Simulation Development, the simulation platform I used for the agent-based models in this thesis. He was always helpful and patient with his e-mails saving me whenever I got stuck with crashing simulations.

After some point in time, you start to care about and seek for the feeling of belonging. This is exactly what I have found recently at Erasmus University College and the University of Twente. I would like to thank my 
employers Christa van Wijnbergen and Jörg Henseler for this and their support in the completion of this dissertation.

I would like to address my thanks to my professors at Istanbul Technical University, Hacer Ansal and Özlem Onaran, not only for paving my way to academic world, but also setting an example of academic and intellectual integrity for me.

Dear Eveline in de Braek was always there for all $\mathrm{PhD}$ students to turn UNU-MERIT building into home. Thank you Eveline for caring about us. I sincerely enjoyed my first year at UNU-MERIT with my PhD batch: Iman Rajabzadeh, Muhammad Shafique, Rodolfo Lauterbach and Ying Zhang. And my roommate from SBE, Kutay Cingiz. Yes, we had such a wonderful room.

I would like to express my gratitude to my family for their never ending support: my mother and father, Süheyla and Hasan Çevikarslan and my sister Gamze Yüksel, and my apologies to my mother and sister for leaving you alone for a PhD in the Netherlands. Our home and city, Değirmendere, was and will always be heaven to me.

This thesis is dedicated to my beloved beautiful wife Nazlıhan Uğur. I am sorry for all the omissions and delays. Thank you for being with me through good and bad. We did it together and we will in the future.

Salih Çevikarslan Amsterdam, January 2019 


\section{Contents}

1. Introduction ...................................................................................... 1

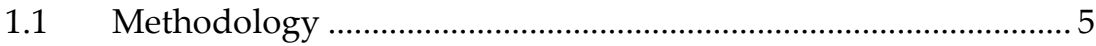

1.1.1 Evolutionary Approach ........................................................... 5

1.1.2 Agent-based Modeling ……………………........................... 7

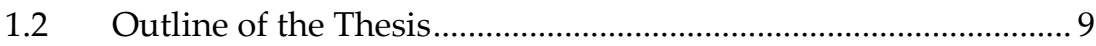

2. A Taxonomic Approach to Innovation Modes with a Firm-Level Latent Class Analysis of CIS 4 ........................................................... 13

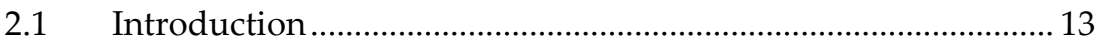

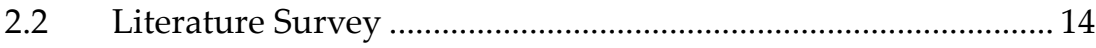

2.2.1 Persistence of Heterogeneity in Innovation Strategies .......... 14

2.2.2 Taxonomic Studies of Innovation Modes................................. 16

2.3 Overview of the Dataset............................................................... 19

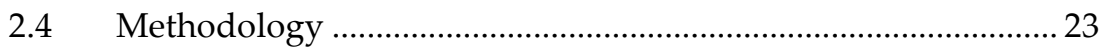

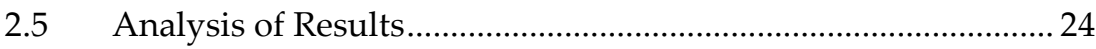

2.5.1 The Relations between Antecedents and Descendants ......... 24

2.5.2 Identifying Innovation Strategies ........................................... 26

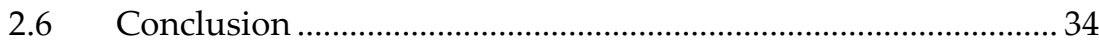

3. Heterogeneity in Innovation Strategies, Evolving Consumer Preferences and Market Structure........................................................... 37

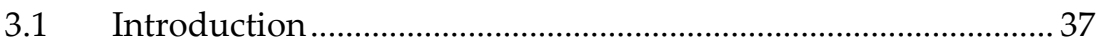

3.2 Literature Review.................................................................... 40

3.2.1 Heterogeneity in Innovation Modes .......................................... 40 
3.2.2 Product Innovation and Competition...................................... 43

3.3 Research Topic ............................................................................ 44

3.4 The Model ....................................................................................... 45

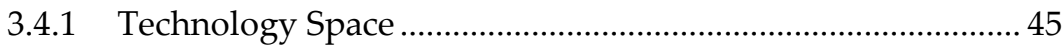

3.4.2 Demand and Supply Structure .................................................. 46

3.4.3 Innovation Function and Strategies .......................................... 50

3.4.4 The Pseudo-Code of the Model ................................................ 54

3.5 Simulation Results ....................................................................... 54

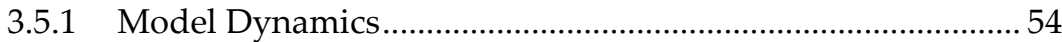

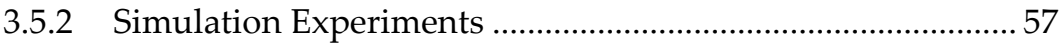

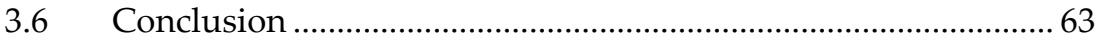

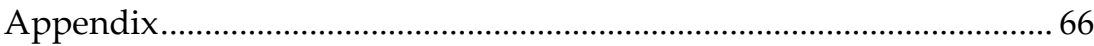

4. Optimal Patent Length and Breadth in an R\&D Driven Market with Evolving Consumer Preferences .................................................. 67

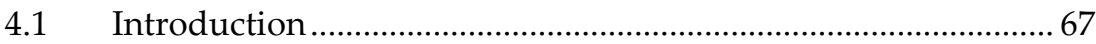

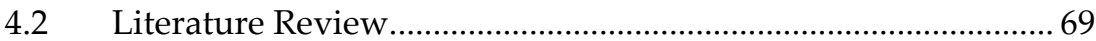

4.2.1 Why do (should) we have patents? ............................................. 69

4.2.2 Why shouldn't we have patents? .............................................. 70

4.2.3 Sequential Innovation ............................................................. 74

4.2.4 Patent Scope .................................................................... 75

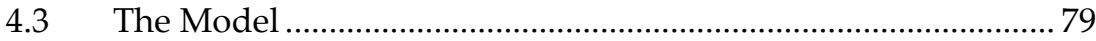

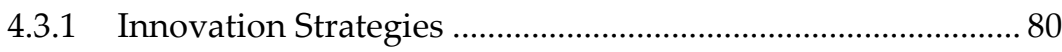

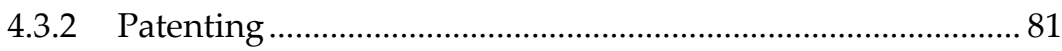

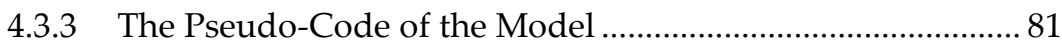

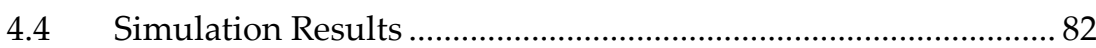

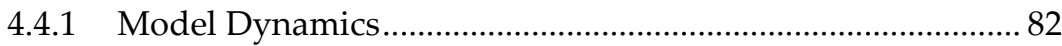

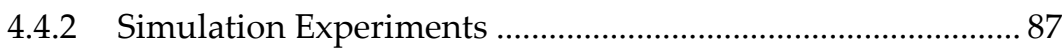

4.5 Conclusion ............................................................................. 93

5. Research Joint Ventures in an R\&D Driven Market with Evolving

Consumer Preferences....................................................................... 97 


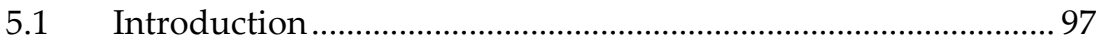

5.2 Literature Survey and Research Questions ................................ 100

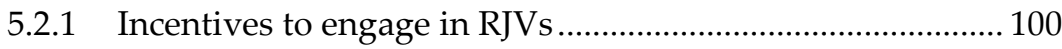

5.2.2 The effect of being in a RJV on market share........................ 101

5.2.3 The effect of competition on RJV ............................................. 102

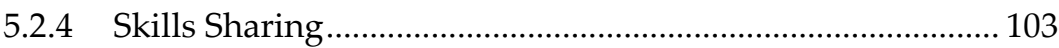

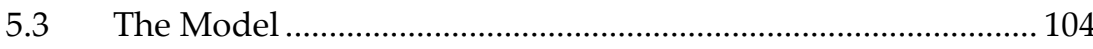

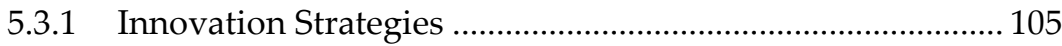

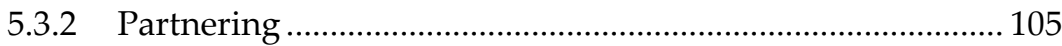

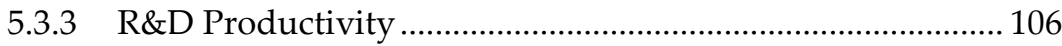

5.3.4 The Pseudo-Code of the Model ............................................... 107

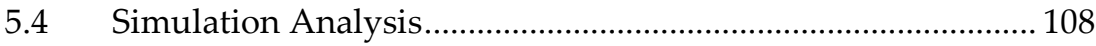

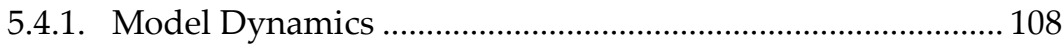

5.4.2 Simulation Experiments .......................................................... 113

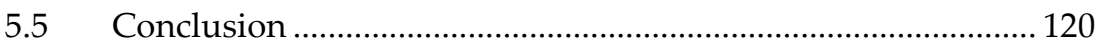

6. Concluding Remarks ........................................................................... 125

6.1 Summary of the main findings ………………........................... 126

6.2 Limitations of the study and avenues for further research ..... 128

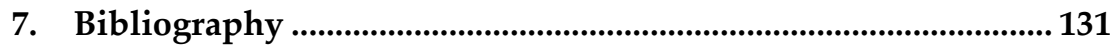

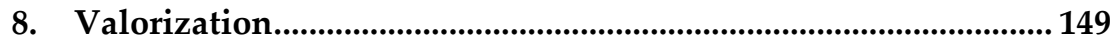

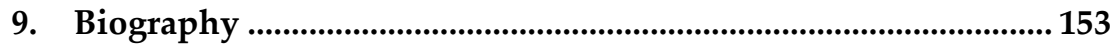





\section{Chapter 1}

\section{Introduction}

..Until the 1980s, the "sea of truth" in economics lay in simplicity, whereas since then it has become recognized that the sea of truth lies in complexity ${ }^{l}$

Kenneth Arrow

This thesis study is about heterogeneity in innovation strategies of firms. It is motivated by the basic premise that innovation strategies are conditioned by what firms do (economic routines, search process, etc.) and have (technological resources, knowledge, etc.) within the firm together with external economic and technological conditions. Firm-level dimensions like motivations and incentives, expectations, capabilities and resources, organization structure, decision making mechanisms and routines, learning and search processes are the possible reasons of this heterogeneity. To be more specific, firms with different motivations in pursuing $R \& D$, or firms with different capabilities and resources or firms with different learning and search mechanisms have their distinct ways of innovating. Innovation strategy is also related with economic conditions in the market (e.g. market size, consumer preferences) and technological developments (e.g. stage of the product cycle, technology diffusion).

\footnotetext{
${ }^{1}$ Speech at the International Conference on Complex Systems organized by the New England Complex Systems Institute in 2000.
} 
In this study, innovation strategies are explored both from an empirical and theoretical perspective. Within the empirical part, a formal statistical procedure is applied on firm-level Community Innovation Survey (CIS) data for the identification of innovation strategies. The CIS is conducted by EU Member States to monitor Europe's progress on innovation. The survey seeks information about product, process, organizational and marketing innovation and it allows us to quantify how much innovation efforts a firm makes together with what kinds of innovation efforts it makes. For the theoretical part, the insights gained from the empirical chapter are supported with an evolutionary, multi-agent based, sector-level innovation simulation model. The simulation model aims at developing a reasonably realistic representation of innovation at sectoral level, specifically by giving more structure to the process by adding to its multi-dimensionality. Then, these dimensions are integrated in a coherent unity with the help of modularity of agent-based modeling (ABM). The model considers both the variety among firms in terms of the ways they carry out their innovation activities and heterogeneity in consumer preferences. Innovation is modelled as an openended search process.

In creating a multi-agent based simulation model of innovation, formalizing the incentives and expectations of the actors involved in innovative work is a conceivable starting point (Dosi et al., 2017). However, this is a challenging task, because each project is unique, goals are hard to specify ex ante, and uncertainties get resolved as the project progresses (Bergmann and Friedl, 2008). Yidizoglu (2001) shows how expectation and adaptation can be used in the modeling of R\&D investment rules in terms of levels. Under uncertainty, expectations reflect the existence of an internal model of the economy that firms use to make simulations about the possible outcomes of their decisions. This internal model is specific to firms and is adapted over time according to observations and experiences. Firms form expectations about their environment and these expectations are a source of better performance.

Once the ultimate target and possible consequences are at least roughly determined, what logically follows is analyzing the formation of capabilities and resources at firm's disposal and their effects on the innovation process 
itself. Firms have to acquire them to succeed in innovation. The ability to continuously reconfigure resources, capabilities and competencies is defined as 'dynamic capabilities' (Teece et al., 1997) or 'combinative capabilities' (Kogut and Zander, 1992). At the centre of this reconfiguration lies the ability to innovate (Rumelt, 1987). These capabilities and resources are dynamically structured in the model by the intentional efforts of the firms. This means the ones involved in the current research directions are increased, whereas others will decrease and eventually might vanish.

Knowledge accumulated at the level of the firm is an important resource that contributes significantly to innovative outcomes. Organizational knowledge is not only incorporated into the minds of organizational members, but also into (a) a set of routines, other organizational practices and shared representations; and (b) a set of material artefacts that shape intraorganizational relations and individual behaviors (Dosi et al., 2008). Because innovation is cumulative, accumulated knowledge provides a guide to the search process (Helfat, 1994a; Nelson, 1982). Knowledge provides researchers with an understanding of the fundamental principles underlying a system and this allows them to better anticipate the result of various possible experiments without actually proceeding with the experiment (Nelson, 1982; Fleming and Sorenson, 2004).

With the knowledge of its aim and capabilities and resources adding to its innovative capability, the firm organizes its R\&D structure in the most efficient way to maximize its chance of success. Organization structure is a set of procedures and mechanisms which is designed to make coordination possible (Marengo, 1992). Arundel et al. (2007) suggests that organization could influence innovation performance through two main mechanisms. First, forms of work organization that stimulate interaction among agents with a diverse set of experiences and competences could be more creative, leading to the development of original ideas for new products and processes. Second, work organizational forms that delegate responsibility for problem solving to a wide range of employees could be more successful both in upgrading the competences of workers and in transforming ideas into new products and processes. 
Any innovative process comprises organizational decision making and routines. Organizational routines are at the center-stage particularly for work influenced by Nelson and Winter (1982). This tradition puts the emphasis on procedural rationality as the key concept for understanding firm's decisionmaking rather than the neoclassical perfect rationality assumption (Dawid, 2006). In a very broad sense, the concept of routines refers to simple decision rules that require low levels of information processing (rules of thumb) and also to complex, automatic behaviors that involve high levels of repetitive information processing (Cohen et al., 1996). The fact that routines are learned implies the possibility of the tacitness and automaticity (Dosi et al., 2008). Organizational routines also entail a 'truce' among potentially conflicting interests (Nelson and Winter, 1982).

Innovation is first and foremost a learning and search process. Organizational learning can be defined as the process of improving actions as a result of reflection on new knowledge and understanding and it involves problem solving, generation of new skills and routines, and building new representations of the environment (Edmondson and Nembhard, 2009; Marengo, 1992). Learning crucially entails cognitive activities of construction and modification of mental models and behavioral patterns hardly reducible to well defined problems of choice under imperfect information and probabilizeable risk. As shown by Yildizoglu (2002) in a simplified version of the evolutionary industry model of Nelson and Winter, learning yields technological and social efficiency as well as market domination for firms.

Saviotti and Mani (1998) define search processes as activities that scan the external environment in order to find either alternatives to existing routines or completely new routines. The authors hypothesize that there is a life-cycle for search activities. Search efforts start very low when the technology is very new and the range of search wide, accelerate at a growing pace as search becomes more applied and focused, and in the end level off as the potential of the new technology is largely exploited. Such life-cycle has a distinctly Schumpeterian character. At the beginning diversity avoids learning getting stuck on local optima while providing multiple 'sources of inspiration' for further development. In time firms' search of a design space seems to become more focused as they move 'down the learning curve' (Cooper, 2000). 
Against this background rises the very concept of innovation itself as a learning and/or search process. In a stylized way, innovation can be conceptualized as a search into technology space. The magnitude, direction and timing of these movements and its determinants give us clues to the nature of innovation. Hence this innovation study first and foremost is going to put the emphasis on how firms learn about / search for new technologies and on consequences of these activities. Possible lock-in situations and pathdependence phenomena will also be considered in the model.

\subsection{Methodology}

\subsubsection{Evolutionary Approach}

Innovation studies call for an analytical treatment of complex, dynamic, nonlinear, adaptive and evolving systems (Carley and Gasser 1999). With its indisputable reliance on equilibrium rather than disequilibrium, homogeneity rather than heterogeneity, risk rather than uncertainty and perfect rationality rather than bounded rationality, mainstream economics is often not the right paradigm in this regard. That is why many scholars turn their faces to evolutionary approach where economic systems in general and innovation processes in particular are regarded as continuing processes in space and time with realistic modeling of microfoundations of the economic behavior working behind (Boulding, 1991).

As stated above, an evolutionary approach will be pursued in the study. This approach has been underlying a large fraction of the agent-based work on innovation and technological change (Dawid, 2006). Evolutionary economics is a hybrid framework of evolutionary theory, complex systems theory, self-organization theory and agent-based computational theory. It is characterized by a methodological combination of Austrian, Behavioral, Institutional, Post-Keynesian and Schumpeterian economics (Dopfer and Potts 2004). While in neoclassical economics there is a strong commitment around a common research core, evolutionary economics lacks a clear analytical framework (Silva and Teixeira, 2008). 
According to Boulding (1991) 'evolutionary economics is simply an attempt to look at an economic system, whether of the whole world or of its parts as a continuing process in space and time' (Dawid, 2006). The lasting contributions of many studies in evolutionary economics, for example, that of Nelson and Winter, are not the actual results that were obtained from the application of the methodology, but the exposition of the methodology itself. This more inductive approach can be justified by the more complex phenomena that the evolutionary economists wish to describe: the evolutionary developments of entire industries or economic systems. It is highly probable that those scientists who are willing to live with such complexity will continue to build their evolutionary models to describe a world which they see as being every bit as complex as their models (Mueller, 2004).

Nelson and Winter in their seminal work An Evolutionary Theory of Economic Change reject the two fundamental assumptions of neoclassical economic modelling: that individuals are rational in the sense that they maximize well-defined objective functions and that markets and other economic systems are in (or tend toward) equilibrium. They suggest replacing the first-order conditions that one obtains from maximization problems with equations that represent the routines or rules of thumb that people in the real world follow. A mark-up pricing rule is a good example of such a rule of thumb (Mueller, 2004). In their perspective, socioeconomic evolution is characterized by the emphasis on the organism's adaptation rather than on the environmental selection of the organism and that is why there is a place for intentionality and novelty in human behavior (Silva and Teixeira, 2008).

Evolutionary processes in their most general form might be characterized by three main stages:

- generation of variety by means of individual innovation

- selection based on some measure of success

- reduction of variety due to diffusion and adaptation

In all three stages, population characteristics dominate the processs. So, an evolutionary approach always calls for 'population thinking' and requires 
an integrated analysis of the micro and the population level (sometimes called meso level) as well as the feedbacks between the two (Dawid, 2006).

\subsubsection{Agent-based Modeling}

An analytical treatment of innovation is difficult since organizations are heterogeneous and complex systems and organizational action is a result of interactions among adaptive humans or firms (Carley and Gasser, 1999). $\mathrm{ABM}$ technique, which can handle heterogeneity, complexity and interaction between agents, is used for the theoretical chapters of this thesis. Nearby getting a deeper understanding of the inherent forces that drive a system and influence the characteristics of a system, agent-based models are also used as computational laboratories to explore various institutional arrangements, various potential paths of development so as to assist and guide e.g. firms, policy makers etc. in their particular decision context (Dosi et al., 2015). ABM uses methods and insights from diverse disciplines such as evolutionary economics, cognitive science and computer science in its attempt to model the bottom-up emergence of phenomena and the top down influence of the collective phenomena on individual behavior (Grebel and Pyka, 2003).

In terms of code, there are generally three key elements in all neoSchumpeterian simulation models: a search algorithm, a selection algorithm, and a population of objects in which variation is expressed and on which selection operates. The existence of a population of firms provides selection mechanism with a platform on which to work while allowing us to model interactions among the firms and to take environmental effects into consideration. Since Nelson and Winter's growth model, the search algorithm has contained two components, one behavioral and one stochastic, in order to capture the complex nature of innovation. On the one hand, agents' search their environment in a structured way, i.e. there are identifiable behaviors, organizational rules and responses. On the other hand, innovation has a stochastic component. Not only can purely random, serendipitous discoveries occur, but also the payoffs for truly radical innovations (i.e. those that are unlike anything previously introduced) cannot be predicted ex ante. Indeed, a common distinction is often made between gradual and radical innovation. Behavioural search is typically associated with incremental 
innovation, associated with a gradual improvement in the performance of existing objects, often drawing upon the experiences of other agents as well as one's own. By contrast, radical innovation involves the blind search of the unknown. Lessons cannot be learnt from the past or from the experience of others (Windrum, 2004).

There is a voluminous and relentlessly expanding literature on innovation modeling. Nevertheless, there is still scope for further developments. A quick look at the literature reveals that models either tackle sectoral innovation activities somehow neglecting what is really going on at firm level or focus on firm level innovation without adequately formalizing the links with the external world. Developing an evolutionary multi-agent based model design may succeed in doing justice to both sides of the coin. To this end, a modular approach should be pursued where each module represents a distinct dimensionality of innovation. This is exactly what we will try to do in this thesis study; shedding light on various dimensions with the aim of investigating how heterogeneity in innovation modes emerge. A preceding empirical study will set the stage for this theoretical exercise. The model results will hopefully contribute to the knowledge of innovation scholars, firm managers and policy makers in developing a holistic approach to wealth of innovation processes.

We believe that this thesis study will have both theoretical and managerial implications. Innovation modeling exercises in the literature from an evolutionary economics perspective are generally sector-level models which frequently fall short of adequately addressing the mechanisms at work within the firm itself. In a parallel vein, similar models in the organization study and management literature concern themselves with firm-level innovation activities frequently omitting the interactions with the external world and other firms. As a theoretical contribution, this thesis dissertation is intended to fill this void by bridging the gap between the interior and exterior of the firm by simultaneously drawing upon both literatures. Managerially, the results of this study will provide insights for managers regarding heterogeneity in innovation strategies. The results will equip policy makers with the required tools to assess whether there is a generic innovation 
strategy viable and sustainable for all firms and which policies should be pursued to create maximum benefits for the society.

\subsection{Outline of the Thesis}

The following chapter is a taxonomic exercise over innovation strategies. It relies on firm-level survey data on innovation indicators from 16 countries participated CIS 4 . Latent class analysis is first used to show how a cluster of firms following a specific innovation strategy is linked to other clusters at different levels. Then a 4-cluster model (science-based, market-based, external-based and low-profile innovators) is selected for an in-depth analysis of innovation strategies.

This exercise mainly aims at grouping the firms into a number of categories which are, with respect to the variables under investigation, as homogenous as possible within the categories and at the same time as different as possible between the categories. Such taxonomic studies of innovation patterns give us insights into the the major features of the innovative processes. They also inform policy makers to identify firm groups with distinct innovation strategies for a more efficient innovation and technology policy. Lastly, this empirical part also acts as a background for the ensuing modelling chapters. The simulation models will analyse how technological and market outcomes are affected by some of the innovation indicators (e.g. in-house R\&D, competitors as a source of information, application for a patent, cooperation on innovation, etc. ) according to which the firms are clustered in the empirical chapter.

The study continues with an evolutionary, multi-agent based, sector-level innovation model simulating firm groups with heterogeneous innovation strategies in the spirit of the empirical part. Such a simulation model enables one to explore the possibility of persistent heterogeneity in innovation strategies observed in the previous chapter, the interaction between these firm groups and its effects on technological change and market outcomes. Together with the inclusion of the demand side with heterogeneous and evolving consumer preferences, this simulation platform helps us to ask and 
answer several "what if" questions that would not be possible in an empirical study mostly due to data constraints.

Chapter 3 explores heterogeneity in firms' innovation strategies: is heterogeneity sustainable in the long term and what happens to the market shares of firms having different innovation strategies when a structural market characteristic (market size) or a behavioural rule ( $R \& D$ intensity) is changed. Hence we will observe whether the firm group with the best fitting innovation strategy to its environment will dominate its ecosystem or firm groups following a variety of innovation strategies can create a niche for themselves to survive in the long term. To answer these research questions, an evolutionary, multi-agent based, sector-level innovation model is designed. The model addresses supply and demand side of the market simultaneously with the coevolution of heterogeneous consumer preferences, heterogeneous firm knowledge bases and technology levels at the micro level.

Chapter 4 explores the effects of patent length and breadth on market outcomes. We will observe how patent scope determines the extent of monopoly power of the market leader, hence concentration rate and market sharing between innovators vs. imitators, the pace of technological progress and wealth creation in the market. Within the simulation model, firms compete on quality and price of their products in an oligopolistic market whereas consumers, constrained by their computational limits, act to maximize their utility with their product choices in a boundedly rational way. There is continuous firm entry and exit depending on the competitive performance of the firms.

Chapter 5 presents an alternative approach to R\&D collaborations using an evolutionary, multi-agent based and sector-level R\&D model. The model will firstly be used to simulate the evolution of an $R \& D$ driven market composed of profit-driven firms and boundedly rational consumers. Next, frequently discussed research questions in the relevant empirical literature will be explored. The first question will be whether R\&D collaborators command a higher market share than non-collaborators. The second question is what kind of a relationship there is between competition level and the market share of R\&D collaborators. The last research question will be 
whether higher capability heterogeneity among firms means higher market share of collaborators motivated by knowledge sharing. This modeling exercise will extend beyond a basic confirmation/rejection of these research questions.

The findings in chapters 2 to 5 are summarized in chapter 6 . The limitations of this study and further avenues for research are also discussed in this chapter. 


\section{Chapter 2}

\section{A Taxonomic Approach to Innovation Modes with a Firm- Level Latent Class Analysis of CIS 4}

\subsection{Introduction}

Evolutionary theory and strategic management research claim that there are important differences between firms in terms of how they innovate, because firm-specific factors play a fundamental part in shaping a complex phenomenon such as innovation. Identifying innovation patterns of firms has attracted increasing academic attention in recent decades to understand the major features of the innovative processes. A stream of empirical studies at the micro level of the firm emerge to group firms into distinct innovation modes according to a number of characteristics of innovation using innovation surveys (Srholec and Verspagen, 2012; Clausen et al., 2011; Filippetti, 2011; Frenz and Lambert, 2012; Jensen et al., 2007; Peneder, 2010; Leiponen and Drejer, 2007). Then these modes are used to provide insights 
into the nature of the underlying innovation systems and the relevance of national and sectoral contexts.

This study is a taxonomic exercise over innovative firms. Taxonomic studies help reduce variety among firms to make it analytically manageable and creating such manageable firm groupings supports an effective technology policy. Policy makers should acknowledge firm-level variety and sectoral contingencies and be able to discern groups of firms following strategies conductive to public policy objectives (Peneder, 2010).

The empirical identification is based upon the $4^{\text {th }}$ Community Innovation Survey (CIS 4) micro-data for 16 European countries using latent class analysis (LCA). The analysis will first show how innovation modes within clustering solutions with different number of groups are linked to each other. Then the 4-cluster solution is picked for an in-depth characterization of the innovation strategies.

This chapter proceeds as follows. The next section surveys the literature on the persistence of heterogeneity in innovation strategies and previous taxonomic studies of innovation modes. Section 3 is an overview of the dataset, innovation indicators used in the analysis section and standardization of the data. The mechanism of LCA is given in Section 4 . Section 5 presents the results of the empirical analysis. Section 6 concludes and suggests new paths for further research.

\subsection{Literature Survey}

\subsubsection{Persistence of Heterogeneity in Innovation Strategies}

In the biological literature, there are at least four reasons why considerable heterogeneity may be persistent even after selection has been working for a considerable amount of time. The first is that the exogenous parts of the selection environment are highly variable. Another reason is the neutral theory of evolution (Kimura, 1983), which states that large parts of the genome do not have any particular influence on fitness of the organism. The idea of neutral evolution is related to complexity catastrophe (Kauffman, 1993), which emerges in models of evolution on rugged fitness landscapes, 
where the expected fitness of local peaks decreases with complexity. When the selection environment contains many local niches rather than one global one, heterogeneous behavior tends to be "punished" relatively less by selection. A final reason can be found in evolutionary game theory (MaynardSmith, 1982) which claims that a mixed strategy may be an evolutionary stable strategy (Bergstrom and Godfrey-Smith, 1998) (Srholec and Verspagen, 2012).

The observation that firms with distinct innovation strategies coexist in the same market in the long run is against the basic assumption that selection process based on profitability eats away heterogeneity leading to a dominant firm behavior (Friedman, 1953). Evolutionary economic theory criticizes this view drawing upon bounded rationality, routine behavior and a dynamic interplay between variety generation and selection (Nelson and Winter, 1982; Metcalfe, 1998; Durand, 2001). Technological complexity coupled with myopic search and path dependence is another explanation that favors firmlevel heterogeneity. In this regard evolutionary economics is in parallel with "resource-based" theory of the firm (Wernerfelt, 1984; Barney, 1991) and organization theory (Christensen, 2002; Massini et al., 2005) (Srholec and Verspagen, 2012). According to resource based theories of the firm, firms differ in preferences, capabilities and cognition of entrepreneurial opportunities which result in strategic differentiation and intrinsic individualism (Peneder, 2010).

There is a wide literature that has focused on the importance of industryspecific factors to explain patterns of innovation of firms and the dynamic of industrial structure (Pavitt, 1984; Archibugi et al., 1991; Breschi et al., 2000; Malerba, 2004). The main assumption of these studies is that patterns of innovation of firms are sector-specific, depending on the very nature of the technological domain. Even though this body of literature has provided important insights about the way firms innovate, further analysis shows that sectors matter to a certain extent and heterogeneity among firms plays a crucial role within both sectors and countries (Srholec and Verspagen, 2012; Filippetti, 2011).

Hollenstein (2003) differs from Hollenstein (1996) which only reported sectoral differences by showing that most of the innovation modes that he has 
detected came out distributed quite widely across sectors. Jensen et al. (2007) found their innovation modes to be quite evenly distributed across sectors with the exception of a noticeable under-representation of science-centered strategies in services. Leiponen and Drejer (2007) revealed that three or more different modes of innovation can be identified in almost all industries under their consideration and about half of them do not have a dominant pattern (Srholec and Verspagen, 2012).

\subsubsection{Taxonomic Studies of Innovation Modes}

By the mid-1980s it was increasingly accepted that R\&D efforts provide only a partial assessment of the innovative activities of firms, and efforts began to measure innovation more directly. This led to the first 'subject-based' innovation surveys, and to the development of the OECD's Oslo Manual (OECD, 1992), which provides 'proposed guidelines for collecting and interpreting technological innovation data'. Whilst the Oslo Manual extended the measurement of innovation beyond R\&D, initially at least, it deliberately confined itself to technological product and process innovation (Tether and Tajar, 2008).

Several studies that perform taxonomic exercises of innovation patterns use principal component or factor analysis as a way to reduce the number of dimensions to be used in the clustering. However, sector-level studies may suffer from having too few observations (Evangelista, 2000; Peneder, 2002). Firm-level studies provide a greater number of observations, and thus more robust results. Principal component and factor analysis reduces the risk that any single indicator dominates the outcome of the cluster analysis and helps prevent including irrelevant (non-discriminative) variables (Everitt, 1993; Hair et al., 1998). The factors obtained are also uncorrelated. Then a cluster analysis of these factors is performed in order to group the firms into a number of categories which are, with respect to the variables under investigation, as homogenous as possible within the categories and at the same time as different as possible between the categories.

Srholec and Verspagen (2012) based their analysis on micro data from the third CIS in 13 countries provided by Eurostat (2007) for the period between 1998 and 2000 (or in some countries from 1999 to 2001). They interrogate the 
claim that national and sectoral differences account for much of the heterogeneity in innovation strategies and their main finding is that heterogeneity among firms is the dominating tendency in the data. With exploratory factor and hierarchical cluster analysis, four ingredients of an innovation (research, user, external and production), and five distinct innovation strategies (high profile, user-driven, externally-sourced, opportunistic, low profile) are identified. The analysis concludes that there is a considerable diversity in how firms innovate, and these differences remain very substantial once effects due to different sectoral and national contexts are cancelled out.

In Clausen et al. (2011) paper, the results obtained from the factor analysis were used in a subsequent cluster analysis to categorize a sample of innovative Norway firms into five innovation strategies. The least strategic innovators regard innovation in a sporadic manner. Supplier-based strategy relies mostly on suppliers of machinery and equipment as knowledge sources. The market-driven innovation strategy focuses on customer-driven innovation and seeks knowledge from industry sources, such as competitors and clients. R\&D intensive firms tend to have a broad spectrum of goals and sources for innovation, but especially tend to focus on internal and external $R \& D$. The last group is the science-based innovators, which rely heavily on scientific sources of knowledge, such as patents, universities, and research institutes, in their innovation process.

Based on Innobarometer Survey 2009, Filippetti (2011) grouped firms into 5 categories using factor and cluster analysis: outward-oriented nontechnological innovation, cost-saving innovation, R\&D-focus with strong basic collaboration, inner-oriented non-technological innovation and outward-oriented multifaceted innovation. The paper concludes that specifically, firms belonging to the outward-oriented multi-faceted innovation and outward-oriented non-technological innovation modes are more likely to show faster rates of turnover's growth.

Frenz and Lambert (2012) used CIS 2006 to identify five innovation modes with factor analysis: IP/technology innovating, marketing based innovating, process modernizing, wider innovating and networked innovating. In most countries one or more innovation modes are positively associated with labour 
productivity. However, there is no consistent cross-country pattern which shows significant associations with productivity.

Jensen et al. (2007) contrasts two modes of innovation: "the science, technology and innovation" mode, based on the production and use of codified scientific and technical knowledge and "the doing, using and interacting" mode, based on informal processes of learning and experiencebased know-how. Drawing on the results of the 2001 Danish DISKO Survey, LCA is used to identify groups of firms that practice the two modes with different intensities. Logit regression analysis shows that firms combining the two modes are more likely to innovate new products or services than those relying primarily on one mode or the other.

Peneder (2010) presents a new and integrated set of innovation taxonomies of firms and sectors. Using the micro-data of the CIS III, covering 78,000 individual firms from 22 European countries over the period 19982000, the firms are identified according to Schumpeter's distinction between creative and adaptive behaviour as well as three essential characteristics of technological regimes (i.e. opportunities, appropriability, and cumulativeness) into five distinct classes based on their innovation intensity. Despite the huge variety of individual innovation behaviour, the final cluster validations demonstrate that distinct technological regimes exhibit systematic differences in the distribution of heterogeneous firm types.

In an empirical study by Leiponen and Drejer (2007) analyzing the patterns of innovation within and across industries using CIS II data from Finland and Denmark, firms within most industries are found to follow multiple patterns of innovation behavior. These are scale/science-based, market-driven, production intensive, supplier-dominated and ad hoc strategies. Even at very detailed levels of industry classification (four- and five-digit NACE industries) and including all industries for which six or more observations are available, only about half of the observed industries have a dominant innovation regime, defined as $50 \%$ or more of the firms in an industry being affiliated with the same regime. The authors interpret this as strategic differentiation or local search activities overcome pressures in the technological environment towards homogenous behaviour, at least in the short term. The multiple patterns of behavior with regard to innovation may 
be related to intra-industry differentiation: initial strengths and weaknesses of firms, time of entry into the business, and historical accidents.

Table 2.1 provides a (non-exhaustive) overview of previous empirical studies identifying innovation modes. The table gives information on data sources, the name and number of different modes and the methodology used for identifying them. An immediate observation is that except for one, every study has ended up with either four or five innovation modes. The most frequently encountered innovation modes are science and $R \& D$ based, external and supplier based, market and customer based and low-profile, respectively.

\subsection{Overview of the Dataset}

This work relies on the data of all enterprises with more than 10 employees in the participating countries coming from CIS 4 collected by Eurostat in 2004 and covering the years 2002 to 2004. It is a harmonized survey based on Oslo Manual (1997) in order to get comparable, harmonized and high quality statistical results. The core target population is industry (NACE sections C, D and E), wholesale trade (NACE 51), transport, storage and communication (NACE 60-64), financial intermediation (NACE 65-67), computer and related activities (NACE 72), architectural and engineering activities (NACE 74.2) and technical testing and analysis (NACE 74.3) (OECD, 2006).

Measures feeding into the analysis and, thus, forming the modes of innovation include both inputs and outputs of the innovation process. They span technological and non-technological activities, including marketing and organization innovations. Specific emphasis is on the type of innovation activities, information sources, effects of innovation, protection methods, innovation types and innovation collaborations. The innovation indicators used in the analysis section of this study are reported below.

In the questionnaire firms reported whether they engaged in a variety of innovation activities which are: (i) Intramural (in-house) R\&D, (ii) Extramural R\&D, (iii) Acquisition of machinery, equipment and software to 
Table 2.1. An overview of studies identifying innovation modes

\begin{tabular}{|c|c|c|c|}
\hline Paper & Data & Methodology & Innovation Modes \\
\hline Asikainen 2015 & CIS 2006 Luxemburg & Factor analysis & $\begin{array}{l}\text { 1. R\&D maker, buyer, and cooperator } \\
\text { 2. knowledge retriever with IPR } \\
\text { 3. process renewer } \\
\text { 4. active innovation marketer } \\
\end{array}$ \\
\hline $\begin{array}{l}\text { Clausen et } a l \text {. } \\
2011\end{array}$ & $\begin{array}{l}\text { CIS2 and R\&D survey for } \\
\text { Norway industry }\end{array}$ & Factor and cluster analysis & $\begin{array}{l}\text { 1. ad hoc group } \\
\text { 2. supplier-based } \\
\text { 3. market-driven innovation } \\
\text { 4. R\&D intensive } \\
\text { 5. science-based innovators } \\
\end{array}$ \\
\hline $\begin{array}{l}\text { Srholec \& } \\
\text { Verspagen } 2012\end{array}$ & CIS III & Factor and cluster analysis & $\begin{array}{l}\text { 1. high profile } \\
\text { 2. user-driven } \\
\text { 3. externally sourced } \\
\text { 4. opportunistic } \\
\text { 5. low profile }\end{array}$ \\
\hline $\begin{array}{l}\text { Hollenstein } \\
2003\end{array}$ & $\begin{array}{l}\text { Swiss Innovation Survey } \\
1999 \text { Services }\end{array}$ & Factor and cluster analysis & $\begin{array}{l}\text { 1. science-based high-tech firms with full } \\
\text { network integration } \\
\text { 2. IT-oriented network-integrated developers } \\
\text { 3. market-oriented incremental innovators } \\
\text { with weak external links } \\
\text { 4. cost-oriented process innovators with } \\
\text { strong external links along the value chain } \\
\text { 5. low-profile innovators with hardly any } \\
\text { external links }\end{array}$ \\
\hline $\begin{array}{l}\text { de Jong \& } \\
\text { Marsili } 2006\end{array}$ & $\begin{array}{l}\text { EIM Business \& Policy } \\
\text { Research } 2003 \text { Netherlands } \\
\text { SMEs }\end{array}$ & $\begin{array}{l}\text { Principal component and } \\
\text { cluster analysis }\end{array}$ & $\begin{array}{l}\text { 1. small innovative firms } \\
\text { 2. science-based specialised suppliers } \\
\text { 3. supplier-dominated } \\
\text { 4. resource-intensive } \\
\end{array}$ \\
\hline Trigo 2013 & $\begin{array}{l}\text { PITEC } 2004 \text { Spain Services } \\
\text { derived from the CIS }\end{array}$ & Latent class analysis & $\begin{array}{l}\text { 1. knowledge developers } \\
\text { 2. knowledge developers and adopters } \\
\text { 3. technology adopters } \\
\text { 4. hidden innovators }\end{array}$ \\
\hline Filippetti 2011 & Innobarometer Survey 2009 & Factor and cluster analysis & $\begin{array}{l}\text { 1.outward-oriented non-technological } \\
\text { innovation } \\
\text { 2. cost-saving innovation } \\
\text { 3. R\&D-focus with strong basic collaboration } \\
\text { 4. inner-oriented non-technological } \\
\text { innovation } \\
\text { 5. outward-oriented multifaceted innovation }\end{array}$ \\
\hline $\begin{array}{l}\text { Frenz \& } \\
\text { Lambert } 2012\end{array}$ & CIS 2006 & Factor and cluster analysis & $\begin{array}{l}\text { 1. IP/technology innovating } \\
\text { 2. marketing based innovating } \\
\text { 3. process modernising } \\
\text { 4.wider innovating } \\
\text { 5. networked innovating }\end{array}$ \\
\hline $\begin{array}{l}\text { Jensen et } a l \text {. } \\
2007\end{array}$ & 2001 Danish DISKO Survey & Latent class analysis & $\begin{array}{l}\text { 1. low learning } \\
\text { 2. science, technology and innovation (STI) } \\
\text { 3. doing, using and interacting (DUI) } \\
\text { 4. DUI/STI combined }\end{array}$ \\
\hline Peneder 2010 & CIS 1998-2000 & Cluster analysis & $\begin{array}{l}\text { 1. high innovation intensity } \\
\text { 2. intermediate to high innovation intensity } \\
\text { 3. intermediate innovation intensity } \\
\text { 4. intermediate to low innovation intensity } \\
\text { 5. low innovation intensity }\end{array}$ \\
\hline $\begin{array}{l}\text { Tether \& Tajar } \\
2008\end{array}$ & Innobarometer 2002 & $\begin{array}{l}\text { Multiple correspondence } \\
\text { analysis }\end{array}$ & $\begin{array}{l}\text { 1. product-research mode } \\
\text { 2. process-technologies } \\
\text { 3. organisational-cooperation mode }\end{array}$ \\
\hline $\begin{array}{l}\text { Leiponen \& } \\
\text { Drejer } 2007\end{array}$ & $\begin{array}{l}\text { CIS II for Finland and } \\
\text { Denmark }\end{array}$ & Factor and cluster analysis & $\begin{array}{l}\text { 1. science-based } \\
\text { 2. market-driven } \\
\text { 3. production intensive } \\
\text { 4. supplier dominated } \\
\text { 5. ad hoc innovators }\end{array}$ \\
\hline
\end{tabular}


produce new or significantly improved products and processes, (iv) Acquisition of other external knowledge (patents, non-patented inventions, know-how, etc.), (v) Internal or external training for your personnel specifically for the development and/or introduction of new or significantly improved products and processes, (vi) Market introduction of innovations including market research and launch advertising, (vii) Procedures and technical preparations to implement new or significantly improved products and processes that are not covered elsewhere. These are nominal variables that take on the value 1 if the firm engaged in that activity and 0 otherwise.

Firms were asked how important the following information sources are to their innovation activities on a four-point scale: (i) Within the enterprise or enterprise group, (ii) Suppliers of equipment, materials, components, or software, (iii) Clients or customers, (iv) Competitors and other enterprises in their sector, (v) Consultants, commercial labs, or private R\&D institutes, (vi) Universities or other higher education institutions, (vii) Government or public research institutes, (viii) Conferences, trade fairs, exhibitions (ix) Scientific journals and trade/technical publications, (x) Professional and industry associations. Answers were coded by integers from zero for "not used" to four for "high".

Firms were further required to evaluate the following effects of their innovations on a four-point scale: (i) Increased range of goods or services, (ii) Entered new markets or increased market share, (iii) Improved quality of goods or services, (iv) Improved flexibility of production or service provision, (v) Increased capacity of production or service provision, (vi) Reduced labor costs per unit output, (vii) Reduced materials and energy per unit output, (viii) Reduced environmental impacts or improved health and safety, and (ix) Met regulatory requirements. Again, the answers were coded by integers from zero for "not relevant" to four for "high".

The survey reports how firms protect outcomes of their innovation activity. Firms were asked to indicate whether they used any of the following methods to protect their inventions or innovations: (i) Application for a patent, (ii) Registration of an industrial design, (iii) Registration of a trademark, (iv) Claim copyright. A dummy variable for each option has value 1 if the firm reported using it and 0 otherwise. 
The analysis also includes whether firms introduce different innovation types as dichotomous variables with values of either 1 or 0: (i) New or significantly improved goods, (ii) New or significantly improved services, (iii) New or significantly improved methods of manufacturing or producing goods or services, (iv) New or significantly improved logistics, delivery or distribution methods for their inputs, goods or services, (v) New or significantly improved supporting activities for their processes, such as maintenance systems or operations for purchasing, accounting, or computing, (vi) New or significantly improved knowledge management systems to better use or exchange information, knowledge and skills within their enterprise, (vii) A major change to the organization of work within their enterprise, such as changes in the management structure or integrating different departments or activities, (viii) New or significant changes in their relations with other firms or public institutions, such as through alliances, partnerships, outsourcing or sub-contracting, (ix) Significant changes to the design or packaging of a good or service, (x) New or significantly changed sales or distribution methods, such as internet sales, franchising, direct sales or distribution licenses. Lastly, a single dummy for cooperation with value 1 if the firm had at least one cooperation arrangement, regardless of the partner, is also included in the analysis.

Standardization of the sample has been conducted as in Srholec and Verspagen (2012). First, missing data have been replaced by zeros if there was at least one valid answer within the particular set of questions. For some countries this has been apparently done already before distributing the dataset by Eurostat, while for others not, so that this procedure was necessary to harmonize the data. Second, firms with missing information on any of the variables used in the analysis, even after the preceding imputation procedure, were omitted. Third, firms with only zeros in the sets of questions on the various innovation activities, the effects of innovation or the sources of information were deleted, because every innovating firm must by principle engage in at least some innovation activity, etc. However, the same logic does not necessarily apply on methods of protection; product, service, process, marketing and organization innovations; and cooperation on innovation, so that these sets of questions were not checked for this. After this 
standardization process, the survey provides a dataset of 32440 firms in 16 European countries (number of observations in brackets): Belgium (1256), Bulgaria (2148), Czech Republic (2407), Germany (2862), Estonia (886), Spain (8230), Greece (395), Hungary (845), Italy (5387), Lithuania (499), Latvia (487), Norway (1442), Portugal (2043), Romania (2166), Slovenia (696), Slovakia (691).

\subsection{Methodology}

Different data analysis techniques have been used in the literature to classify firms into innovation modes, which include factor analysis (Asikainen, 2015; Frenz and Lambert, 2012), cluster analysis (Peneder, 2010), factor and cluster analysis together (Clausen et al., 2011; Srholec and Verspagen, 2012; Hollenstein, 2003) and multiple correspondence analysis (Tether and Tajar, 2208). LCA is a relatively less frequently adopted technique for this purpose (Trigo, 2013; Jensen et al., 2007, Drejer and Vinding, 2006). In this study, latent class and finite mixture program 'Latent GOLD 5.0' is used for all segmentation exercises.

LCA is a multivariate technique to distinguish clusters of related cases based on the analysis of the probability distribution of observed categorical variables. It examines whether the association between observed categorical variables can be explained from a structure or unobserved latent variable (Heinen, 1996; Hagenaars and McCutcheon, 2003 as cited in Trigo (2013). Since the latent variable is categorical, LC modeling differs from more traditional latent variable approaches such as factor analysis, structural equation models, and random-effects regression models that are based on continuous latent variables (Vermunt and Magidson, 2005). LCA is able to cope with data that are measured on a nominal or ordinal measurement scale (Jensen et al., 2007). The latent class model is estimated by maximum likelihood, where the number of classes is determined by goodness-of-fit tests $^{2}$ and two informal information criteria, the Akaike information criterion

${ }^{2}$ Likelihood-ratio chi-squared, Pearson chi-squared and Cressie-Read chi-squared statistics are reported for a goodness-of-fit test upon the estimation of a model in Latent GOLD 5.0. 
and the Bayesian information criterion (BIC) (Drejer and Vinding, 2006). Generally, among models for which the p-value is greater than 0.05 (providing an adequate fit), the one that is most parsimonious (with fewest number of parameters) would be selected. Recent studies show that BIC is the most convenient information criterion for model selection in latent class analysis (Biernacki and Govaert, 1999; Vermunt and Magidson, 2002). Among candidate models, the one with the lowest BIC value should be selected (Magidson and Vermunt, 2004).

\subsection{Analysis of Results}

\subsubsection{The Relations between Antecedents and Descendants}

Figure 2.1 shows how a cluster of firms following a specific innovation strategy is linked to other clusters at different levels. To draw this figure, first LCA is conducted on the data set to classify firms into groups according to their innovation strategies to create from 1 to 10 -cluster solutions. Then how a group of firms is decomposed into lower level groups is tabulated. To exemplify, $68 \%$ and $32 \%$ of the firms following strategy 2 within 2-cluster solution constitutes strategy 2 and 3, respectively, within 3-cluster solution. Lastly, based on this percentile distribution, the reciprocal of the Herfindahl index ${ }^{3}$ is calculated and rounded up to the nearest integer to determine the "equivalent" number of clusters a strategy group is linked to. As an example, these percentage figures for strategy 2 within 3-cluster solution are 58, 40 and 3 giving an inverse Herfindahl index of 2.035 rounded up to 2 .

An interesting observation on the cluster tree is that when the number of clusters is increased by 1 , a new cluster emerges that includes a significant share of the firms of more than a single existing cluster. Only the transitions from 2 to 3 -cluster solution and 6 to 7 -cluster solution are against this tendency, where strategy groups 2 and 1, respectively, split into two to form

${ }^{3}$ The formal definition of the inverse Herfindahl index is $1 / \sum_{i=1}^{n} s_{i}^{2}$ where $s_{i}^{2}$ is the squared market share of firms. 


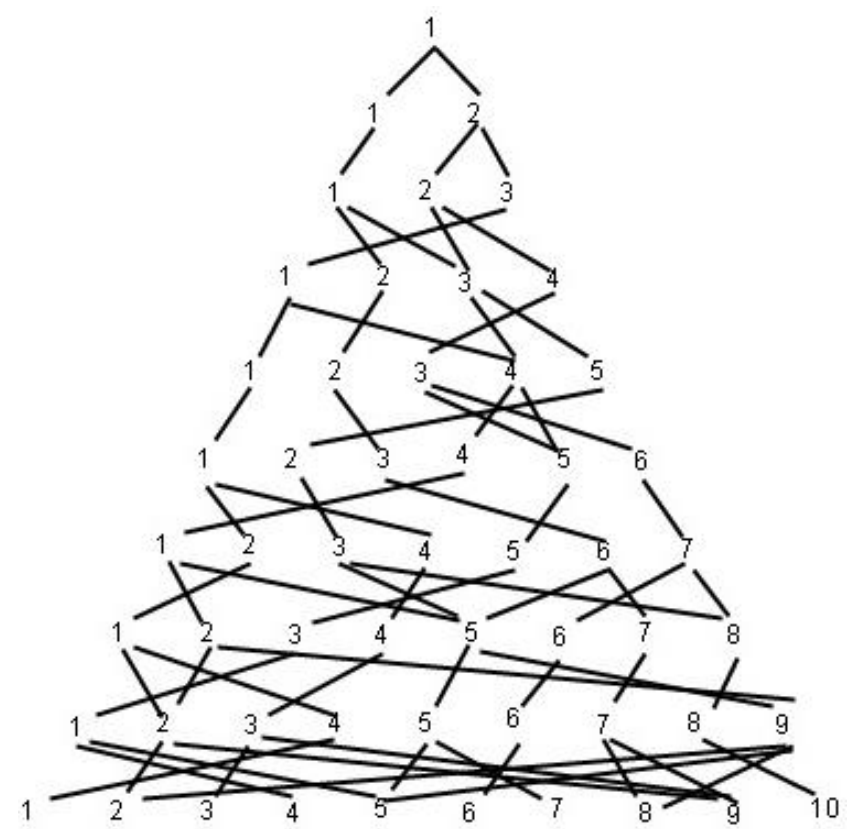

Figure 2.1. The relations between innovation modes at different levels of clustering solutions

the new offspring. Hence the formation of a new cluster as a hybrid of two existing clusters is a frequent occurrence.

One can focus at the transition between 4 to 5 -cluster solution to interpret how this hybrid formation occurs. Strategy group 1 within 4-cluster solution is divided into clusters 1 and 4 at a lower level. A closer look at the innovation indicators used in LCA reveals that the resemblance between parent group 1 and offspring group 1 is higher than it is between parent group 1 and offspring group 4 , the reason being that offspring group 4 consists also of a significant number of firms of cluster 3 within 4 -cluster solution. Clusters 2 and 3 within 5-cluster solution are direct descendants of clusters 2 and 4, respectively, within 4 -cluster solution. The interesting case is cluster 4 within 5-cluster solution, which is a hybrid of clusters 1 and 3 within 4-cluster solution. Offspring group 4 is more similar to parent group 1 according to some innovation indicators and more similar to parent group 3 according to others. In parallel to the relationship between offspring group 1 and parent group 1, offspring group 5 is more similar to parent group 3 than offspring 
group 4 is to parent group 3 because of the hybrid character of offspring group 4.

\subsubsection{Identifying Innovation Strategies}

Ideally in LCA, model choice and hence the determination of the number of clusters should be based on goodness-of-fit tests and BIC. The test results indicate that no model is valid according to these criteria. Previous research has suggested that in general, a larger sample size, more indicators and a higher quality of indicators lead to more converged and proper replications, as well as fewer boundary parameter estimates and less parameter bias. Using a larger sample size will usually result in better model estimation (Wurpts and Geiser, 2014). However, a complication arises with large data sets and this is especially a concern where there are many multi-category variables, such that the number of observed response patterns is extremely large as in the case of this study. For large data sets, the test statistics no longer have a theoretical Chi-squared distribution (Agresti and Yang, 1986). Thus, statistical assessment by goodness-of-fit tests and BIC is inappropriate.

Therefore, interpretability and compatibility with previous taxonomic studies of innovation modes becomes the decisive criteria for the choice between different models in this study. The model with the maximum possible number of clusters to each of which a well-defined innovation strategy can be assigned is selected, which is the 4-cluster solution. The innovation strategy of each cluster, the percentage of all firms belonging to a given cluster and how each cluster of firms score on innovation indicators used in LAC are reported in Table 2.2. In the case of the ordinal indicators (those related to the sources of information and effects of innovation), the figures indicate the percentage of firms in the cluster that assign a medium or high level of importance to that source or objective. For all other indicators, the figures indicate the percentage of firms in the cluster that are engaged in the relevant activity.

Science-based Innovators: Science-based innovators have the highest scores on all indicators except one innovation activity (acquisition of machinery, 
Table 2.2. Innovation modes and indicators (\%)

Cluster Size (\%)

\begin{tabular}{llll}
$\begin{array}{l}\text { Science- } \\
\text { based }\end{array}$ & $\begin{array}{l}\text { Market- } \\
\text { based }\end{array}$ & $\begin{array}{l}\text { External } \\
\text {-based }\end{array}$ & $\begin{array}{l}\text { Low } \\
\text { profile }\end{array}$ \\
\hline
\end{tabular}

$\begin{array}{llll}36 & 24 & 24 & 16\end{array}$

Innovation Activities

Intramural (in-house) R\&D

$\begin{array}{llll}77 & 67 & 34 & 26\end{array}$

Extramural R\&D

Acquisition of machinery, equipment and software

$\begin{array}{llll}50 & 32 & 12 & 13\end{array}$

$\begin{array}{llll}84 & 58 & 84 & 73\end{array}$

Acquisition of other external knowledge

Training

$\begin{array}{llll}39 & 22 & 14 & 13\end{array}$

Market introduction of innovations

$\begin{array}{llll}77 & 50 & 36 & 25\end{array}$

$\begin{array}{llll}66 & 46 & 17 & 11\end{array}$

Other preparations

$\begin{array}{llll}64 & 42 & 30 & 23\end{array}$

Sources of Information

Within the enterprise or enterprise group

\begin{tabular}{llll}
89 & 83 & 75 & 55 \\
78 & 53 & 73 & 49 \\
78 & 67 & 52 & 20 \\
64 & 46 & 37 & 13 \\
47 & 24 & 20 & 13 \\
37 & 21 & 4 & 1 \\
25 & 12 & 2 & 0 \\
71 & 48 & 41 & 14 \\
65 & 41 & 34 & 11 \\
44 & 22 & 22 & 8 \\
\hline
\end{tabular}

Professional and industry associations

Suppliers of equipment, materials, components or software

Clients or customers

Competitors and other enterprises in their sector

Consultants, commercial labs or private R\&D institutes

Universities or other higher education institutions

Government or public research institutes

Conferences, trade fairs, exhibitions

Scientific journals and trade/technical publications

Effects of Innovation

Increased range of goods or services

\begin{tabular}{llll}
85 & 71 & 68 & 25 \\
84 & 63 & 60 & 14 \\
91 & 71 & 85 & 44 \\
84 & 33 & 83 & 35 \\
83 & 29 & 85 & 36 \\
71 & 14 & 68 & 16 \\
55 & 7 & 47 & 5 \\
64 & 17 & 57 & 10 \\
68 & 24 & 58 & 18 \\
\hline
\end{tabular}

Intellectual Property Rights

Application for a patent

Registration of an industrial design

\begin{tabular}{llll}
26 & 19 & 3 & 3 \\
18 & 13 & 2 & 3 \\
35 & 26 & 8 & 9 \\
9 & 6 & 1 & 1 \\
\hline
\end{tabular}




\begin{tabular}{|c|c|c|c|c|}
\hline \multicolumn{5}{|l|}{ Innovation Types } \\
\hline New or significantly improved goods & 71 & 63 & 38 & 25 \\
\hline New or significantly improved services & 46 & 32 & 24 & 18 \\
\hline $\begin{array}{l}\text { New or significantly improved methods of manufacturing or } \\
\text { producing goods or services }\end{array}$ & 70 & 28 & 58 & 29 \\
\hline $\begin{array}{l}\text { New or significantly improved logistics, delivery or distribution } \\
\text { methods for their inputs, goods or services }\end{array}$ & 41 & 12 & 19 & 13 \\
\hline $\begin{array}{l}\text { New or significantly improved supporting activities for their } \\
\text { processes }\end{array}$ & 63 & 26 & 45 & 47 \\
\hline New or significantly improved knowledge management systems & 70 & 33 & 33 & 26 \\
\hline A major change to the organization of work within their enterprise & 70 & 38 & 38 & 26 \\
\hline $\begin{array}{l}\text { New or significant changes in their relations with other firms or } \\
\text { public institutions }\end{array}$ & 44 & 20 & 16 & 9 \\
\hline Significant changes to the design or packaging of a good or service, & 44 & 23 & 15 & 7 \\
\hline New or significantly changed sales or distribution methods & 31 & 18 & 10 & 7 \\
\hline Cooperation on Innovation & 52 & 36 & 14 & 14 \\
\hline
\end{tabular}

equipment and software) and one effect of innovation (increased capacity of production or service provision). These firms are engaged in a wide range of innovation activities and they have a broad spectrum of sources for and goals of innovation. They have strong R\&D capabilities and they rely heavily on scientific sources of knowledge, such as scientific journals and trade/technical publications, consultants, commercial labs and private $R \& D$ institutes. The most emphasized effects of innovation are increased range of goods or services and entering new markets or increasing market share. Science-based innovators attach much more importance to intellectual property rights to protect their inventions than other strategy groups. They frequently introduce product and process innovations and high rates of organisational innovations separate this cluster from the others. More than half of the firms belonging to this cluster cooperate on innovation activities with other enterprises or institutions. Specialization in this strategy is more common in manufacture of coke, refined petroleum products and nuclear fuel, manufacture of chemicals, chemical products and man-made fibres, manufacture of electrical and optical equipment, manufacture of machinery and equipment and manufacture of transport equipment. Similar profiles identified in the previous studies are R\&D maker, buyer and cooperator (Asikainen, 2015), science-based and R\&D intensive innovators (Clausen et al., 2011), high-profile (Srholec and Verspagen, 2012), science-based high-tech 
firms with full network integration (Hollenstein, 2003), science-based specialized suppliers (De Jong and Marsili, 2006), knowledge developers and adopters (Trigo, 2013), innovative strongly integrated firms (Camacho and Rodriguez 2008) and science-based (Leipone and Drejer, 2007).

Market-based Innovators: Market-based innovators can be characterized with R\&D and market introduction of innovations as innovation activities. Clients and customers, and competitors and other enterprises in their market are important sources of information for innovation. Increasing range of goods or services, entering new markets or increasing market share and improving quality of goods or services are the foremost reasons for involving in innovative activities. This is the cluster for which appropriability regime depends most on intellectual property rights after science-based innovators. New or significantly improved goods introduced by these firms are complemented with significant changes to the design or packaging and new or significantly changed sales or distribution methods to collect rents created via innovations. Roughly one third of the firms collaborate on innovation projects. Generally, the sectors in which market-based innovators are frequently observed are the ones which are dominated by science-based innovators; manufacture of machinery and equipment, manufacture of electrical and optical equipment, and post and telecommunications. Computer and related activities is a different case with market-based innovation as the dominant strategy (This interesting result is shared by Leiponen and Drejer 2007, and de Jong and Marsili, 2006). Similar strategies have been detected in existing studies like market-driven innovation (Clausen et al., 2011), user-driven (Srholec and Verspagen, 2012), marketing based innovating (Frenz and Lambert, 2012), active innovation marketer (Asikainen, 2015) and market driven (Leipone and Drejer, 2007).

External-based Innovators: A distinctive characteristic of external-based innovators is that a very high share of the firms (84\%) engages in acquisition of machinery, equipment and software as an innovation activity. Alongside their internal sources, they rely on suppliers of equipment, materials, components and software as an information source. Process-related effects of 
innovation (improving flexibility and increasing capacity of production or service provision, reducing labor costs, materials and energy per unit output) together with improving quality of goods and services are the highlighted motivations for innovation. Reducing environmental impact, improving health and safety, and meeting regulatory requirements also lead these firms to engage in innovation. Hence it can be argued that technological and economic significance of innovative output is high. Intellectual property rights do not play much of a role in protecting external-based innovators from their competitors imitating their inventions. This cluster mainly introduces process-related innovations (new or significantly improved methods of manufacturing or producing goods or services, logistics, delivery or distribution methods for their inputs, goods or services and supporting activities for their processes). In sum, drawing upon their suppliers as an information source, external-based innovators acquire machinery, equipment and software and make process-related innovations to improve their business processes. They rarely collaborate on innovation in this endeavour. Manufacture of wood and wood products, manufacture of pulp, paper and paper products, mining and quarrying, publishing, printing and reproduction of recorded media and construction sectors are crowded with firms belonging to this cluster. Asikainen (2015) (process renewer), Clausen et al. (2011) (supplier-based), Srholec and Verspagen (2012) (externally sourced), Hollenstein (2003) (cost-oriented process innovators with strong external links along the value chain), de Jong and Marsili (2006) (supplierdominated), Camacho and Rodriguez (2008) (low innovative supplierdominated firms), Filippett (2011) (cost-saving innovation), Frenz and Lambert (2012) (process modernizing) and Leipone and Drejer (2007) (supplier dominated) studies characterized similar innovation clusters.

Low Profile Innovators: This cluster gets the lowest scores on all indicators except extramural R\&D, acquisition of machinery, equipment and software, registration of an industrial design and new or significantly improved supporting activities for their processes. Low profile innovators do not draw much on any sources or are not driven by any clear objectives in their innovation activities. Only $25 \%$ of these firms develop product innovations 
and this low percentage is explained by the low importance assigned to objectives such as entering new markets or increasing the market share. Similar to external-based innovators, acquisition of machinery, equipment and software is the main innovation activity. Firms within this cluster consider enterprise itself or enterprise group and suppliers of equipment, materials, components, or software as the important information sources. Improving quality of goods or services, improving flexibility of production or service provision and increased capacity of production or service provision are the foremost effects of innovation. Again, similar to external-based innovation cluster, no importance is attached to intellectual property rights and low-profile innovators seldom cooperate on innovative projects. Roughly half of the firms within this cluster implements new or significantly improved supporting activities for their processes. Real estate, renting and business activities, wholesale and retail trade; repair of motor vehicles, motorcycles and personal and household goods, hotels and restaurants, renting of machinery and equipment are the sectors with low profile innovation as the dominant strategy. Ad hoc (Clausen et al. 2011; Leiponen and Drejer, 2007), low profile (Srholec and Verspagen, 2012), low-profile innovators with hardly any external links (Hollenstein, 2003) and hidden innovators (Trigo, 2013) are similar innovation clusters identified in the literature.

As can be observed from Table 2.1, the innovation strategies characterized in detail above are the most frequently encountered ones in previous taxonomic studies. Strategies 1, 2, 3 and 4 within the 4-cluster model of the cluster tree in Figure 2.1 correspond to external-based, science-based, market-based and low-profile innovators, respectively. External-based innovation mode is descended from strategy 3 within 3-cluster solution, which can be characterized as medium-profile innovators ${ }^{4}$. Science-based innovation mode is an offspring of cluster 1, which is high-profile innovators. Highprofile innovators are also linked to market-based innovators within 4-cluster solution. The main difference between these two offsprings is that sciencebased innovators emphasize process-related and social responsibility effects

\footnotetext{
${ }^{4}$ A detailed identification of the innovation modes will not be made for other clustering solutions.
} 
of innovation much more than market-based innovators descending from high-profile innovation mode. The former also involves in innovation of methods of manufacturing or producing goods or services and supporting activities for their processes more frequently than the latter. Market-based innovation mode is an interesting case as a hybrid formation by high and lowprofile innovators. These two components differ mainly in innovation activities and sources of information. A higher share of market-based innovators linked to high-profile innovation mode carries out intramural $R \& D$, market introduction of innovations and training activities related to innovation and they more heavily rely on universities or other higher education institutions, conferences, trade fairs, exhibitions, scientific journals and trade/technical publications for their innovation projects. Lastly, a part of low-profile innovators within 3-cluster model comprises low-profile innovation mode within 4-cluster model as expected. In comparison to market-based innovators descending from low-profile innovators, these firms put less emphasis on clients or customers as a source of information and on increased range of goods or services and entering new markets or increased market share as an effect of innovation. They also introduce comparatively fewer new or significantly improved goods.

As also can be observed in Figure 2.1, when the number of clusters is increased by 1 , external-based, science-based, market-based and low-profile innovation modes replicate themselves as clusters 1,2, 5 and 3, respectively within 5-cluster model. In this case cluster 4 is a hybrid of external and market-based innovators. External-based innovation mode is split into two to form external-based innovation mode and a part of the hybrid mode within the 5-cluster model. Increasing range of goods or services and entering new markets or increasing market share is more important for the former than for the latter whereas the latter has a wider range of sources of information in innovation activities. Within the new hybrid formation, the ones descending from the external-based innovation mode attach more importance to effects of innovation and a higher share of firms descending from market-based innovation mode has intramural $R \& D$ and draws upon universities and other higher-education institutions. Lastly, market-based innovation mode is decomposed into hybrid innovation mode and market-based innovation 
mode within the 5-cluster model. These two groups are separated by the former's reliance on scientific journals and trade/technical publications and on professional and industry associations and latter's emphasis on increasing range of goods or services and entering new markets or increasing market share together with their frequent introduction of new or significantly improved goods.

As a final point, Figure 2.2 shows distribution of firms belonging to four distinct innovation modes in percentage points by standard industrial classification (NACE, rev. 1.1). A relatively even sectoral distribution of innovation strategies is in line with previous taxonomies of technological regimes (e.g. Pavitt, 1984; Clausen et al., 2011). In all industries there are at least two strategies with more than $20 \%$ of firms and in half of the industries the most frequent strategy does not exceed $36 \%$. This finding gives support to the evolutionary theory, which predicts there exists heterogeneity of innovation strategies within sectoral categories.

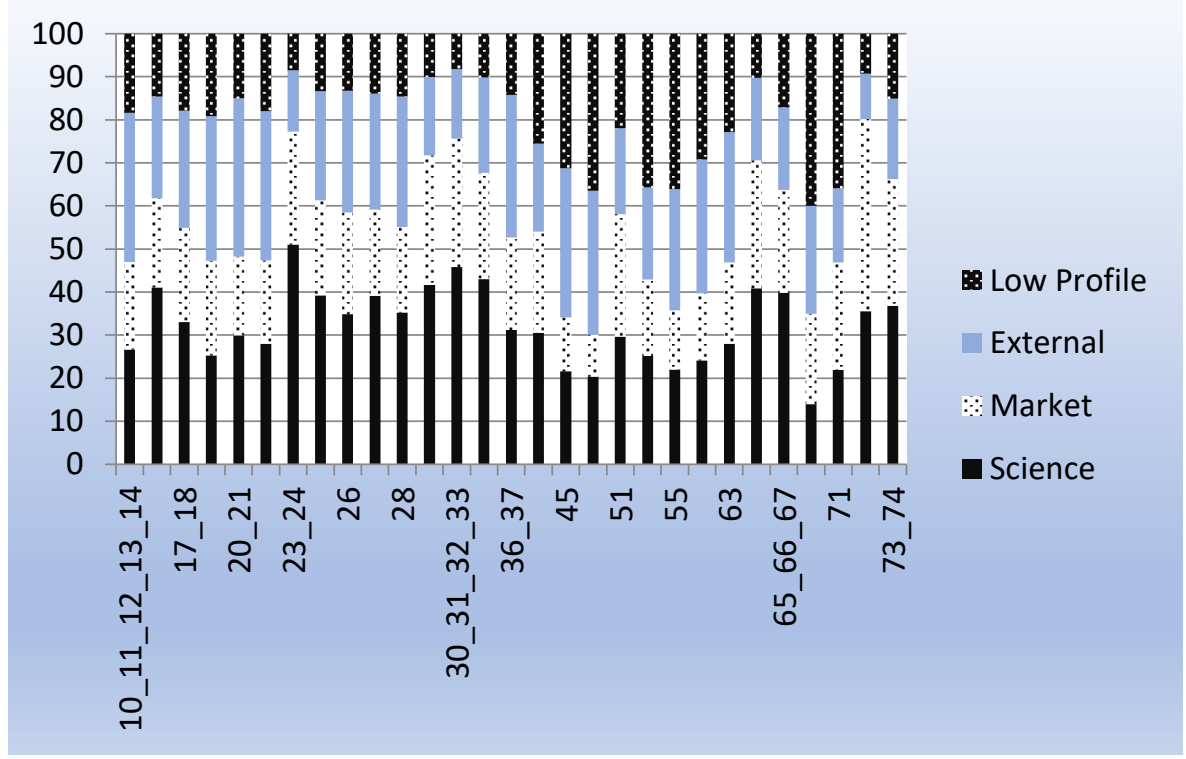

Figure 2.2. Innovation Modes by Sector (\%) 


\subsection{Conclusion}

Taxonomic studies help to explore the existence of several peculiarities in the process of innovation and reduce their variability to analytically manageable levels. The grouping of firms implicitly assumes more or less homogeneous entities with respect to their innovation behaviour, which can inspire us in the formation of our firm groups in the following theoretical modelling chapters. This taxonomic exercise also informs our decisions about the modelling of innovation and imitation behaviour, technology-push vs. demand-pull dichotomy, patenting schemes and technology collaborations between firms.

An original contribution of this study is to show how a cluster of firms following a specific innovation strategy is linked to other groups within models of different number of clusters. LCA of the sample data concludes that a newly formed cluster takes in a significant share of the firms of more than a single existing cluster. A hybrid formation of a new cluster of two already existing clusters is a frequent occurrence. This finding indicates that the empirical identification of innovation modes using a variety of statistical techniques is strictly contingent on model choice. One can lose track of an innovation strategy defined in a given clustering model and/or a new innovation mode undefined in the previous steps can be identified with an increase in the number of clusters.

Based on interpretability and compatibility with previous taxonomic studies of innovation modes, 4-cluster model is selected for an in-depth analysis of innovation strategies. The first identified innovation strategy is science-based innovator. These firms tend to have a broad spectrum of goals and sources for innovation. With strong R\&D capabilities, they rely heavily on scientific sources of knowledge and frequently introduce product, process and organizational innovations. The market-based innovation strategy consists of firms that complement new products with marketing innovations and seek knowledge from their clients and customers, and competitors and other enterprises in their market. As firms that rely mostly on their suppliers as a knowledge source, external-based innovators acquire machinery, equipment and software and make process-related innovations. The low- 
profile innovators is the group with the lowest scores on most of innovation indicators. These innovation strategies are the most frequently identified ones in the empirical literature.

Taxonomic studies of innovation strategies have implications for innovation policy and management, as well as for scholarly research on innovation. The extent to which technology policies can be applied homogeneously has a bearing on economic returns. Governments strive to support firms that are expected to behave in a way conducive to their policy objectives. Therefore, they have to identify categories of such firms towards which the support should be targeted. For example, incentives for collaborative innovation programs may successfully influence the behavior of firms which already have the tendency to engage in such collaboration projects. A proper understanding of variety in innovation help policy makers and private capital markets to discriminate between highly innovative companies in traditional sectors considered to be low-tech and lowinnovation potential firms in a 'high-tech' industry for a more efficient allocation of resources.

This study is designed as a snapshot of the innovation patterns of firms which participated CIS 4 . New waves of CIS's will enable scholarly researchers to observe the evolution of these innovation strategies. A more dynamic interpretation of these strategies based upon market conditions and technological change will help policy makers to adopt more efficient innovation policies. 



\section{Chapter 3}

\section{Heterogeneity in Innovation Strategies, Evolving Consumer}

\section{Preferences and Market Structure}

\subsection{Introduction}

The structure of industrial R\&D has undergone considerable change since 1985, particularly in the United States (Mowery, 2009). This change is mostly related with the increase in the number of and heterogeneity among the agents involved and the complexity of the interrelationships. It had everlasting effects on the innovation process. Innovation is a multifaceted phenomenon at the intersection of economics and technology. However, the economics discipline frequently falls short of developing a holistic approach embracing this multi-dimensional phenomenon. Economists develop theories and models to explain social processes, but when the object of analysis is innovation, the intrinsic gap between reality and the representation of reality by scientific endeavor is generally wider than that 
can be legitimized by its very nature. The size of this gap is even more pronounced when one considers the ever-increasing roles innovation plays in the social matrix. Any modelling exercise should address aforementioned heterogeneity among the agents involved and the complexity of their interrelationships. Therein, it is completely plausible that economists should put maximum effort into discovering analytical methods and modeling techniques exploring the mechanisms at work and testing their models against real life data.

For this purpose, following the footprints of eminent work by Nelson and Winter (1982), the Schumpeterian research tradition has been merged with organisational and behavioural elements (especially Cyert and March, 1963; Simon, 1955) within an evolutionary framework of variation, selection and historical time, in order to capture the dynamics of innovation and their impact on growth, trade and technological change (e.g. Dosi et al., 1988) (Gilbert et al., 2001). This research tradition can be regarded as a radical step forward in understanding innovation in a number of ways. First, market competition through technological change, hence innovation, is at the core of neo Schumpeterian and evolutionary economics analysis (Nelson and Winter, 1982). Second, incorporating behavioral and organisational elements enables a more realistic representation of innovation. Last but not the least, this line of research is well equipped with the required modelling techniques to deal with the heterogeneity among the agents involved and the complex interactions between these agents.

This study is designed as an evolutionary, multi-agent based, sector-level innovation modeling exercise. First, this model will be used to analyze the interaction between R\&D activities of firms and differentiated consumer preferences in structuring the evolution of an industry. Then, we will explore the heterogeneity in firms' innovation strategies: how the market shares of firms having different innovation strategies are affected by a change in a structural market characteristic; market size or a behavioural rule; R\&D intensity. The model addresses the supply and demand side of the market simultaneously with the coevolution of heterogeneous consumer preferences, heterogeneous firm knowledge bases and technology levels at the micro level. In line with the evolutionary modeling tradition, we have a 
search algorithm (innovation and imitation of products by firms), a selection algorithm (revealed preferences of the consumers), and a population of objects in which variation is expressed and on which selection operates: namely, firms (Windrum, 2007). Firms compete on quality and price of their products in an oligopolistic market whereas consumers, constrained by their computational limits, act to maximize their utility with their product choices. There is continuous firm entry and exit depending on the competitive performance of the firms.

$\mathrm{ABM}$ is the most frequently utilized technique in evolutionary settings (Grebel and Pyka, 2006). In case of innovation at industry level, we are exploring a highly decentralized dynamic search process under strong substantive and procedural uncertainty, where numerous heterogeneous agents search in parallel for new products/processes, but are interlinked through market and non-market interactions (Dawid, 2006). Several evolutionary modeling exercises in the literature repeatedly showed that $\mathrm{ABM}$ is capable of simulating such a platform where these peculiarities are successfully mapped into model designs. Furthermore, ABM is offering a platform for inter and trans-disciplinary research, which is again congruent with the requirements of innovation studies. With ABM we hope to stretch the trade-off between simplicity in modeling and the complexity of the socioeconomic reality.

This chapter contributes to evolutionary modeling tradition in a few dimensions. To begin with, it includes an explicit modeling of specific innovation modes. There are three strategy pairs which makes a total of eight exclusive strategies: innovation vs. imitation, technology-push vs. demandpull, and focused vs. diversified. These innovation modes are selected because they are frequently adopted strategy sets by real firms. Secondly, whereas most evolutionary models focus on process innovation, this one exclusively models product innovation, i.e. technical progress is embodied in products. Thirdly, firms compete both in the R\&D process and goods market rather than in any one of them. Lastly, rather than single-product firms, the market is populated with multi-product firms which can serve to different niches of consumers concurrently. With the continuous introduction of new innovations, products transform from undiscovered to discovered and then 
from cutting edge product to obsolete. As the product space steadily shifts, the consumers are compelled to redefine their product choices within the given product range.

The rest of this chapter is organized as follows: Section 2 is a literature review on product innovation and competition in product markets, and heterogeneity in firms' innovation strategies. The first part of the review presents some empirical findings on the existence of and reasons for heterogeneity in innovation modes from several studies. The second part is on how theoretical models conceptualize product innovation and competition. Section 3 details the simulation model. In section 4 , the results of the simulation analyses are discussed. Section 5 concludes.

\subsection{Literature Review}

\subsubsection{Heterogeneity in Innovation Modes}

From the perspective of evolutionary theory, firm diversity is an essential aspect of the processes that create economic progress (Nelson, 1991). Firms differ in many respects, unavoidably including their innovation patterns. Helfat (1994a, b) for example drawing upon the evolutionary theory argued that tacitness of knowledge and cumulativeness of learning lead to highly firm-specific R\&D applications. In the economics of innovation literature, this heterogeneity is either explained by the sectoral (e.g. Pavitt, 1984; Malerba and Orsenigo, 1996; and Dosi et al., 1995) or national (e.g. Lundvall, 1992; Nelson, 1993) differences (Srholec and Verspagen, 2012).

The question of heterogeneity in firm innovation strategies is extremely relevant both from a theoretical and practical point of view. At the theoretical level, it is one of the subjects of discussion between the evolutionary and mainstream traditions. From the evolutionary point of view, it provides an insight into the selection mechanism in different market environments. Evolutionary economists predict that selection process picks the firms adopting the strategy that fits best with the environmental conditions. In a similar vein, neoclassical economists assume that agents are perfectly rational and make the best possible choice for themselves or only the firms following 
the best strategy survive in a competitive environment which corresponds to perfectly rational agents operationalizing the "as if" argument (Friedman, 1953). Hence, the question of heterogeneity in firm innovation strategies addresses the question whether the mainstream prediction of homogenous behavior is observationally equivalent with the outcome of the selection process. From the practical point of view, heterogeneity in innovation provides insights with regard to whether a generic technology policy is likely to be effective (Srholec and Verspagen, 2012).

In an empirical study by Leiponen and Drejer (2007) analyzing the patterns of innovation within and across industries using firm-level survey data from Finland and Denmark, firms within most industries are found to follow multiple patterns of innovation behavior. Even at very detailed levels of industry classification (four- and five-digit NACE industries) and including all industries for which six or more observations are available, only about half of the observed industries have a dominant innovation regime, defined as $50 \%$ or more of the firms in an industry being affiliated with the same regime. The authors interpret this as strategic differentiation or local search activities overcome pressures in the technological environment towards homogenous behaviour, at least in the short term. The multiple patterns of behavior with regard to innovation may be related to intraindustry differentiation: initial strengths and weaknesses of firms, time of entry into the business, and historical accidents.

Arundel et al. (2007) explores the link between the organizational forms and innovation modes (how firms innovate) by developing national aggregate indicators for the EU member states. The innovation mode indicators are calculated using the results of the third Community Innovation Survey (CIS) for innovation activities between 1998 and 2000 to develop a typology of innovation at the firm level and to calculate the distribution of these innovation types within each of 14 EU countries for which data are available. The paper draws on a taxonomy developed by Arundel and Hollanders (2005), in collaboration with Paul Crowley of Eurostat, in order to classify all innovative CIS respondent firms into three mutually exclusive innovation modes that capture different methods of innovating (lead innovators, technology modifiers and technology adopters), plus a fourth 
group for non-innovators. The classification method uses two main criteria: the level of novelty of the firm's innovations, and the creative effort that the firm expends on in-house innovative activities.

By applying cluster analysis to a large set of innovation indicators based upon Swiss Innovation Survey 1999 (which, to some extent, also capture nontechnological aspects of innovation), Hollenstein (2003) identified five specific innovation modes: science-based high-tech firms with full network integration, IT-oriented network-integrated developers, market-oriented incremental innovators with weak external links, cost-oriented process innovators with strong external links along the value chain and low-profile innovators with hardly any external links. These modes are characterized by the use of several groups of variables: (a) innovation indicators, (b) demandand supply-side determinants of innovative activity, (c) the firms' position in knowledge networks, (d) several structural characteristics of firms, and (e) measures of firm performance. This study found firstly, that the firms in most innovation modes are distributed across several industries; however, taking the service sector average as the benchmark, three of five innovation modes are heavily concentrated in specific industries. Secondly, economic performance is related to the affiliation with a specific innovation mode in only one or two of the five modes, depending on the performance measure used. These results imply that neither the "classical" ranking of industries according to innovativeness nor the classification of firms into unordered categories representing innovation modes of equal "economic value" capture the whole reality.

Srholec and Verspagen (2012) use exploratory factor analysis on micro data from the 3rd CIS in 13 countries to interrogate the claim that national and sectoral differences account for much of the heterogeneity in innovation strategies. The study identifies four ingredients of an innovation (research, user, external and production), and five distinct innovation strategies (high profile, user-driven, externally-sourced, opportunistic, low profile). The analysis concludes that there is a considerable diversity in how firms innovate, and these differences remain very substantial once effects due to different sectoral and national contexts are cancelled out. Variance 
decomposition analysis revealed that firm-level heterogeneity is the dominating tendency in the data.

\subsubsection{Product Innovation and Competition}

Today a big part of the innovative effort is directed towards product innovation and generating a continuous stream of product innovations gives firms a competitive edge in many industries. Besides, process innovation also often originates by a stream of (product) innovations in capital goods and this motivates us even more to explore the economic effects of innovations embodied within products (Marengo and Valente, 2010).

Again, in many industries this continuous stream of product innovation goes in parallel with product diversification. Rather than competing on homogeneous products, firms use innovation to bring to the market ever new varieties of products and this creates new market niches. Product differentiation on the supply side is the counterpart of the differentiation of demand. Buyers have heterogeneous needs and preferences and markets are segmented. Thus, product innovation is constantly creating sub-markets (Klepper and Thompson, 2006), i.e. transforming industries into systems of weakly competing heterogeneous market segments, with new segments appearing all the time and attracting new potential buyers, and old segments disappearing (Marengo and Valente, 2010).

Economists have developed models explaining creative destruction outlined by Schumpeter. A model of endogenous growth through product innovation by Romer (1990) explicitly incorporates the number of product designs. These new designs (i.e. horizontal innovations) are never close substitutes for existing goods and this precludes Schumpeterian destruction. Five studies that have built on Romer's work, adding product obsolescence, are Segestrom et al. (1990), Segestrom (1991), Aghion and Howitt (1992), and Grossman and Helpman (1991a, 1991b). These papers advance models in which firms compete against one another through vertical product innovations. Grossman and Helpman coin the phrase "quality ladder" to describe the stages in a product's life: undiscovered to discovered cutting edge product to obsolete due to newly discovered products. In adding obsolescence to Romer's framework, these models have abandoned 
horizontal innovation altogether, although Grossman and Helpman (1991b) show that their vertical innovation model shares an identical reduced form with Romer's horizontal innovation model for some variants. Each model reaches an equilibrium in which the rate of innovation is constant. While equilibria bring analytical tractability, the notion of steady state rates in innovative progress is intuitively unappealing. Indeed, work by Stein (1997) suggests that innovations tend to come in waves (Teitelbaum and Dowlatabadi, 2000).

\subsection{Research Topic}

The model in this study addresses the issues raised in the literature review. Firms are endowed with their fixed innovation strategies. They compete on price and quality of their products and they engage in innovation activities to increase their quality. This continuous stream of product innovations shifts consumers' preferences towards higher quality products. Firms reaching higher quality levels on the quality ladder earlier than their competitors gain a competitive edge in the market. Buyers are heterogeneous, and markets are segmented.

This model will enable us to analyze the interaction between R\&D activities of firms and heterogeneous consumer preferences in structuring the evolution of an industry. In order to stay competitive, firms introduce ever increasing quality of products to the market either by innovation or imitation. Consumers with heterogeneous preferences act to maximize their utility with their product choices shifting their preferences towards higher quality goods. The model will show how firms and consumers interact in the market environment and how this interaction leads to technological progress. We will also explore whether heterogeneity in innovation strategies is sustainable in the long term as observed in real life examples and what happens to the market shares of firms having different innovation strategies when a structural market characteristic (market size) or a behavioural rule (R\&D intensity) is changed. 


\subsection{The Model}

This is an agent-based model, agents being firms and consumers. The agents follow pre-specified heuristics (e.g. innovation routines, marketing expenses, product purchases) and react to competitors and environmental conditions (e.g. pricing) and the interactions between these agents at the micro level determine macro outcomes. The model will show how these outcomes are conditioned by the parameters of interest.

Firms pick a price for their goods and put them on the market for consumers' purchase. To make their products visible to potential buyers they make some marketing expenses. Consumers sample a few products and compare them with their previous experiences to buy one that fits best with their preferences. A part of the revenue raised with product sales finances firms' R\&D activities. In accordance with their strategy, firms engage in R\&D activities and if they succeed, new products are added to their portfolio. Depending upon their competitive performances goods and incumbent firms leave the market leaving their places to new generation of goods and newcomer firms.

\subsubsection{Technology Space}

Each product and technology (knowledge) embodied by this product is labeled by an integer number. The words "product", "quality" and "technology" will be used interchangeably in the following. A bigger number corresponds to a higher quality product and a better technology. The units digit of this number shows the version of the product while the rest of the number shows the class the product belongs to. As an example, the number 23 refers to the third version of the second class of products. Hence, each class consists of ten versions. A class is significantly different from any other in terms of its technological level whereas there are only incremental differences between versions in this regard. Products high on the quality ladder (Grossman and Helpman, 1991a; 1991b) -products belonging to higher classes or higher versions within a given class- are intrinsically better than the lower ones. The distance between the highest version in a given class and 
lowest version in a consecutive higher class is a parameter of the model and there are no defined products in between. Hence the technology space resembles an infinite series of quality ladders on top of each other, each ladder stands for a technology class and each step for a version, and a move from one class to the next requires a jump between the ladders which is only possible with a radical innovation.

\subsubsection{Demand and Supply Structure}

Firms compete on quality and price of their differentiated products in an oligopolistic market. There are no production quantity constraints on the firms and all demand is satisfied in every period; there is no stock ac cumulation or unsatisfied demand. The production cost of a product is linearly related with its quality. Price is initialized as a mark-up over cost and this is the minimum price allowed, which means that sales of a product always bring positive profits and ceteris paribus higher quality products mean higher profits. Pricing strategy is a dynamic mark-up heuristic through which firms decide price of each good every period as a function of quality of and profits from that product. Specifically, the proportional change in price is a linear function of the proportional change in the profits on that product in the last two periods. The responsiveness of price to a change in profit is smoothed by a parameter ${ }^{\S}$. A product with no sales in the last but one period is priced at its initial price.

$$
\begin{aligned}
& C(n)=m q(n) \\
& p_{i}=(1+\mu) C(n) \\
& p(n, t+1)=p(n, t)+s p(n, t)\left(\frac{\pi(n, t)-\pi(n, t-1)}{\pi(n, t-1)}\right)
\end{aligned}
$$

where $C(n)$ : cost of product $n$

$m$ : cost multiplier

$q(n)$ : quality of product $n$

$p_{i}(n)$ : initial price of product $n$

$\mu$ : mark-up rate

$p(n, t)$ : price of product $n$ at time $t$ 
$s$ : smoothing parameter

$\pi(n, t)$ : profit on product $n$ at time $t$

If a product's average market share over a specific number of periods is below a threshold level, it is deleted from the market. A firm with no products to sell goes bankrupt. Every period a constant number of firms enter the market, each as an exact copy of an already existing firm, except for its innovation strategy that is randomly determined. The firms that are copied by the new entrants are selected among the firms below a certain market share. This seems a reasonable approximation of reality because in practice most firms start small (de Wit, 2005; Dunne et al. 1988).

Consumers have what we call a memory set which consists of a number of goods selected among all the products the consumer considered to buy in the previous periods. This selection is based on the utility level the product would bring to the consumer in case of a purchase. At every period, the consumer checks whether the products in the memory set are still provided by the market. If any of them is removed from the market, it is replaced by a new randomly selected product. Again, at every period, consumers randomly sample a number of products from randomly selected firms. The probability that a product is selected is proportional to the marketing expenses by the firm on that product.

A constant share of the last period's revenue, which is equal for each firm, is spent on marketing activities to make goods visible to the consumers and this marketing budget is shared among products according to their quality level. Specifically, the visibility of a good is the average of the marketing expenses on that good for the last five periods. Price is initialized as a markup over cost, which is a linear function of quality, and this is the minimum price allowed. Hence higher quality products bring higher profits and this is why goods consume a share of marketing budget in proportion to their quality.

The newly selected product is compared with the current minimum utility promising product in the memory set and replaces this if it corresponds to a higher utility level for the consumer. Out of this dynamically structured memory set, the good that brings the highest utility is chosen to buy in every 
period. There are no income constraints faced by the consumers. This product selection heuristic is a decent representation of the basic evolutionary processes of reproduction-keeping the highest utility promising products from the previous periods-, selection-choosing among products to maximize utility-, and variation-a continuous and random selection of new products-. The existence of a memory set and the peculiar way products become visible to the consumers enable us to model brand loyalty and advertising effects, respectively (Malerba et al., 1999).

Utility is a positive function of the quality and a negative function of the price, and the distance between product's profile and idiosyncratic ideal good specific to each customer profile (Marengo and Valente, 2010). At the outset, the consumers position themselves within the available technology space into consumer profiles or let us say, submarkets. The number of submarkets is constant and each submarket corresponds to a point in the technology space between current minimum and maximum quality levels. The total number of consumers is uniformly distributed into these submarkets and this relative positioning somewhere between the minimum and maximum available technology level in the market is constant through the simulation run. Figure 3.1 exemplifies this distribution. This formulation allows one to model heterogeneity in consumer preferences; consumers consist of early adopters with a strong preference for high-tech goods, low-price lovers who are content with low quality goods and the ones seeking a balance between price and quality. As technology develops, the level of minimum and maximum available technology improves, preferences shift towards higher quality products increasing the quality of the ideal type good for each consumer. The fact that homogeneous consumers are populating submarkets can be interpreted either as there are as many consumers as the number of submarkets and each of these consumers is making a group buying every period or the submarkets consist of a number of homogenous consumers buying the very same product.

$$
\begin{aligned}
& U(n, k, t)= {[r\{q(n)-\bmod (q(n), 10)\}+\bmod (q(n), 10)]-p(n, t) } \\
&-\left|q(n)-q_{i}(k, t)\right| \\
& q_{i}(k, t)=q_{\text {min }}(t)+u(k)\left(q_{\max }(t)-q_{\min }(t)\right)
\end{aligned}
$$


where $U(n, k, t)$ : utility of good $n$ for customer $k$ at time $t$

$r$ : radical innovation constant

$\bmod (q(n), 10): q(n) \bmod 10$

$q_{i}(k, t)$ : ideal good profile for consumer $k$ at time $t$

$q_{\min }(t)$ : minimum quality level at time $t$

$q_{\text {max }}(t)$ : maximum quality level at time $t$

$u(k)$ : a random pick from a uniform distribution between 0 and 1 for each customer at the outset

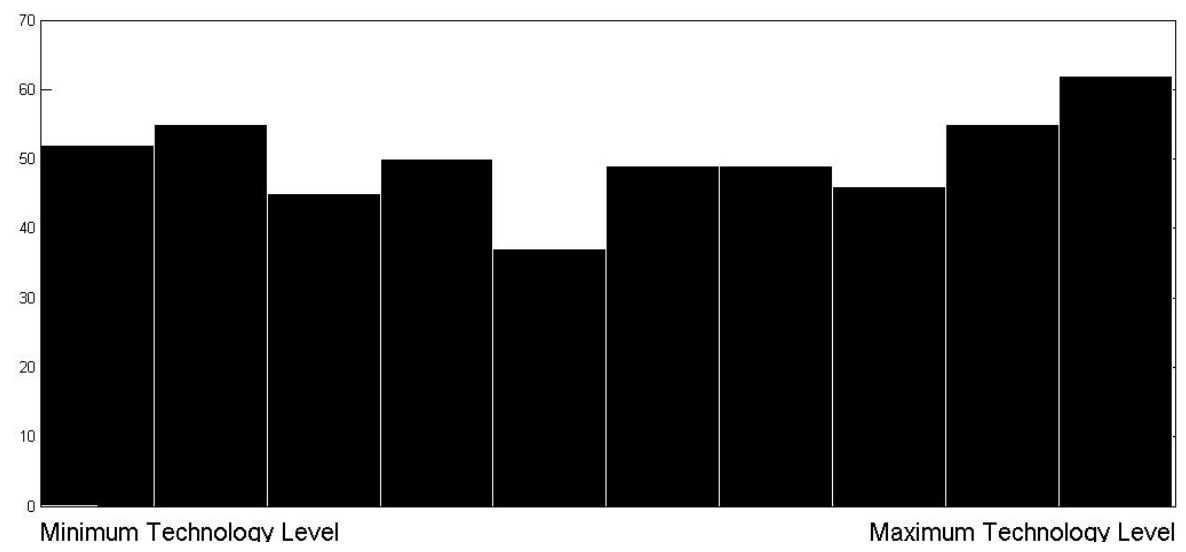

Figure 3.1. A histogram showing the uniform distribution of the customers' ideal product profiles within the available technology space

The first part of the utility function in the square brackets gives the positive utility derived from the quality of the product. This part is separated into two dimensions: the class that the product belongs to, as given by the part in the curly brackets, and the version of the product within that class which is represented by the unit digit of the product quality number. This separation between class and version of a product in utility terms requires us to use modular operation. Modular operation finds the remainder of division of one number by another. To give an example, A mod B can be thought of as the remainder, on division of A by B. The divisor (B in our example) in our case is 10 , because there are exactly 10 versions within each class. A distinction is made between the class and version of a product since consumers attach different levels of values to these dimensions. 
Consumers care more about the class of a product rather than its version within a given class. This distinction is operationalized by the parameter $r$. The parameter $r$ is defined as the radical innovation constant and determines, ceteris paribus, by how much two consecutive versions in different classes differ from each other compared to two consecutive versions in the same class in utility terms. To put it another way, $r$ indicates by how much the first version in a class is evaluated better than the last version in a lower class in comparison to one version is evaluated higher than a one degree lower version in the same class holding all else constant. The higher $r$ the higher is the possibility that higher-class products will be preferred over lower-class products. $r=1$ presents a special case where there is no more a distinction between the class and the version of a product. Under such a circumstance it will take longer for the inferior products to be eliminated, product range will increase and technological change and hence wealth creation will slow down, since consumers no more put a premium on radical innovations.

The price of a product appears in the utility function with a negative term. The last part of the utility function in the absolute terms gives the negative utility due to consuming a non-ideal product. This form of the utility function allows one to model heterogeneity in consumer tastes with the inclusion of the distance of the candidate product from the ideal one and to model the process whereby products transform from non-invented to invented and from cutting-edge to obsolete in time with a continuous shift of preferences towards higher quality products as explained in the preceding paragraph. This process is especially accelerated with an $r$ value higher than 1 .

\subsubsection{Innovation Function and Strategies}

Innovation is defined as the emergence of a new product. The firm chooses a product to invest in from its portfolio and does R\&D. The quality level of this product also shows the knowledge base of the firm in that specific project. Innovation size is modeled as a random pick from a Poisson distribution with an arrival rate which is a function of the quality of the product invested in and the R\&D budget devoted to that project (Minniti et al., 2013). The arrival rate is a negative function of the quality of the product to invest in: complexity of the product decreases the likelihood of the research success and 
there are diminishing returns to $R \& D$; additional investments increase the arrival rate in a decreasing manner. Hence, a lower level for the complexity of the knowledge base and more R\&D investment increases the size of an innovation. A constant share of the last period's revenue is allocated to $R \& D$ every period and this share does not differ among firms.

When innovation occurs, the resulting difference (the size of the innovation) is added to the chosen product's technology level. A new product embodying a new technology and a higher technology base emerges. If the newly innovated product is in a higher class, then we have a radical innovation. Otherwise we have an incremental innovation. Depending on the radical innovation constant $(r)$ parameter value, radical innovations may render old technologies in the market obsolete whereas incremental ones do not have such an impact. Hence a radical innovation may disturb the profit stream from the lower-class products which means that a firm can cannibalize its own products. This feature is introduced to the model with the specification of the utility function whereby higher-class products will have a market stealing effect on the lower-class products.

In the case of a radical innovation, the size of the innovative step is large enough to cover the sum of the distances between the knowledge base and cutting-edge technology in the respective class and the distance between two consecutive classes where no products are defined. The size of an innovative step is limited to a maximum of one radical innovation at a time. When there is a radical innovation, the newly innovated product will be allowed at most to be the lowest version in the new class and nothing higher. This constraint negates the possibility that knowledge base achieved in the previous class helps explore the technology space of the new class of products. If the resulting innovation appears to be in the interval between two classes where no products are defined, then the innovation project is assumed to fail.

$$
\begin{aligned}
& \lambda(n, i, t)=\frac{R(n, i, t)^{\alpha}}{q(n)} \\
& \delta(n, i, t) \sim \operatorname{Pois}(\lambda) \\
& q\left(n^{\prime}\right)=q(n)+\delta
\end{aligned}
$$

where $\lambda(n, i, t)$ : innovation arrival rate for product $n$ of firm $i$ at time $t$ 
$R(n, i, t): R \& D$ investment of firm $i$ in product $n$ at time $t$

$\alpha$ : innovation productivity parameter

$\delta$ : innovation size, a random pick from a Poisson distribution with arrival rate $\lambda$

$q\left(n^{\prime}\right)$ : quality level of the innovated product

Imitation is defined as creating an exact copy of another firm's product. Once the product to invest in is chosen within a firm's own portfolio, the firm determines the expected size of the imitative step given its R\&D budget and base technology. Then, it searches through the product sets of other firms to find this prospective target product. If this product is not innovated yet or not extant anymore, or if the number of imitative projects is higher than one, the firm seeks for a one step lower product and continues this search until the number of target products found is equal to the number of imitative projects. If needs be, the firm repeats this search cycle with the next base product. After this search process is over, if the number of target products falls short of the number of imitation projects the firm plans to carry out, idle R\&D budget is transferred to the marketing budget for the next period. The size of the imitative step is modeled with the same function given for innovation projects except for the fact that $R \& D$ investment is more productive in imitation than in innovation. If imitation succeeds, -the imitative step is at least as large as the distance between the base product and the target product- the result of the project can only be the target product itself and nothing else. Even if the imitative step is bigger than the difference in the technology levels, the firm will be assumed to achieve the target quality, but no higher.

$\lambda(n, i, t)=\frac{R(n, i, t)^{\beta}}{q(n)}$

$\delta(n, i, t) \sim \operatorname{Pois}(\lambda)$

$q\left(n^{\prime}\right)=q(n)+\delta$

where $\lambda(n, i, t)$ : imitation arrival rate for product $n$ of firm $i$ at time $t$

$R(n, i, t): R \& D$ investment of firm $i$ in product $n$ at time $t$ $\beta:$ imitation productivity parameter 
$\delta$ : imitation size, a random pick from a Poisson distribution with arrival rate $\lambda$

$q\left(n^{\prime}\right)$ : quality level of the imitated product

In picking R\&D projects, firms pursue either a technology-push or a demandpull strategy. Technology-push firms select R\&D projects starting from the highest technology base they possess to come up with cutting edge technology possible for them (technology-driven). Demand-pull firms start from the technologies with the highest market share with the hope of attaining products which will maximize their profits in the following periods (market-driven). The number of $R \& D$ projects a firm plans to realize in every period is a parameter of the model and this value is higher for "diversified" firms in comparison to that of "focused" firms. If a firm engages in more than one project at a time, $R \& D$ budget is equally distributed among the projects.

Hence, the firms are bound to follow one of the eight strategies throughout the simulation run: diversified demand-pull imitation, focused demand-pull imitation, diversified technology-push imitation, focused technology-push imitation, diversified demand-pull innovation, focused demand-pull innovation, diversified technology-push innovation and focused technology-push innovation. The financial resources required to imitate a product are lower than to innovate one and the chance of success is higher. However, the profits especially from a new-to-the-market innovation are higher compared to an imitated product for which the market is already satisfied at least to some degree. In the case of demand-pull projects, as market conditions guide the decisions, there is a higher prospect for new products bringing about above-average profits with a small variance. However, for technology-push $R \& D$, despite prospects of profitability are more uncertain, the likelihood of ending in top-notch or new to the market products is stronger compared to market-driven R\&D. As for the difference between a focused vs. diversified strategy ("breadth" of the innovation strategy, Marengo et al., (2012)), some firms prefer spreading their R\&D budget over a range of products whereas others go for focusing on one product. A wider scope of search may help distributing the risk and bring about better prospects for profits in different market niches (classes of goods). 
However, the size of the innovative and imitative step will decrease in the number of projects as total R\&D budget will be shared among a larger set of products.

\subsubsection{The Pseudo-Code of the Model}

At the initialization period market is populated with $\mathrm{N}$ firms with a random product portfolio and each consumer is assigned to a submarket. The routine for the rest of the simulation is implemented as follows:

1. Firms set a price for each product as a function of profits from that product in the previous periods.

2. Firms make marketing expenses for each product as a function of the quality.

3. Each consumer determines her ideal product.

4. Consumers structure their memory sets and purchase the best product within this set.

5. Products with an average market share below a threshold level are deleted from the market. Firms with no products to sell leave the market. New firms with random strategies enter.

6. Firms do R\&D in accordance with their innovation strategies and new products are added to firms' portfolio.

\subsection{Simulation Results}

\subsubsection{Model Dynamics}

In the following we will present the results of the simulation analysis. ${ }^{5}$ The data for the analysis is produced as an average over 100 simulation runs of

\footnotetext{
${ }^{5}$ The model was implemented on the Laboratory for Simulation Development platform (Valente, 2008). Software and documentation for the platform are available at www.labsimdev.org. The code and configuration file of the model is available from the author upon request. The initialization of the main parameters of the model can found in the appendix to this chapter.
} 
1000 steps using the base model configuration. The only thing that changes from one simulation to the other is the seed value which is a number used to initialize the pseudorandom generation process. This seed value governs all the stochastic processes within the model and two simulations with the same seed value always give the very same results. We start with introducing the evolution of the main variables of interest in the model to answer our two research questions: whether heterogeneity in innovation strategies is sustainable in the long run and how R\&D activities of firms and heterogeneous consumer preferences interact in structuring the evolution of an industry.

Figure 3.2 traces the time-path of the market shares of the groups of firms following one of eight different strategies. The figure shows that heterogeneity in firms' innovation strategies is sustainable; every strategy enjoys a positive market share throughout the simulation run. Figure 3.2 also signifies a shake-out of the market shares in the initial periods followed by a dispersion and stabilization for the following terms.

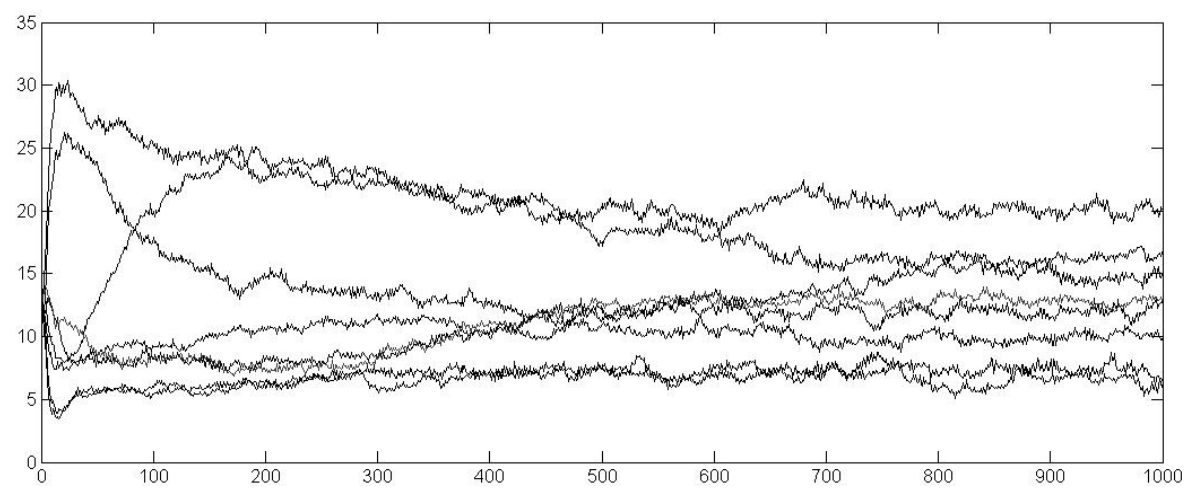

Figure 3.2. Market shares (\%) of firm groups following different innovation strategies

Figure 3.3 allows us to observe the maximum (upper series) and the minimum (lower series) level of qualities available in the market. Whereas the maximum quality level is mainly determined by the R\&D activities of the firms and the minimum level mainly by the competitive forces and heterogeneous consumer tastes, the interaction between demand and supply 


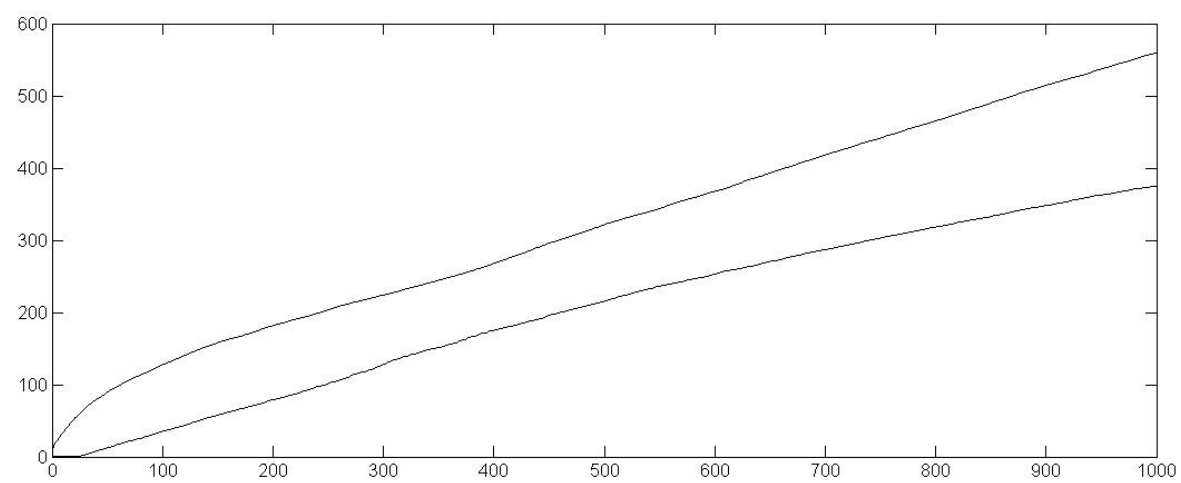

Figure 3.3. Maximum (upper series) and minimum (lower series) quality levels available

dynamics affects these levels both. The continuous introduction of new products by innovation raises the maximum quality and renders low quality products obsolete by shifting consumer preferences towards high-tech products. Technological change is the engine of economic growth in this model. If for some reason technology creation comes to a halt (e.g. imitators conquer innovators dominating the whole market and leaving innovators with no financial resources to innovate), wealth creation also stagnates. Therefore, both consumers and imitator firms depend upon innovator firms to prosper. Drawing upon this graph, the reader should not be deceived that the model produces innovative progress at a steady state growth rate. It should be reminded that Figure 3.3 is created using data as an average over 100 simulation runs. When we observe the same series for a single as in Figure 3.4, we see that innovations come in waves; times of rapid technological change is followed by stable periods when there is no technological advancement at the sector level. This is due to the way the product space is defined; classes and versions within classes or in other terms successive ladders and steps of the ladders. When a firm reaches the top of a ladder (technology class), it has to jump over the gap between two ladders to continue climbing. This requires higher financial resources compared to previous R\&D projects and generally a few trials. Hence technological change stagnates at these points. Once this is achieved, it is relatively easier to climb 


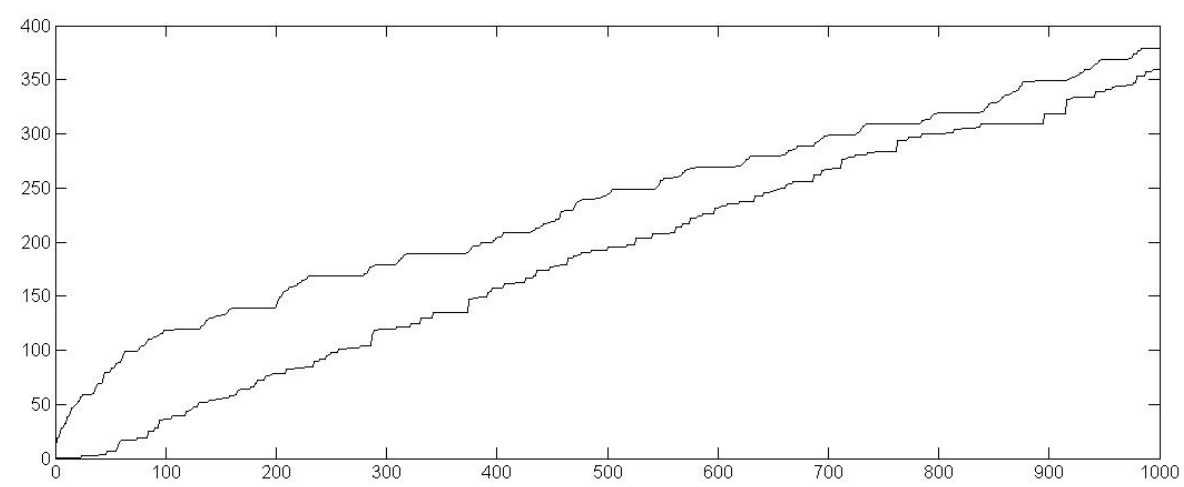

Figure 3.4. Maximum (upper series) and minimum (lower series) quality levels available for a single run

up the steps (technology versions) of the next ladder. That is why innovations come in waves.

\subsubsection{Simulation Experiments}

This subsection includes the results of a series of simple experiments designed to help us explain our next research question; what happens to the market shares of firms having different innovation strategies when a structural market characteristic-market size-or behavioral rule-R\&D intensity- is changed is. The analysis in this section is based on data derived as averages of end of simulation values of variables over 100 simulation runs each with a different seed value. At this point the reader should be reminded that there are three strategy pairs which make a total of eight exclusive strategies: innovation vs. imitation, technology-push vs. demand-pull, and focused vs. diversified.

The first of our graphs is to explore the relationship between market size and market share of innovative firms. Figure 3.5 depicts that a bigger market size is more conductive to the imitative firms than it is to innovative ones. Within this model, market size refers to the total number of consumers populating each homogenous submarket. The explanation for this downward sloping line lies in the fact that $R \& D$ investments are more productive in imitation than in innovation. A bigger market with many consumers means higher revenues and hence higher budgets allocated to 


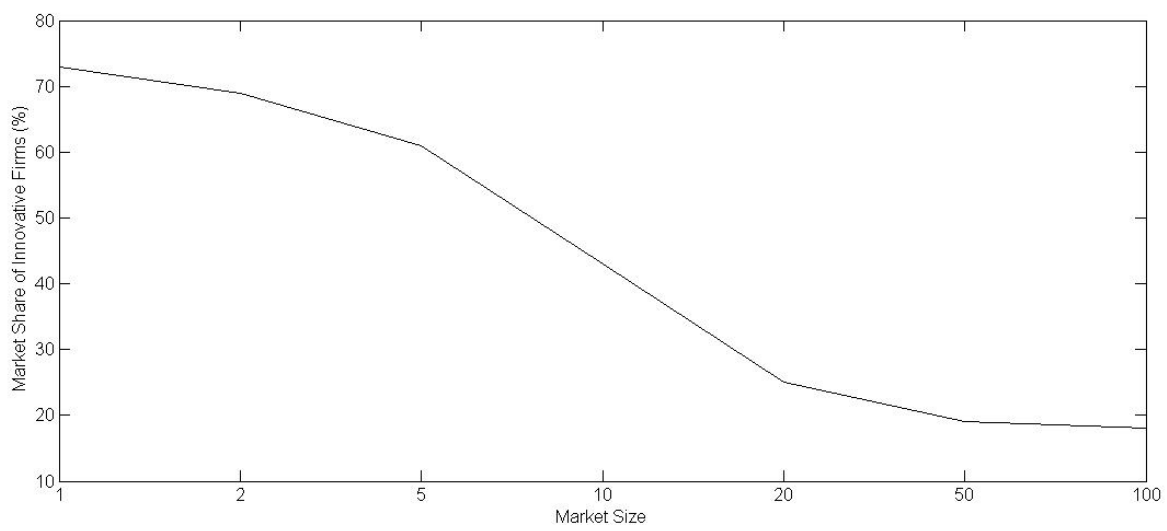

Figure 3.5. Market share (\%) of innovative firms as a function of market size

R\&D. Working with these higher R\&D budgets emphasizes the productivity differential between imitators and innovators. It is easier to imitate a product than to innovate one with a given R\&D budget. We can conclude that a higher number of consumers means a higher change of living for imitators.

Figure 3.6 shows that focused firms lose their market share to diversified firms as market size increases. Focused firms conduct a single R\&D project at a time whereas diversified firms share their R\&D budget equally among a few projects. Multi-project firms have a better chance to have a richer product portfolio which enables them to service several submarkets simultaneously; hence they can control a larger share of the market. But the drawback to this strategy is that this is only possible if $R \& D$ budgets are high enough to finance these projects. Because, the size of the innovative and imitative step will decrease and the possibility of failure in these projects will increase in the number of projects as total R\&D budget will be shared among a larger set of products. A limited R\&D budget means a slower technological progress for diversified firms in comparison to focused ones if no technological progress at all. This trade-off explains the general downward trend in Figure 3.6. An increase in markets size gives a boost to R\&D budgets which gives and edge to diversified firms over the focused ones. 


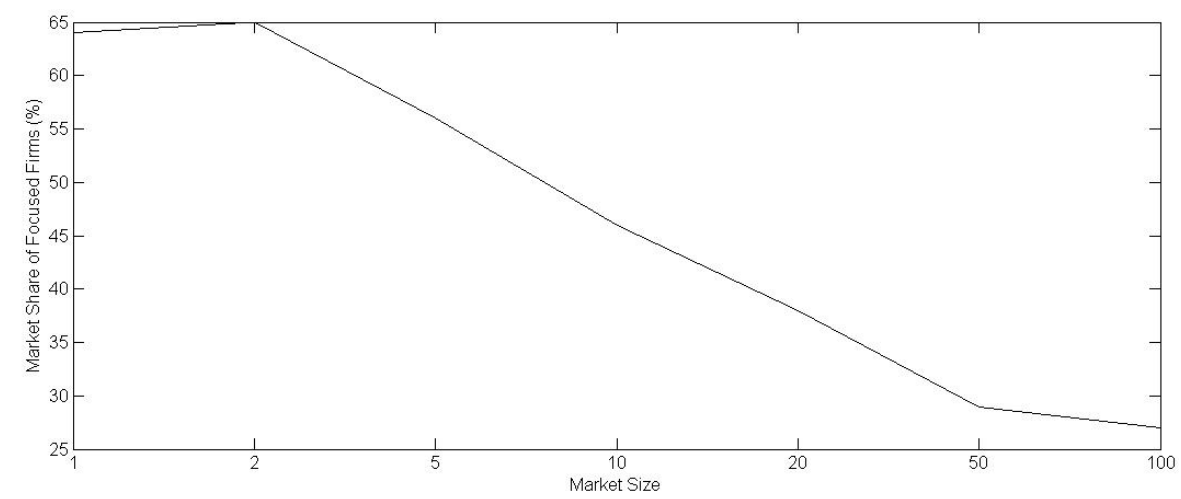

Figure 3.6. Market share (\%) of focused firms as a function of market size

Our next graph is to see the effect of market size on market sharing between technology-push and demand-pull firms. Demand-pull firms, guided by market conditions, search the technology space within the vicinity of their products with the highest market share while technology-push firms aim at fastest technological progress possible. Especially in the short-term technology-push firms investing in the most developed technologies they have lose their market share to demand-pull firms investing in the products most preferred by the consumers. When market size is larger, it is more rewarding to behave according to the signals from the market. That is why demand-pull firms increase their market share as market size enlarges as seen in Figure 3.7.

Figure 3.8 reports maximum and minimum technology levels as a function of market size. As market enlarges, there is an initial increase in the level of maximum technology interrupted by a local peak and then it starts to decrease. After a local minimum, further enlargement of the market results in higher levels of maximum technology. One expects the maximum level to rise monotonically; a larger market means higher revenues which in turn mean higher R\&D budgets. Additional financial resources for innovation accelerate technological change and minimum technology level keeps pace with maximum technology level. However, there is more to this explanation than what is covered above. Innovator firms mainly determine the pace of technological change and a larger market decreases the market share of innovators as explained in Figure 3.5, depriving them of highly needed R\&D 


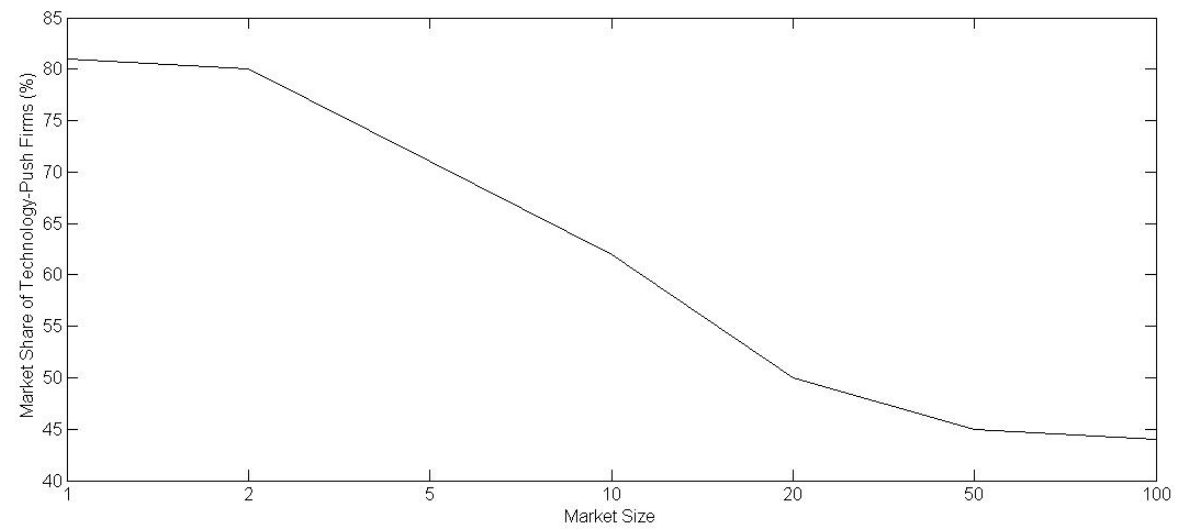

Figure 3.7. Market share (\%) of technology-push firms as a function of market size

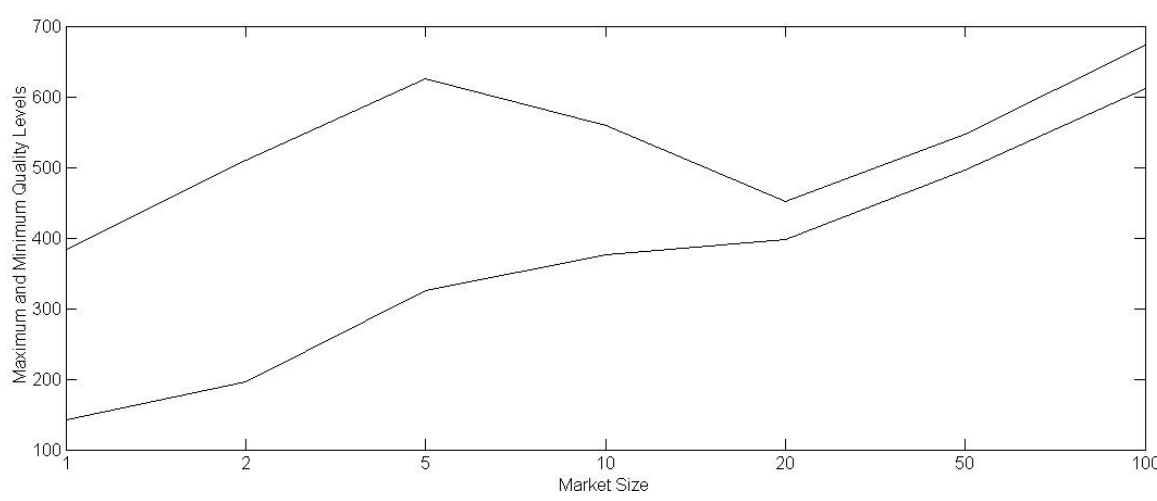

Figure 3.8. Maximum (upper series) and minimum technology levels (lower series) as a function of market size

investments to achieve the highest technology level possible. This explains why for the middle ranges of the market size a decrease rather than an increase is observed in the maximum technology level. Hence, the negative relationship between the market share of innovators and market size is the reason why the initial expectation does not come true. Beyond a critical value, even further increases in the market size equip innovators with adequate R\&D budgets to speed up technological development even if that increase brings about market share shrinkages on the part of innovators. 
From this point onwards, the analysis continues with the effects of R\&D intensity on market sharing between different strategies. Figure 3.9 shows the market share of innovative firms as a function of R\&D intensity. The figure depicts that a higher R\&D intensity decreases the market share of innovative firms. The explanation for this is parallel to the explanation of Figure 3.5. Imitator firms are more productive than innovators in doing R\&D. A higher $R \& D$ intensity means a larger part of the revenue income is devoted to $R \& D$ and this financial resource is more effectively used by the imitators.

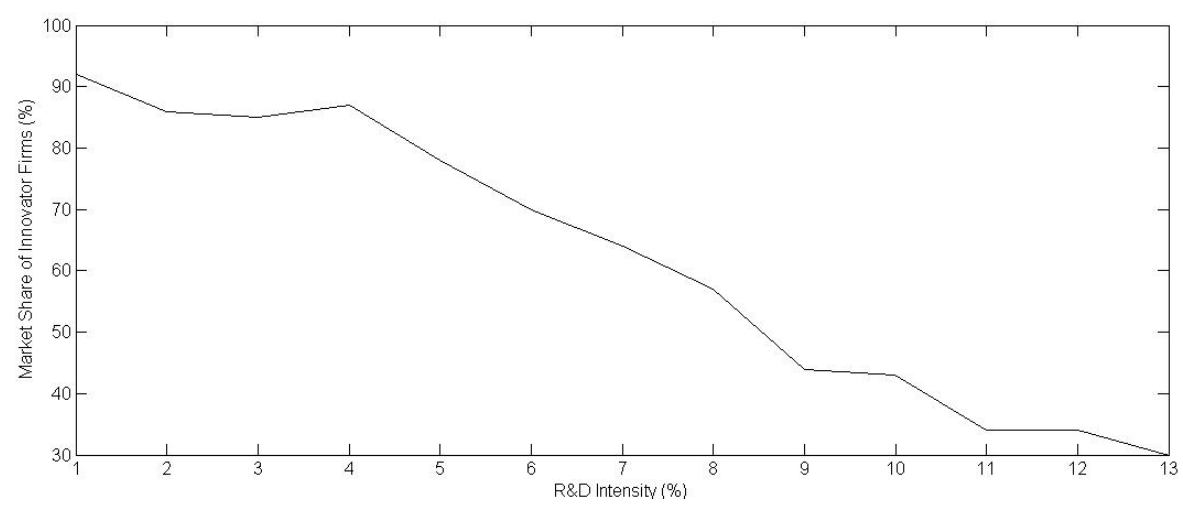

Figure 3.9. Market share (\%) of innovator firms as a function of R\&D intensity $(\%)$

In Figure 3.10, we observe how the market share of focused firms decreases with an increase in R\&D intensity. As one would remember, focused firms conduct a single $R \& D$ project at a time whereas diversified firms share their R\&D budget equally among a few projects. Multi-project firms' advantage is the higher chance of achieving a more diversified product portfolio which helps them satisfy heterogeneous consumer submarkets simultaneously whereas focused firms' advantage lies in a higher chance of success in R\&D projects and a higher size of an imitative or innovative step-faster technological progress- since they invest their R\&D budget in only one project at a time. Whether imitators or innovators exploit their strategic advantages more effectively is determined by the level of $R \& D$ resources. When R\&D intensity is low, diversified firms do not possess the required financial resources to succeed in more than one project conducted at the same 


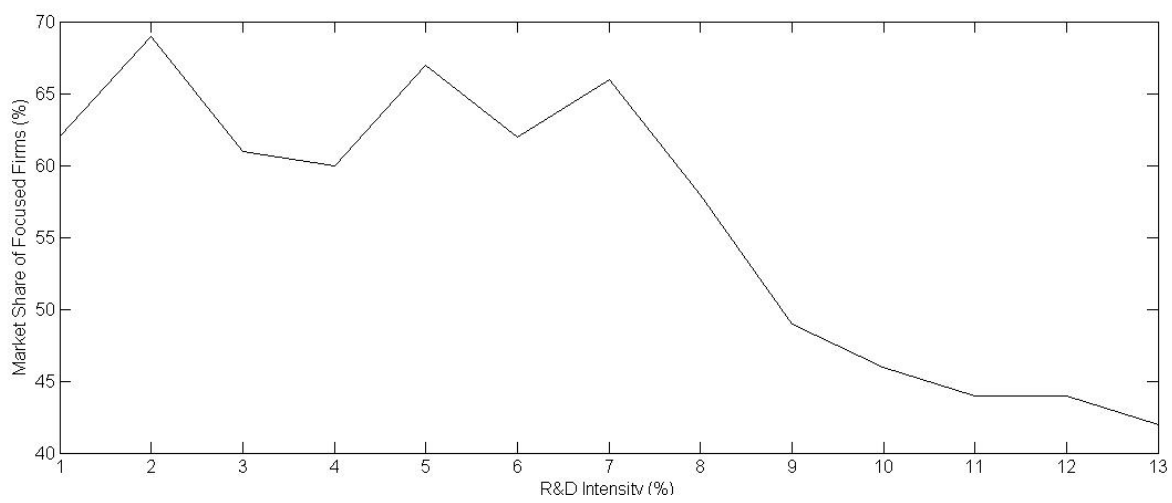

Figure 3.10. Market share (\%) of focused firms as a function of R\&D intensity $(\%)$

time. A high R\&D intensity equips them with the highly needed finance to achieve a diversified product portfolio.

Our next graph (Figure 3.11) is to see the effect of R\&D intensity on market sharing between technology-push and demand-pull firms. Demand-pull firms invest in the technologies with the highest market share whereas technology-push firms invest in the most improved technologies they possess. Therefore, we can argue that demand-pull firms aim at short-term profit maximization and technology-push firms go for the fastest technological progress. This difference in the followed strategies favor technology-push firms in the long-run as consumers shift their preferences towards the highest quality goods, and hence towards technology-push firms owning these technologies. Being technology leaders brings with it being market leaders in the long-run. But this is only possible if the $R \& D$ resources are binding, because the maximum innovative or imitative step is limited by one radical innovation at a time. When R\&D intensity is low, technologypush firms pace technological change as they always invest in the most improved technology they have and this gives them advantage over the demand-pull ones. However, when R\&D intensity is high and hence financial resources are abundant, $R \& D$ budgets are no more binding and independent of their base technology choices in their R\&D projects, demand-pull firms can keep up with the pace of technological change which is limited with one radical innovation at a time. The inverse relationship between the market 


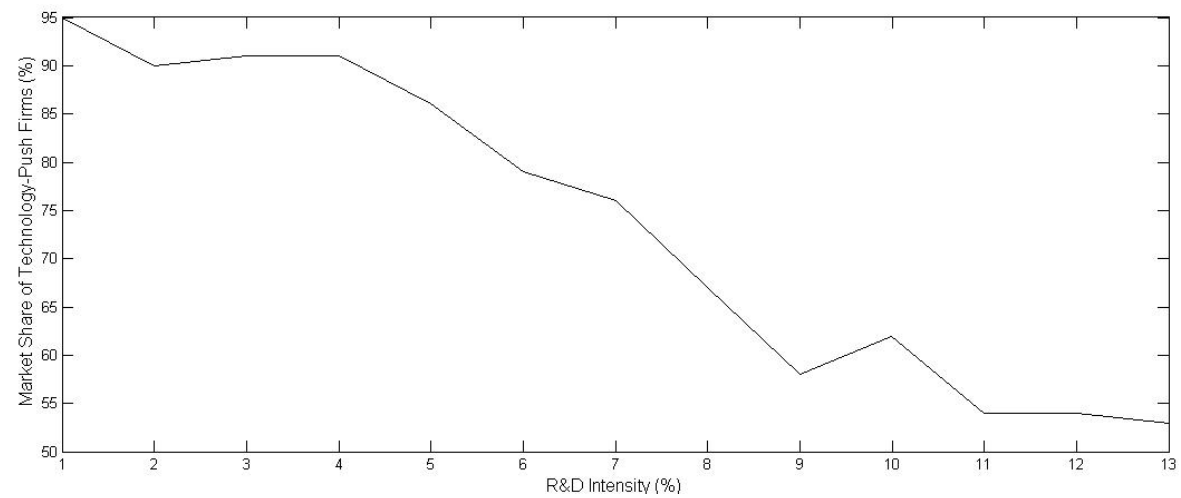

Figure 3.11. Market share (\%) of technology-push firms as a function of R\&D intensity (\%)

share of technology-push firms and R\&D intensity in Figure 3.11 confirms this explanation.

Figure 3.12 reports maximum and minimum technology levels as a function of R\&D intensity. An immediate expectation is having consistently positively sloped lines; a higher R\&D intensity means higher R\&D budgets which lead to faster technological progress. But as seen in the figure this is not the case after the middle ranges of the R\&D intensity value. The reason for the maximum technology level to peak at a middle range of the R\&D intensity and to level off thereafter should be looked for within Figure 3.9. A higher R\&D intensity causes innovators to lose their market share to imitators diminishing their revenues. Working with a higher R\&D intensity does not compensate for the loss in revenues and hence cannot accelerate technological progress continuously.

\subsection{Conclusion}

This study is meant to analyze the interaction between $R \& D$ activities of firms and heterogeneous consumer preferences in structuring the evolution of an industry and heterogeneity in firms' innovation strategies. The question whether heterogeneity in firms' innovation modes is sustainable in the long run and how market sharing between firms following different strategies is 


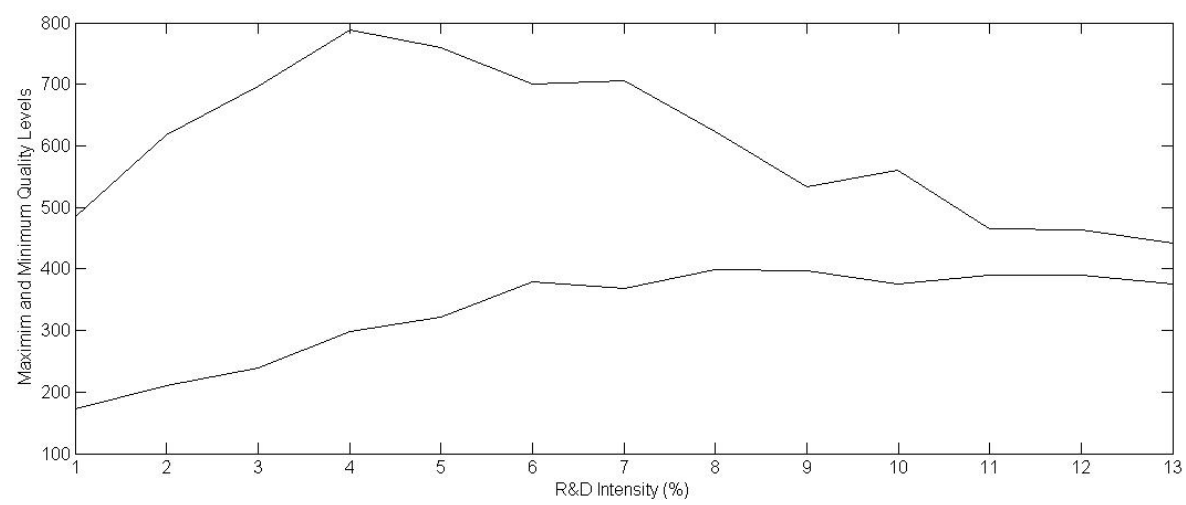

Figure 3.12. Maximum (upper series) and minimum (lower series) technology levels as a function of R\&D intensity (\%)

determined by a structural and a behavioral parameter of the model is examined. The proposed methodology is to develop an evolutionary, multiagent based, sector-level innovation model addressing the supply and demand side of the market simultaneously with the coevolution of heterogeneous consumer preferences, heterogeneous firm knowledge bases and technology levels at the micro level. The main discretionary activities of the firms are product innovation and imitation together with pricing of these products. The consumers, under computational constraints, aim at maximizing their utility with product choices. The competitive market provides these actors the required medium for interaction. A simultaneous consideration of technological progress and market dynamics with the help of ABM techniques allowed us to analyze such a multi-faceted phenomenon of heterogeneity in firm innovation strategy. The model concludes that coexistence of a variety firms with distinct innovation strategies is viable even in the long run. There are exactly three strategy pairs which makes a total of eight distinct strategies: innovators vs. imitators, technology-push vs. demand-pull firms and focused vs. diversified firms. Innovators can live together with imitators; the existence of technology-push and demand-pull firms is not mutually exclusive, and one can observe focused and diversified firms simultaneously within the same industry. This outcome is consistent with the empirical findings referred to in literature review; selection process does not pose homogeneous behaviour in innovation modes. This 
heterogeneity emerges as a dynamic equilibrium with continuous technological change and firm entry/exit.

The model results also show that the fate of firms with distinct strategies is determined both by market size and R\&D intensity. A larger market favours imitators against innovators, demand-pull firms against technologypush ones and diversified firms against focused firms. In a similar vein, adopting a higher R\&D intensity at the industry level increases the market shares of imitator, demand-pull and diversified firms. The pace of technological progress is affected by this very market sharing between different strategies throughout the simulation run. A larger market or a higher R\&D intensity does not directly translate into a faster technological change, since it is also a function of the innovators' market share. If an increase in the size of the market or in R\&D intensity cannot compensate for the loss of market share by innovators, one can even observe a slowdown in technological change.

In this model, firms are endowed with an innovation strategy and they do not change it throughout the simulation. A radical extension to this study will be the endogenization of the innovation strategies by letting firms freely choose and possibly change them in time due to varying market and technological conditions. Firms can even adopt different strategies simultaneously in different product development projects. Such a formulation would be a much more realistic representation of firms and let us study firm specific and aggregate factors leading to adoption of and shift from/to different strategies. 


\section{Appendix}

Initialization of the main parameters of the model

FirmNum=200: the initial number of firms

SubmarketNum=500: the number of submarkets

marketsize=100000: the number of consumers

MinTech=1: the minimum initial technology level

MaxTech=10: the maximum initial technology level

betainn $=0.5$ : the productivity of innovation

betaimit $=0.65$ : the productivity of imitation

ris=3: the size of the gap between two consecutive goods in different

classes where no products are defined

pricespeed $=0.1$ : the speed with which price of a product respond to change

in its profits

pm=30\%: profit margin

$\mathrm{cm}=1$ : the parameter that links the initial price of a product to its quality

MaxNumProd=5: the minimum initial number of products

MinNumProd=10: the maximum initial number of products

marketingshare $=10 \%$ : the share of marketing expenses in total revenue

$r \mathcal{E}$ dintensity $=10 \%$ : the share of $\mathrm{R} \& \mathrm{D}$ budget in total revenue

ric $=2$ : radical innovation constant in utility function

techidealconst Uniform $(0,1)$ : the parameter picked from a uniform

distribution that defines the ideal product for a consumer between minimum and maximum technology level available

MemorySize=5: the number of goods in the memory of a consumer

GoodNum=5: the number of new goods consumers evaluate for a purchase every period. 


\section{Chapter 4}

\section{Optimal Patent Length and \\ Breadth in an R\&D Driven}

\section{Market with Evolving Consumer}

\section{Preferences $^{6}$}

\subsection{Introduction}

Use of patents for the sake of technological progress and wealth creation is a long lasting debate in economics. As a policy tool to intervene in a subject as complex as technology development, it is easy to understand why patents cause such controversy. It is a very compelling if not an impossible endeavor to isolate the effects of patents from those of other factors on policy targets due to severe interaction. Even if that is achieved, one should discriminate between short and long run effects and effects on different agents with distinct capabilities in a market (Falvey, et al., 2006).

\footnotetext{
${ }^{6}$ This chapter is published in "Cevikarslan, S. (2017). Optimal patent length and breadth in an R\&D driven market with evolving consumer preferences: An evolutionary multi-agent based modelling approach. Technological Forecasting \& Social Change, 118, 94-106."
} 
A patent is a form of intellectual property and it gives the patent holder the exclusive rights over an invention for a limited period. Until the patent expires, others are prevented from using this invention which gives the original inventor a temporary monopoly power to collect the returns to their investment in R\&D. Thereby inventors are provided with the required financial incentives to continue with their technology development activities in exchange for the disclosure of the knowledge embodied in the patent. However, the use of patents as an incentive to engage in R\&D is not costless to society. Granting exclusive rights to the patent holder creates a monopoly which introduces inefficiencies to market. Besides patents can be a serious impediment to further technological developments.

Once the policy makers decide to set a patent system, the obvious following question will be how strong a patent system this will be. For how long will a firm be given monopoly power over its new invention? What is the range of products the competitors are prevented from using due to patent enforcement? Hence, what are the optimum patent length and breadth, respectively in order to realize the fastest technological and economic progress possible? These are the questions a patent authority should answer in designing a patent system.

This study is an ABM exercise to simulate the dynamics of an R\&D driven sector and to observe the effects of patent length and breadth on market outcomes. Firms engage in innovation or imitation activities to compete in product markets. Heterogeneous consumers make the best possible purchases that fit best with their preferences. These preferences coevolve with technology production by firms. Demand is differentiated and new products create new sub-markets loosely competing with the existing ones.

$\mathrm{ABM}$ is the most frequently utilized technique in evolutionary settings (Grebel and Pyka, 2006). In case of innovation at industry level, we are exploring a highly decentralized dynamic search process under strong substantive and procedural uncertainty, where numerous autonomous and heterogeneous agents search in parallel for new products/processes, but are interlinked through market and non-market interactions (Dawid, 2006). Analytical models frequently fall short of integrating such heterogeneous agents and their interactions in their complex adaptive environments, which 
are non-linear and path-dependent. Several evolutionary modeling exercises in the literature repeatedly showed that ABM is capable of simulating such a platform where these peculiarities are successfully mapped into model designs. Furthermore, ABM is offering a platform for inter and transdisciplinary research, which is again congruent with the requirements of innovation studies. With ABM, we hope to stretch the trade-off between simplicity in modeling and the complexity of the socio-economic reality, which would be harder with an analytical model.

There are a few advantages of this evolutionary model over the ones in the relevant literature. To begin with, it is one of the few models studying two patent dimensions (patent length and breadth) simultaneously from an agent-based perspective. Secondly, whereas most evolutionary models focus on process innovation, this one exclusively models product innovation, i.e. technical progress is embodied in products. The third is that firms compete both in the R\&D process and goods market rather than in any one of them. Lastly, rather than single-product firms, the market is populated with multiproduct firms which can serve to different niches of consumers concurrently. With the continuous introduction of new innovations, products transform from undiscovered to discovered and then from cutting edge product to obsolete. As the product space steadily shifts, the consumers are compelled to redefine their product choices within the given product range.

The rest of the chapter is organized as follows: Section 2 is a literature review on patents where the pros and cons of having a patent system, the concept of sequential innovation, the role of patents when innovation is sequential, and the effects of patent scope from an empirical and theoretical perspective are discussed. Section 3 details the simulation model. In Section 4 , the results of the simulation analyses are discussed. Section 5 concludes.

\subsection{Literature Review}

\subsubsection{Why do (should) we have patents?}

A strong rationale for patents is protecting innovators from imitators. By preventing imitators from selling goods embodying patented technologies, 
patent holders are given the exclusive rights to enjoy profits on their inventions either by commercialization or licensing their technologies. These temporary monopoly rents enhance the incentive for the innovators to engage in $R \& D$ activities. Patents also create incentives to disclose and trade technology so that others can use and build upon research results (Encaoua et al., 2006; Gallini, 1992; Foster, 2014).

Patent protection is justified by specific particularities of technical knowledge: nonrivalry and nonexcludability. Knowledge has a non-rival character, which means that once an invention is known, everyone can use it with no additional cost. Nonexcludability means once knowledge is created by an agent, others cannot be excluded from using it. Hence, technical knowledge is a source of externalities in $R \& D$ and traditional economic theory claims that patent protection is a possible remedy for this free-rider problem (Encaoua et al., 2006; Vallée and Yildizoglu, 2006).

Patents can be effective means of protection for inventors to recover R\&D investments specifically when imitation is not costly and first mover advantages are not critical. It is argued that perfectly competitive markets do not allow firms to profit from their innovations when the production of knowledge requires fixed and indivisible $R \& D$ expenditure, and the goods and services in which the knowledge is embedded can be produced and distributed at low marginal cost. Industrial surveys show that patents are effectively used only in industries such as medical equipment and drugs, special purpose machinery, computers and auto parts, but are relatively less emphasized than other appropriability mechanisms like first mover advantages and secrecy, complementary sales and services in almost all other industries (Levin et al., 1987; Cohen et al., 2000; Encaoua et al., 2006).

\subsubsection{Why shouldn't we have patents?}

Creating monopoly rents for the patent holder is a costly endeavour for society. The monopolist's profit maximizing price will be higher than welfare maximizing price for the society and this will create a deadweight loss. We can add to this loss the costs of bureaucracy (strongly increased during the recent patent surge), court personnel and lawyers. This means a large amount of financial resources diverted from the innovation process itself (Encaoua et 
al., 2006). Patent rights advocates argue that this static deadweight loss is more than compensated in the long run with faster technological progress due to stronger incentives to do R\&D. Hence, one should discriminate between short-run and long-run effects of patents on market outcomes (Bessen and Maskin, 2009).

A specific patent policy constitutes a tradeoff between encouragement of prior innovation and reduction of incentives for subsequent research. Before the patent is granted, there is every incentive to compete in the patent race as the reward is still there waiting for the winner. But once the race is over and one of the competitors is granted the patent, others are discouraged to continue $R \& D$, since the next innovation may infringe the previous patent. Some studies (e.g. Heller and Eisenberg, 1998) emphasize the negative effects of patenting initial inventions on subsequent innovations (building patent fences around discrete innovations constituting patent thickets), while others endorse stronger protection of early innovators who opened new fields of research (see, for example, Kitch (1997) and the critiques in Merges and Nelson (1990)) (Koo and Wright, 2003; Vallée and Yildizoglu, 2006). That a firm is exploiting intellectual property rights (IPR) invariably raises the costs that other firms incur when trying to access and utilize existing knowledge (Dosi et al., 2006). Alongside, patent races create some duplication of resources and they are much more oriented to creating substitutes than complementary goods which poses a coordination problem (Eswaran and Gallini, 1996; Encaoua et al., 2006).

Teece (1986) states that profits from innovation depend upon the interaction of three families of factors, namely, appropriability regimes, complementary assets and the presence or absence of a dominant paradigm. Appropriability conditions, in addition to patent and copyright protection, include secrecy, lead times, costs and time required for duplication, learning, sales and service assets. Apart from profiting from innovation, according to Dosi et al. (2006), evidence suggests that appropriability conditions are just one among many (possibly a second order one) determining the propensity to innovate. The relative importance of the various factors and their interaction is highly sector and technology specific. The rates of innovation, they suggest, fundamentally depend on paradigm-specific opportunities 
rather than on mere appropriability conditions (at least above some threshold) and even less so on the specific subset of appropriability devices represented by legal IPR protection. They also add that the differential ability of individual firms to economically benefit from innovation stem from idiosyncratic organizational capabilities.

Levin et al. (1987) reports that patents are by and large viewed as less important than learning curve advantages and lead time in order to protect product innovation and the least effective among appropriability means as far as process innovations are concerned. As a follow-up study, Cohen et al. (2000) found that firms protect profits due to invention with a range of mechanisms, including patents, secrecy, lead time advantages and the use of complementary marketing and manufacturing capabilities. Patents are generally the least emphasized among these mechanisms by firms in the majority of manufacturing industries, and secrecy and lead time tend to be emphasized most heavily. For the protection of product innovations, secrecy now appears to be much more heavily employed across most industries than previously. When secrecy is a feasible means of protection and the cost of imitation is high, first mover advantages and network externalities are emphasized (Encaoua et al., 2006). Pharmaceuticals and other fine chemical products are exceptions to this general trend, but the above is true for firms in the computer, semiconductor, and aircraft industries. A number of industries with relatively slow technological progress also reported that patents were not particularly effective for them (Mazzoleni and Nelson, 1998).

However, there are two important points any empirical study should take into account in that regard. The first is that the case can be completely different for large firms with an established presence in their product markets and thus having access to the complementary assets needed to commercialize the end-product of their innovative efforts than it is for a small firm which cannot benefit from a head start or timely establishment of an effective production and sales program, or rapid movement down the learning curve, unless there is some way of holding off the large competitors like patenting. For such firms, patents can be used either as a means to appropriate returns through licensing or as a means to maintain control of the technology while 
a production and sales capability is established. The second point is whether the prospect of patents motivates firms and other organizations outside of a particular industry to undertake inventions which would be used inside that industry (Mazzoleni and Nelson, 1998). Some studies (e.g. Jewkes et al., 1969) have reported the importance of such outsiders to technical advance in a number of industries. For these industry outsiders without the complementary assets needed to appropriate the returns from innovation by being first to market or by rapidly moving down the learning curve, a patent may be essential to create incentives to invest in $R \& D$. Once a strong patent is gained, such a firm can bargain a joint venture or a license deal with a firm that has production and market capabilities (Teece, 1986).

In many areas of technology, the role of patents has fundamentally changed recently. Kash and Kingston (2001) links the recent explosion in patent applications to their growing use as bargaining chips for crosslicensing issues rather than as providers of the limited monopoly control. Patenting is also used for other strategic reasons like constructing patent fences around discrete inventions and the prevention of suits. Cohen et al. (2000) finds that in "discrete" product industries, such as chemicals firms appear to use their patents commonly to block the development of substitutes by rivals whereas in "complex" product industries, such as telecommunications equipment or semiconductors, firms are much more likely to use patents to force rivals into negotiations.

Patents may also play a role in driving the industries prematurely into standardization on the wrong system where decentralized decision making within the private sector subsequently exacerbates such "lock-in" situations. These lock-ins are not uncommon and are more frequent in the presence of strong technical interrelatedness, scale economies, and irreversibilities due to learning and habituation (David, 1985). Patent thickets around an initial innovation may lock an economy into a path that is both inferior and difficult to escape. Also, exclusive patent rights give even further market advantages to the patent holder making the relevant market subject to lock-in. 


\subsubsection{Sequential Innovation}

When innovation and imitation is sequential, each successive invention builds on its predecessors. In such a situation, innovation may be very valuable because it has spillover benefits for future innovators. Patent protection which is a necessity in a static world, since the prospect of being imitated inhibits inventors otherwise, becomes less important in a dynamic world with sequential innovation and imitation where imitation can provide benefit to both the original inventor and to society more generally. For industries like software and computers theory suggests that imitation may promote innovation and that strong patents (long-lived patents of broad scope) might actually inhibit it. Imitators may exploit the original innovation to develop valuable ideas not readily available to the first inventor. Then, the first inventor may come up with a new innovation based on these new ideas. If this cumulativeness is impeded by the presence of patents, the pace of innovation may slow down (Bessen and Maskin, 2009). If the first-generation invention falls into the category of "essential facilities" in the sense that there is no possibility to invent around them to proceed with further research (e.g. basic discoveries, genetic material and research tools), patenting may even block new lines of research (Encaoua et al., 2006).

Nordhaus's (1969) patent protection model with a single, isolated invention predicts that stronger patents will induce more investment in $R \& D$. This model falls short of explaining innovation processes particularly in high technology sectors experiencing rapid technological change. Modern models of innovation expand upon this framework by recognizing that innovation is a cumulative process that builds upon previous discoveries. While stronger patents provide the patent holder with the means to "hold up" future innovations by threatening to litigate infringers, they also increase the possibility of the patent holder being held up by previous innovators. In this setting, the link between patent strength and innovation incentives is ambiguous. When innovation is cumulative, it is acknowledged that followon researchers (as well as pioneers) respond to changes in patent policy. Extending the single-invention model to incorporate these features can overturn fundamental predictions of the basic model (Gallini, 2002). When innovation is sequential and complementary, imitation becomes a spur to 
innovation, while strong patents become an impediment. Bessen and Maskin (2009) conclude that even if the initial rents earned by an innovator in the absence of patents may be lower than with patents, the benefits that accrue to him when he is allowed in his turn to build around the next innovation made by a competitor may outweigh the current loss.

\subsubsection{Patent Scope}

Within the context of this study, patent scope refers to patent length and patent breadth. Patent length is the time period between a patent is granted and it terminates when its statutory life is over and patent breadth is the degree to which a product or process must differ from a patented one to avoid infringement of the patent (Hunt, 2004). Patent offices grant patents to inventions complying with the patentability criteria of industrial application, novelty, and inventive step (Encaoua et al., 2006). The scope of the claims of a patent determines the monopoly power of the patent holder (Merges and Nelson, 1994). Dosi et al. (2006) claims that a positive and uniform relation between patent scope and innovation holds only for a specific (and highly disputable) representation of markets, their functioning and their "failures", on the one hand, and of knowledge and its nature on the other. Merges and Nelson (1990) shows that a stronger patent system can have very different effects on different industries distinguishing four classes of technologies in which the role of patents can be strongly contrasted: discrete inventions (new pharmaceuticals), cumulative technologies (aircraft), chemical technologies and science-based technologies (biotechnology).

Dosi et al. (2006), in their critical assessment of both the theory and the empirical evidence on the role of appropriability and IPR as incentives for technological innovation, suggest that appropriability is likely to display a threshold effect; a minimum degree of appropriability is necessary to motivate innovative effort, but above such a threshold further strengthening of appropriability conditions will not bring further increases of R\&D investments and rates of innovation. Rather, social inefficiencies such as "anti-commons" effects- in which people underuse scarce resources because too many owners can block each other (Heller and Eisenberg, 1998)-, rent seeking behaviours, dissipation of quasi-rents into litigation etc. are much 
more likely to emerge. There seems to be no clear evidence of a positive relation between the tightening of IPR regimes and the rates of innovation. The software industry in the United States presented itself as a natural experiment in the 1980s and 1990s. Patent protection for computer programs was significantly strengthened by several court decisions. Evidence suggests that the firms that acquired most of these patents actually reduced their R\&D spending relative to sales (Bessen and Hunt, 2007).

In an international analysis of the relationship between patent strength and innovation, Lerner (2002) examines 177 policy shifts in 60 countries over 150 years. Patent strength is measured by four features: a) whether protection existed in whole or in part for important technologies; b) the duration of the patent; c) the patent fee; and d) the existence of various limitations on patent awards (for example, compulsory licensing). The dependent variable is the growth of patent applications by residents in the country and the independent variables include a dummy variable on whether the policy change is protection enhancing or reducing and the strength of protection prior to the change, among other controls. Lerner finds some support for an "inverted- $U$ " relationship between patent strength and innovation. That is, strengthening patents has a positive effect on innovation if protection is initially low and a negative impact if patent protection is initially high (Gallini, 2002).

In their essay on the effects of the scope of a patent for many historical cases, Merges and Nelson (1994) argues that this depends on the topography of technical advance in a field, in particular on how inventions are linked to each other, and on the extent to which rapid technical advance requires a diversity of actors and minds, as contrasted with being facilitated by express coordination of inventive activity. They examined technical advance in several different fields, with a focus on how patents influenced the pace and quality of development. They conclude that allowing and enforcing broad patent claims tends to hinder technical progress.

From a theoretical point of view, the standard analysis of optimal patent life is based on the Nordhaus (1969) analytical model of an independent, stand-alone innovation that reduces the production cost of a consumer good. A finite optimal patent life balances the gain in size of the cost-reducing 
innovation from an increased period of monopoly granted by the patent against the associated deadweight loss from higher cost to consumers due to an extension of the period in which royalties must be paid. However, this model assumes no competition in the innovation process (Koo and Wright, 2003).

Gallini's (1992) theoretical model with positive imitation costs predicts that an increase in patent life over some range may have no effect on or paradoxically may reduce both R\&D activity and the incentive to patent. The explanation is that increasing the length of patent protection gives rivals a greater incentive to imitate (invent around) a patented product: the longer the patent life, the longer rivals must wait to use the technology. Increasing patent life increases the number of competing products, thus reducing any added incentives to research and to disclose the innovation that typically result from longer patent protection. These effects have implications for optimal patent policy. When the length of patent protection is the only tool of patent authorities, she shows that optimal patent life is generally short to discourage imitation. When the patent policy is extended to include both patent life and patent breadth, social surplus is maximized when patents are broad (no imitation) and patent life is adjusted to achieve the desired patent reward. She adds that her results contrast sharply with those of Tandon (1982), Gilbert and Shapiro (1990), and, to some extent, Klemperer (1990), in which narrow, infinitely long patents are optimal and explains this with the increasing costly imitation that displaces the patentee's output as patent life increases. The previous literature noted here considers market situations in which imitation, while constraining the innovator's profits, never occurs in equilibrium for any patent life.

In their 1998 study based on an analytical innovation model, O'Donoghue et al. observe that the profitability of $R \& D$ depends on the effective patent life, and that effective patent life is determined not only by statutory patent life but also by patent breadth. They ask the question whether patents should be long-lived but narrow, so that they effectively expire at an endogenous time when a better product is made or they should be relatively broad but short-lived, so that the effective patent life coincides with the statutory patent life. They find that the two policies are not equivalent, even if both lead to the 
same rate of innovation. To sustain a given rate of innovation, the effective patent life in the first policy must be longer than the effective (statutory) patent life in the second policy, which exacerbates the inefficiencies due to market power (O’Donoghue et al., 1998).

Winter (1993) uses a simple evolutionary model of innovation and imitation to compare the properties of the dynamics of a simulated industry with and without patent protection. He shows that the total surplus is lower under the patent regime than under the non-patent one and the non-patent regime yields significantly higher total investment in $R \& D$ and produces higher best practice productivity.

Vallée and Yildizoglu (2006) claim that the main results are generally too strongly sensitive to the rational expectations (or perfect foresight) assumption and to the assumed homogeneity of the firms for the patent race models. Alternatively, they develop an evolutionary simulation model of industry dynamics in order to carry out a richer theoretical analysis of the consequences of a stronger patent system. Their results do not favor the case for a stronger patent system: higher social welfare and technical progress are observed in their model in industries with milder patent systems (lower patent height and patent life).

Marengo et al. (2012) develop a simulation model of product innovation and industry evolution in complex product industries and shows that strong patent regimes are likely to hinder rather than foster innovation. Their results are driven by two major properties of technologies and markets for complex products. First, both innovative and imitative search are costly and difficult, with complementarities and interdependencies among components putting heavy constraints on possible search paths. If many of these possible paths are blocked by patents, very few opportunities for further innovation might be left open. Second, competition in these complex product spaces typically proceeds through the creation of sub-markets: demand is heterogeneous and firms can diversify products by offering different combinations of components and characteristics. Competition is not a winner-takes-all process, but is mainly a never-ending creation of new sub-markets. They conclude that that product complexity is a key factor determining the long run efficiency or inefficiency of the patent system and as the complexity of 
the product spaces increases, stronger patent regimes yield lower rates of innovation, lower product quality, and lower consumers' welfare.

Whereas several studies have analyzed the role of patent scope in the design of an optimal patent system (Green and Scotchmer, 1995; Chang, 1995; O'Donoghue, 1998), the implications of patent length itself in the context of a competitive dynamic research sequence have been relatively neglected (see Gallini (1992) for an exception). Patent with finite life has been insufficiently appreciated in the current literature (see Nordhaus (1969) for an exception) (Koo and Wright, 2003). This chapter exactly targets this gap by concentrating on the implications of patent length and patent breadth for several market outcomes within the context of a dynamic R\&D driven market with sequential innovation, heterogeneous firms and ever-changing consumer preferences (O'Donoghue et al., 1998). Whereas most evolutionary models focus on process innovation (Winter (1993), Vallee and Yildizoglu (2006)), this one explicitly models product innovation (see Marengo et al. (2012) for an exception). One last contribution of this study to evolutionary innovation modeling on patent rights is to drop one product-one firm equivalence by introducing multi-product firms, which can serve to different niches of consumers simultaneously.

\subsection{The Model}

The simulation analysis will be based on the agent-based model developed in Chapter 3. Within this section, the peculiarities of the model used in this chapter will be explained, including the $R \& D$ intensity rule and patenting mechanism. The model analyses how macro outcomes are conditioned by patent scope. One will observe how patent scope determines the extent of monopoly power of the market leader, hence concentration rate and market sharing between innovators vs. imitators, the pace of technological progress and wealth creation in the market. With this aim, firstly the model will show how firms and consumers interact in the market environment and how this interaction leads to technological progress. Firms compete on price and quality of their products and they engage in innovation and imitation 
activities to increase their quality. Consumers shift their preferences towards higher quality products as technology progresses.

This is ultimately an evolutionary innovation model with a search algorithm (innovation and imitation of products by firms). The revealed preferences of the consumers, which is a selection algorithm, serve as a rewarding mechanism. The population of objects in which variation is expressed and on which selection operates are the firms themselves (Windrum, 2007). An innovation is granted a patent if it meets the criteria imposed by the patent authority.

\subsubsection{Innovation Strategies}

A firm is either an innovator or imitator from the beginning and stays as such throughout the simulation. Every firm engages in one R\&D project at a time and in picking R\&D projects, they pursue a technology-push strategy. They select R\&D projects starting from the highest technology base they possess to come up with cutting edge technology possible.

A share of the last period's revenue is allocated to $R \& D$ every period. This share, which is limited between a maximum and minimum level is a function of the patent policy and market share of the individual firm. The longer an invention is protected by a patent (the higher the patent length) and the wider the range of products the competitors are prevented from using (the wider the patent breadth) the higher the maximum R\&D share a firm is ready to spend. If a firm knows that its competitors will be prevented from using a wider range of products once it is granted a patent and that patent rights will be protected for a long period, it will increase its $R \& D$ expenses out of its revenues. The actual $R \& D$ intensity within these limits is inversely related with the market share of a firm. If a firm controls a significant share of the market, it will feel less threat from its competitors and cut down its R\&D budget. Smaller firms are more aggressive in doing R\&D. A negative relationship between firm size and $R \& D$ intensity is confirmed by many empirical studies in the literature (Ortega-Argilés and Brandsma, 2010; Akcigit, 2009; Stančík and Biagi, 2012). 


\subsubsection{Patenting}

If a newly innovated technology is not patented before, it is eligible for being granted a patent. The technologies within the range defined by the patent breadth are also patented by the innovator if these technologies are not patented in advance. Patent breadth is symmetrical around the innovated technology. To exemplify, if patent breadth is 1 , the two technologies (one step higher and one step lower than the innovated one on the quality ladder) around are also patented by the innovator together with the innovated product itself. From the time a patent is granted until it expires (patent length), competitors are not allowed to use these technologies either for selling or using in their R\&D projects. The competitors are allowed to possess a patented technology either by innovation or imitation, or new entrants can inherit this technology as exact copies of the patent holder. But a patent prevents the competitors from using these technologies.

\subsubsection{The Pseudo-Code of the Model}

At the initialization period market is populated with $\mathrm{N}$ firms each either as an innovator or imitator with a random product portfolio and each consumer is assigned to a submarket. The maximum $R \& D$ intensity which is constant for all firms is determined as a function of the patent policy. The minimum $R \& D$ intensity is also constant for all firms. The routine for the rest of the simulation is implemented as follows:

1. Firms set a price for each product as a function of profits from that product in the previous periods.

2. Firms make marketing expenses for each product as a function of the quality.

3. Patents with an age over the patent life die.

4. Each consumer determines her ideal product.

5. Consumers sample a few random products, structure their memory sets and purchase the best product within this set.

6. Products with an average market share below a threshold level are deleted from the market. Firms with no products to sell leave the market. New firms with random strategies enter. 
7. Firms compute their R\&D intensity as a function of their market share.

8. Each firm either innovates or imitates.

9. Both innovators and imitators check with the patent office to see whether their inventions are protected by an active patent. Innovators check with the patent office to see whether they can get a patent on their invention.

\subsection{Simulation Results}

\subsubsection{Model Dynamics}

The results of the simulation analysis will be presented within this section. The data for the analysis is produced as an average over 100 simulation runs of $1000^{7}$ steps with a patent length of 50 and a patent breadth of 5 . The only thing that changes from one simulation to the other is the seed value which is a number used to initialize the pseudorandom generation process. This seed value governs all the stochastic processes within the model and two simulations with the same seed value always give the very same results. We start with introducing the evolution of the main variables of interest in the model to answer our very first research question: how R\&D activities of firms and heterogeneous consumer preferences interact in structuring the evolution of an industry.

Figure 4.1 reports inverse Herfindahl index. The inverse Herfindahl index is the number of firms with equal market share that would generate the same concentration as that measured in the actual market, consequently measuring the dispersion (or inverse of concentration) of the market (Marengo and Valente, 2010). Figure 4.1 signifies a severe shake-out of firms from the beginning of the simulation run until the figure reaches its lowest value when the market concentration is at its maximum. This is followed by dispersion where a higher number of firms share the market creating a more competitive environment and stabilization for the following periods. The model is

7 The experiments with longer time scales show that the variables of interest behave in a very stable pattern and all model results are robust to an increase in simulation time steps. 


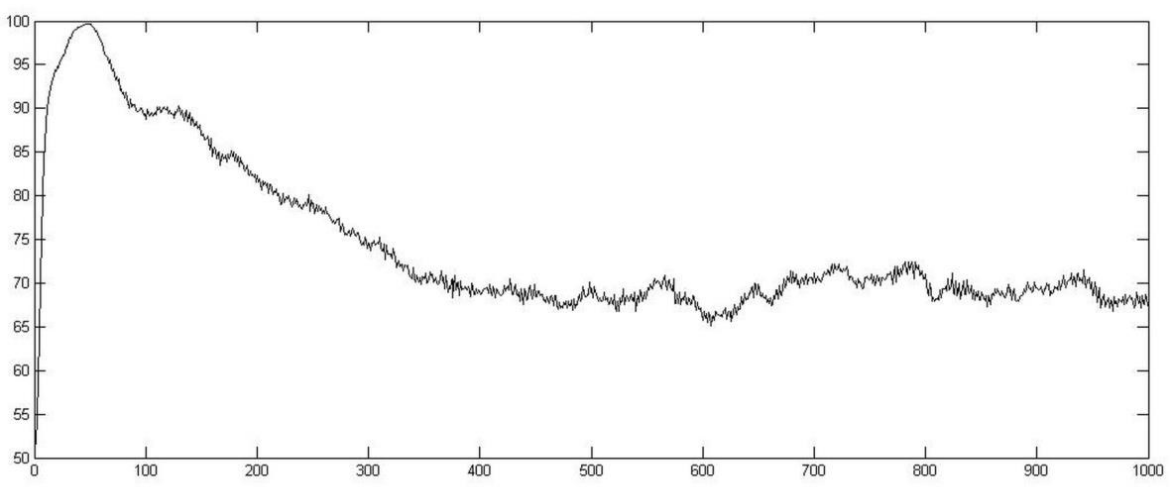

Figure 4.1. Inverse Herfindahl Index

initialized with a population of firms and those which cannot successfully serve to heterogeneous consumer needs are eliminated from the market in the early periods stabilizing the concentration rate for the following terms. Another reason for this rapid increase in the market concentration is the emergence of the patent holder of the first few innovations as a market leader. This situation is traceable in Figure 4.2. At the start of the simulation, half of the firms are innovators and the other half are imitators. Hence innovator firms have approximately $50 \%$ of the total market to begin with. The very first few innovations make the patent holder the market leader increasing the market concentration and market share of the innovators very rapidly. Subsequently imitator firms copy and sell these products after the patents expire decreasing the market share of the leader and increasing dispersion in the market.

Figure 4.3 allows us to observe the maximum (upper series) and the minimum (lower series) level of qualities available in the market. Whereas the maximum quality level is mainly determined by the R\&D activities of the firms and the minimum level mainly by the competitive forces and heterogeneous consumer tastes, the interaction between demand and supply dynamics affects these levels both. The continuous introduction of new products by innovation raises the maximum quality and renders low quality products obsolete by shifting consumer preferences towards high-tech products. Technological change is the engine of economic growth in this model. If for some reason technology creation comes to a halt (e.g. imitators 


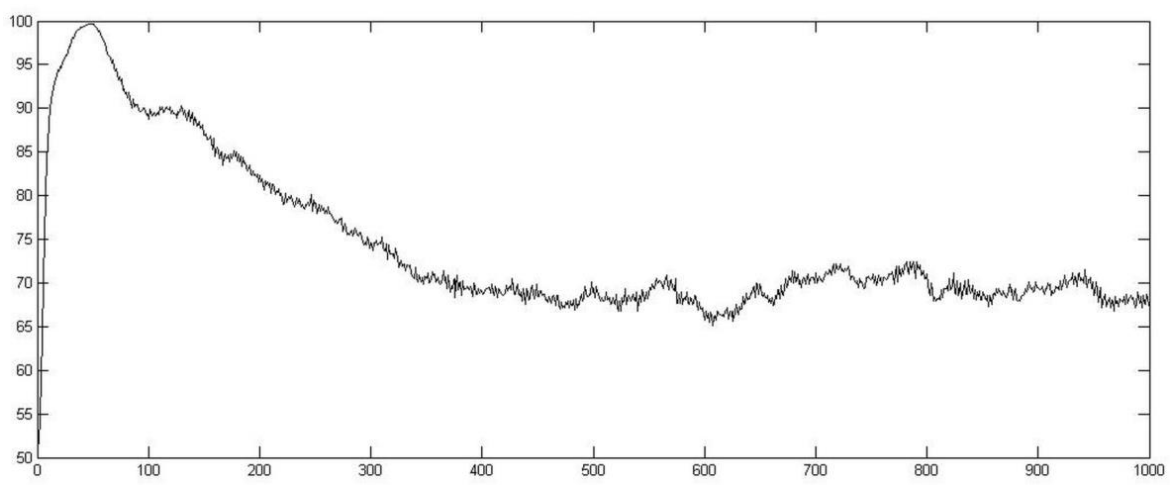

Figure 4.2. Market share of innovative firms (\%)

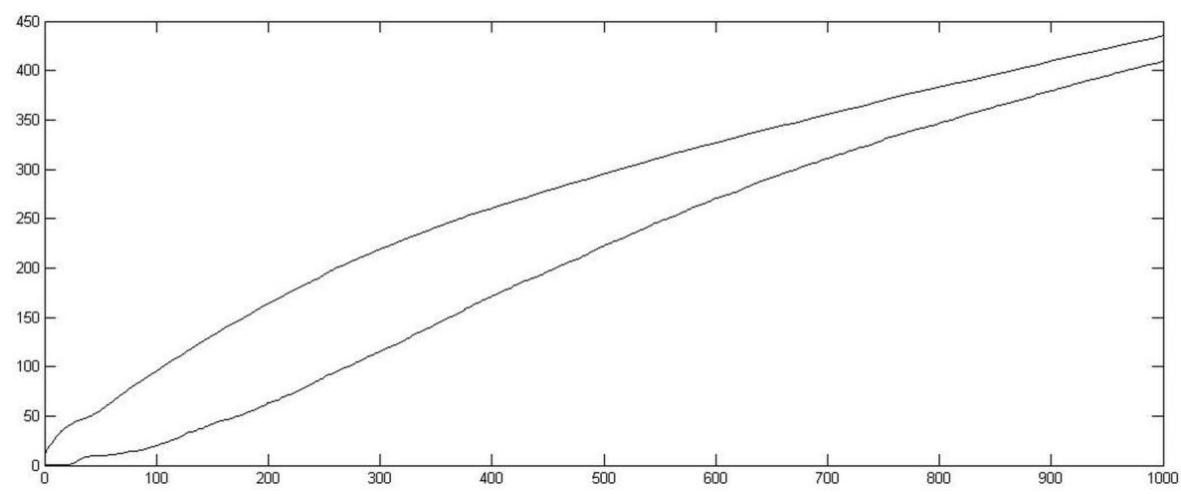

Figure 4.3. Maximum (upper series) and minimum (lower series) quality levels available

conquer innovators dominating the whole market and leaving innovators with no financial resources to innovate), wealth creation also stagnates. Therefore, both consumers and imitator firms depend upon innovator firms to prosper. The change in the slopes of these curves which corresponds to a slowing down in the pace of technological change results from the lower market share of innovators in the later periods than in the previous periods. Drawing upon this graph, the reader should not be deceived that the model produces innovative progress at a steady state growth rate. It should be reminded that Figure 4.3 is created using data as an average over 100 simulation runs. When we observe the same series for a single run as in Figure 4.4, we see that innovations come in waves; times of rapid 


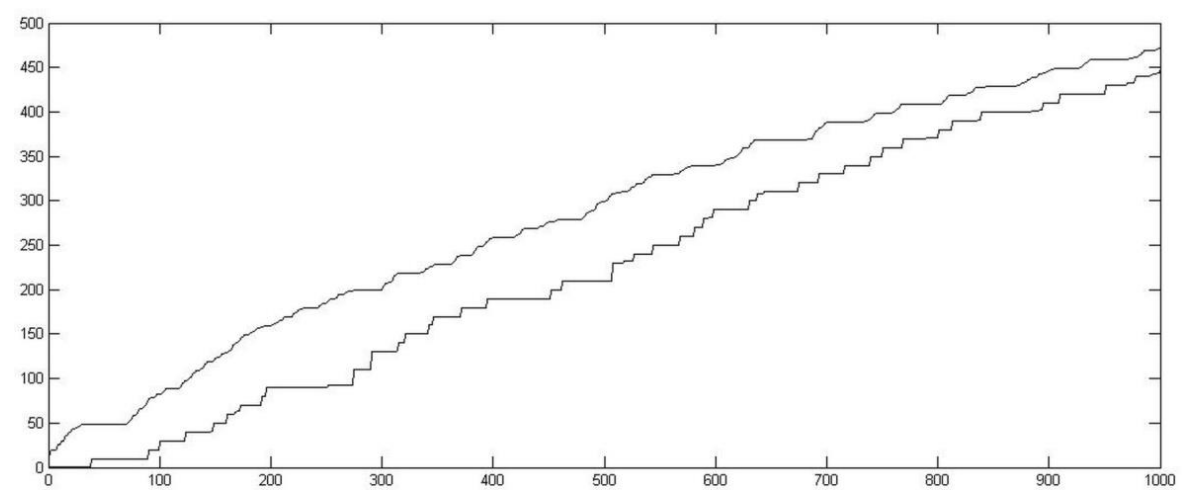

Figure 4.4. Maximum (upper series) and minimum (lower series) quality levels available for a single run

technological change is followed by stable periods when there is no technological advancement at the sector level. This is due to the way the product space is defined; classes and versions within classes or in other terms successive ladders and steps of the ladders. When a firm reaches the top of a ladder (technology class), it has to jump over the gap between two ladders to continue climbing. This requires higher financial resources compared to previous $R \& D$ projects and generally a few trials. Hence technological change stagnates at these points. Once this is achieved, it is relatively easier to climb up the steps (technology versions) of the next ladder. That is why innovations come in waves.

One can see the total number of active patents (patents are active unless they expire at a time fixed by patent length) in Figure 4.5. The initial hike in the number of patents can be explained by the obvious fact that new patents are continuously taken before the time has come for the very first ones to expire. Starting from the simulation period when the very first patent reaches statutory patent life, the graph follows first a gradual decreasing trend and then it stabilizes to a degree. The explanation for this trend should be searched for within the innovation production function and the size of the market share of innovators. Firstly, innovation arrival rate is a negative function of the quality of the product to invest in: complexity of the product decreases the likelihood of the research success. Hence, it is getting harder and harder to come up with an innovation as technology progresses. 


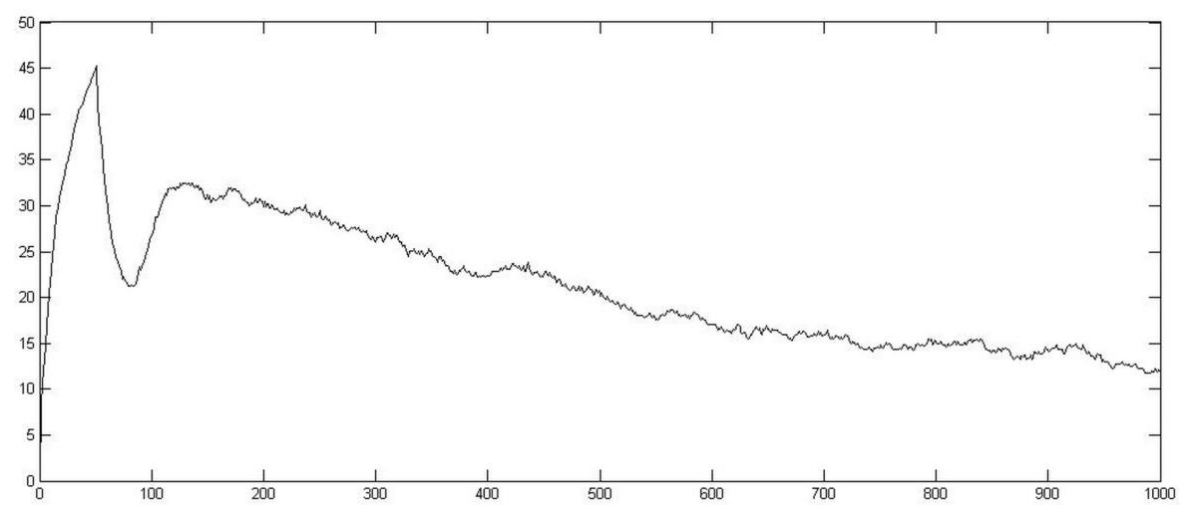

Figure 4.5. Total number of active patents

Secondly, there are diminishing returns to $R \& D$; additional investments increase arrival rate in a decreasing manner. The decrease in the market share of innovators also adds to this declining trend. As an opposite effect, firms and hence their R\&D budgets grow in time which should raise total number of active patents ceteris paribus. Nevertheless, this effect alone cannot buck the declining trend. In the following periods, all these effects combine to create a fairly stable number of patents.

Figure 4.6 shows total profits created at the sector level (dotted), total consumer utility (dash) and total welfare (solid) which is the sum of total profits and consumer utility. Technological progress alone accounts for the sustained upward trend in these variables. The production cost of a product is linearly related with its quality. Price is initialized as a mark-up over cost and this is the minimum price allowed, which means that sales of a product always bring positive profits and ceteris paribus higher quality products mean higher profits. Technological progress boosts consumer utility, because consumers draw more benefit from consuming better quality goods. Another observation is that total profits rise faster than total consumer utility. The ever-increasing general price level which is responsible for the rise in total profits appears with a negative sign in the utility function of the consumers and hence slows down the increase in total consumer utility. 


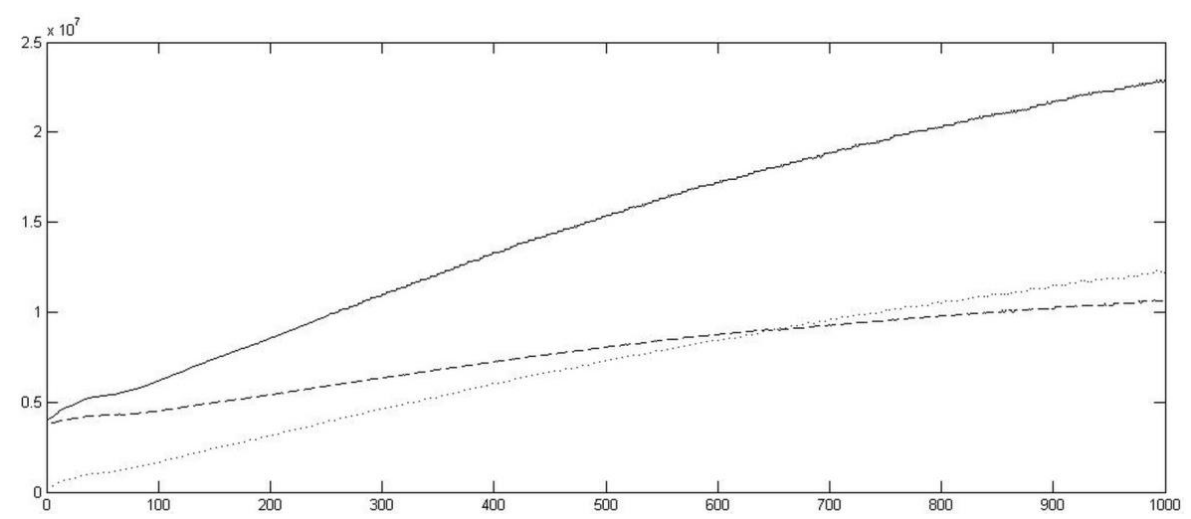

Figure 4.6. Total Profits (dotted), Consumer Utility (dashed) and Welfare (solid)

\subsubsection{Simulation Experiments}

This subsection includes the results of a series of simple simulation experiments designed to analyze how the main variables of interest are conditioned by patent length and breadth. Patent length is the life time of a patent and patent breadth is the range of products protected by patent rights. The following graphs are created by varying patent policy parameters ceteris paribus. The analysis in this section is based on data derived as averages of end of simulation values of variables over 100 simulation runs of 1000 steps each with a different seed value. For the experiments, patent length is varied within a range of 10 to 100 and patent breadth within a range of 1 to 9 . We start with reporting on the effects of the patent policy on the market share of innovative firms.

The model includes two types of firms: innovators and imitators. As imitators can only copy already existing technologies, it is always an innovator who can get a patent. Therefore, a stronger patent system which gives the patent holder the exclusive right of selling a patented technology for a longer period of time will result in innovators seizing a larger share of the market. This line of reasoning is confirmed by Figure 4.7; the higher the patent length the higher the market share of innovator firms. Imitator firms which cannot compete with the patent holder drawing upon their inferior goods lose their market share to innovators. Hence patent policy can be used 


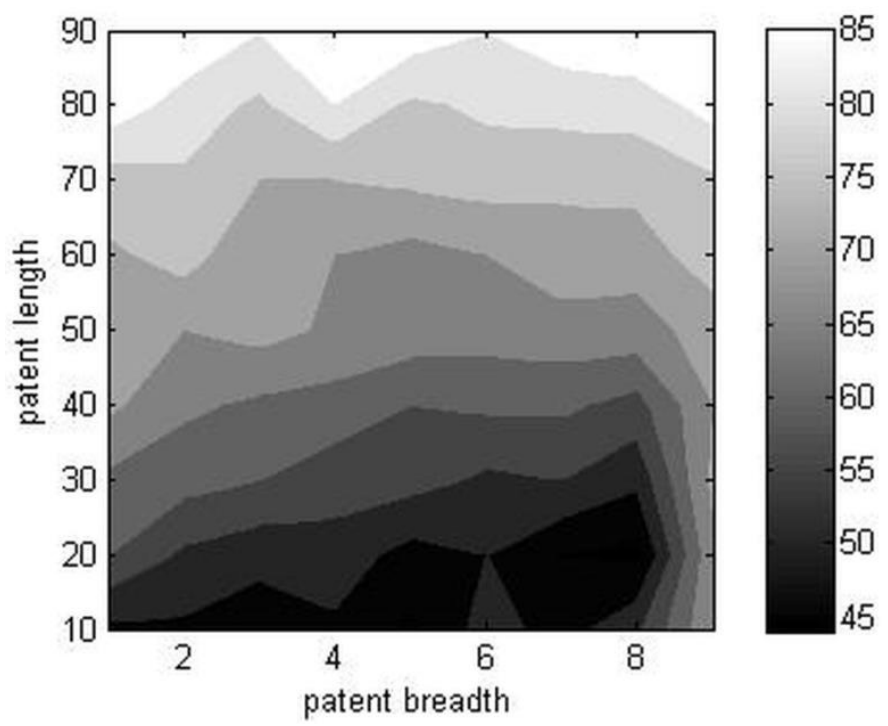

Figure 4.7. Market share (\%) of innovator firms as a function of patent breadth and length

as a tool by the policy maker to transfer resources from imitators to innovators or vice versa. The reader cannot observe a gradual increase or decrease in the market share of innovators as patent breadth changes except for the cases when patent breadth is 9 and patent length is 40 or below. At this point it should be reminded that what bring a superior market advantage to a technology leader are the exclusive patent rights to a new class of technologies in the case of a radical innovation. A patent breadth below 9 does not grant a full patent protection over a new class of technologies and hence followers can draw on unprotected versions in the new class to compete with the technology leader, which prevents this firm from being the only beneficiary of the newly explored technology area. However, this does not apply when patent length is 50 or higher, so when patent system is already restrictive enough for the followers. Therefore, patent length has a continuous positive effect on the market share of innovators whereas patent breadth has a discontinuous effect in the same direction.

Figure 4.8 reports inverse Herfindahl index as a function of patent length and patent breadth. A lower value of this index corresponds to a more 


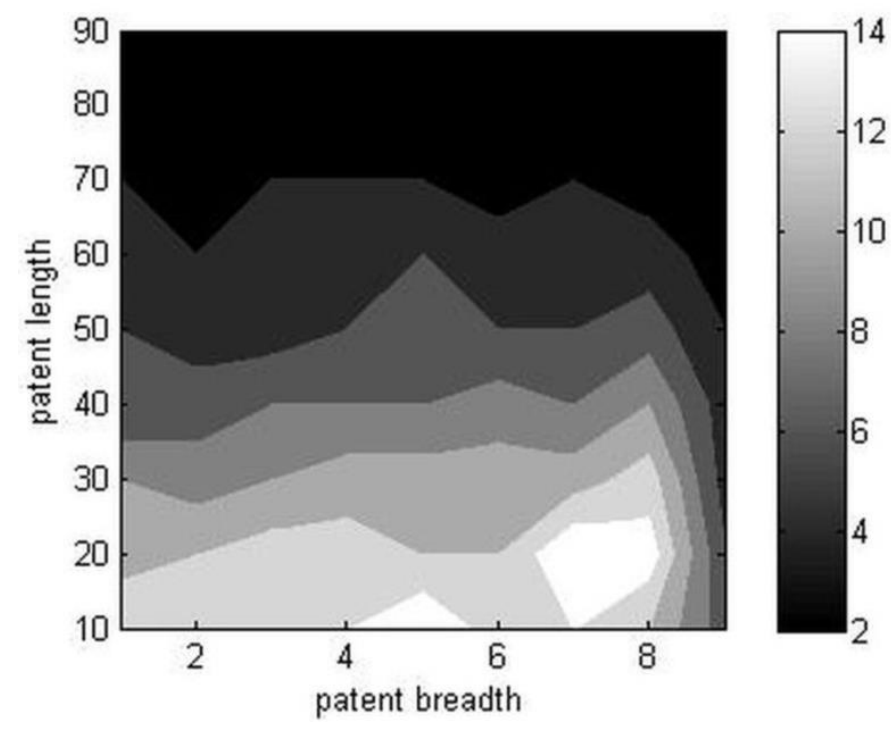

Figure 4.8. Inverse Herfindahl Index as a function of patent breadth and length

concentrated market structure. One would expect that stronger patents consolidate the market position of the patent holders increasing the concentration rate. This is explicitly what we observe as patent length increases. For the same reasons explained in the previous paragraph we do not see a regular change in the index value along patent breadth axis. A patent breadth of 9 corresponding to a full patent coverage of newly innovated technology classes to the technology leader's advantage again presents itself as a special case with a radical increase in the concentration rate.

There are three mechanisms at work determining the level of technological progress in the model. To begin with, it is the innovators who develop the state of the art and they depend on their R\&D budget in this endeavor. So, any intervention shifting resources from imitators to innovators fosters technological change ceteris paribus. Secondly, the maximum $R \& D$ share out of revenues a firm ready to spend for technology development is contingent upon the perception of the patent policy. A firm is more inclined to invest in technology if it can protect a wider range of products when awarded by a patent and the firm can enjoy its exclusive 
patent rights for a longer period. The maximum R\&D intensity is positively related with patent length and patent breadth. If that was all to the story, the diagonal increase at the bottom left hand corner of Figure 4.9 would be continuous and the fastest technological progress would occur where the innovators' market share and the maximum R\&D intensity peak, namely with the highest patent length and breadth. But as Figure 4.9 shows, this is not the case and there is one more mechanism responsible for this result. Accumulation of financial resources in the hands of the innovators automatically creates an oligopolistic market structure. The market leaders with consolidated market positions and weaker threats from the competitors cut back on their $R \& D$ spending. $R \& D$ share out of total revenues is a negative linear function of the market share of the firm. All these mechanisms interact to create the picture as we see in Figure 4.9. The optimum conditions for the maximum technological progress occur for a patent breadth of 9 and a patent length of 40 . The minimum technology levels available to the consumers draw a similar picture as seen in Figure 4.10. This variable also reaches its peak with a patent breadth of 9 and a patent length of 40 .

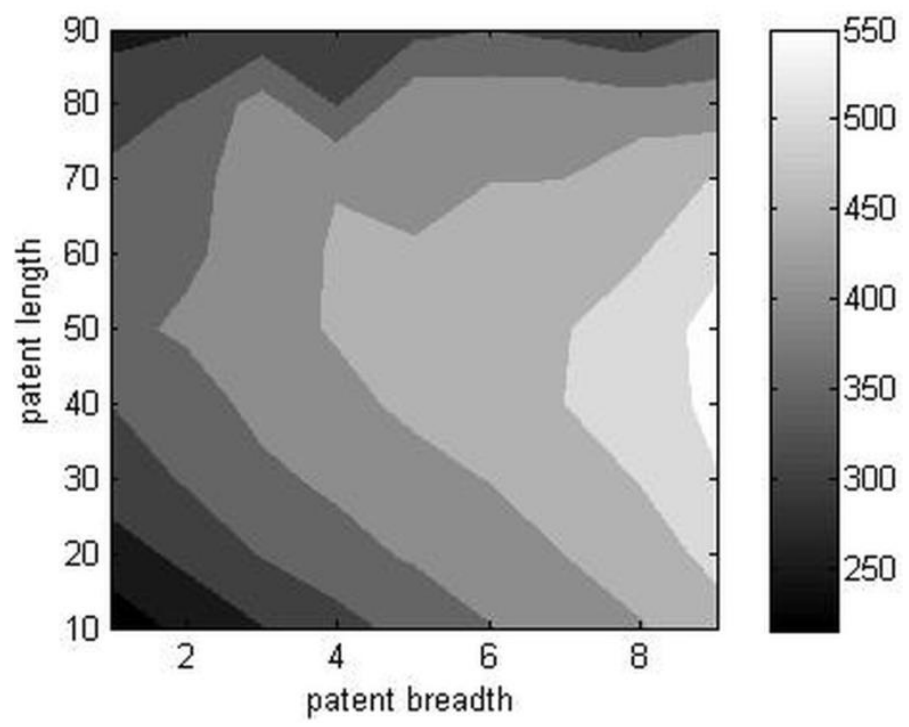

Figure 4.9. Maximum technology levels as a function of patent breadth and length 


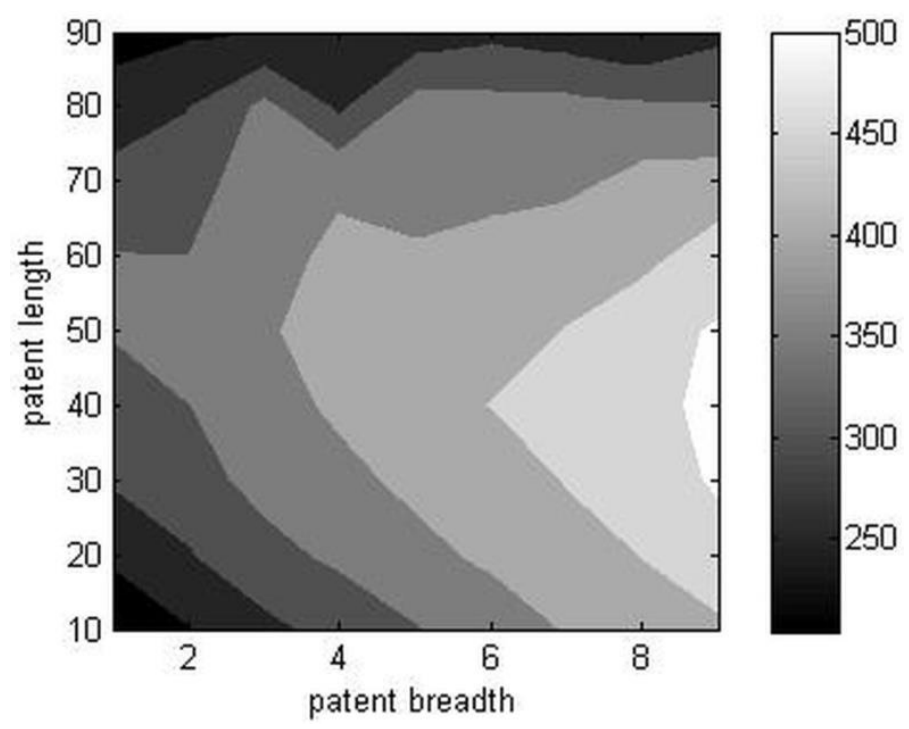

Figure 4.10. Minimum technology levels as a function of patent breadth and length

Figures $4.11,4.12$ and 4.13 report total profits created by all firms, total consumer utility and total welfare at the sector level, respectively. It complies with our expectations that these graphs are very similar to Figure 4.9, maximum technology levels achieved. Firms make higher profits by selling higher quality goods, because production cost is positively related with quality level and price is set as a mark-up over production costs; and consumers draw higher utility from consuming better quality products. Total welfare is a simple sum of total profits and consumer utility. Thereby the parameter space where total welfare is maximized coincides with the one where maximum technology levels peak in Figure 4.9, namely when patent breadth is 9 and patent length is 40 . 


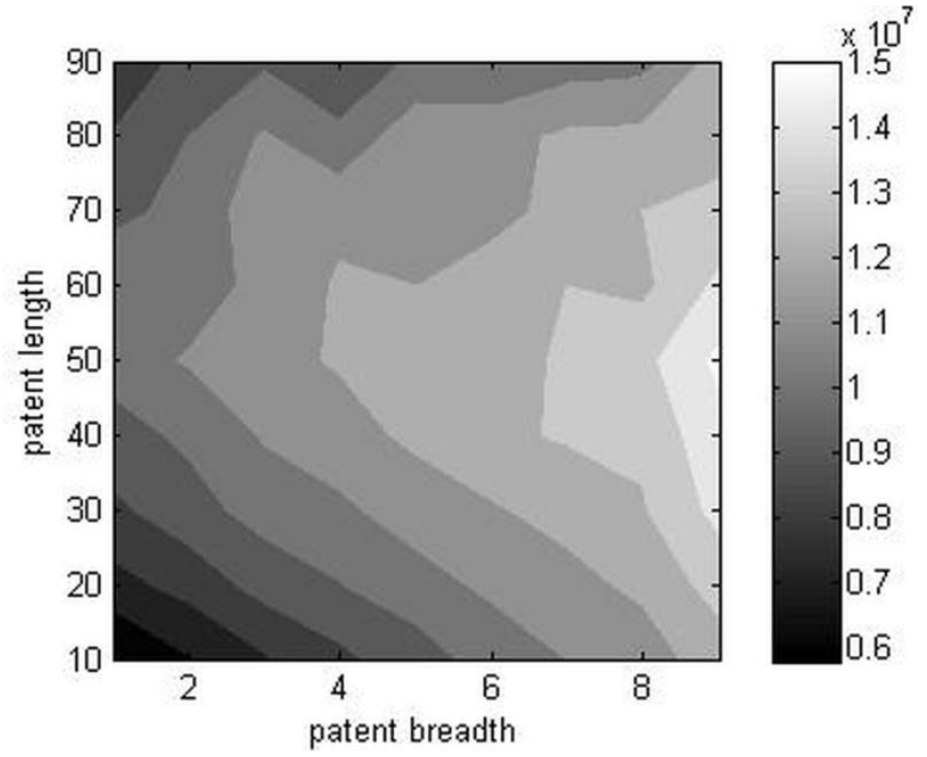

Figure 4.11. Total profits as a function of patent breadth and length

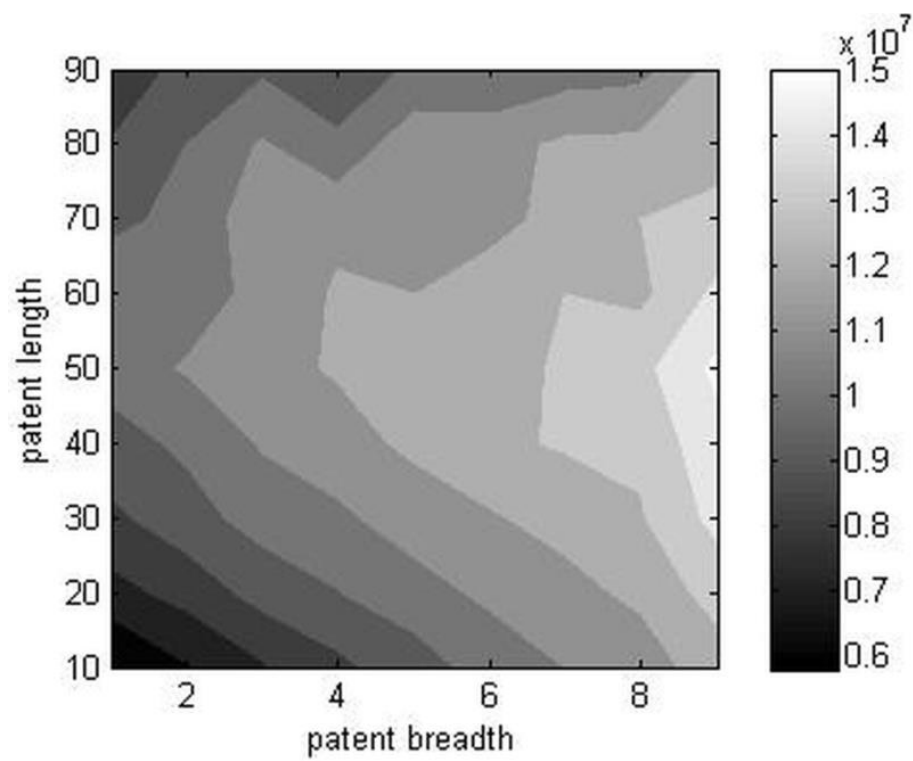

Figure 4.12. Total consumer utility as a function of patent breadth and length 


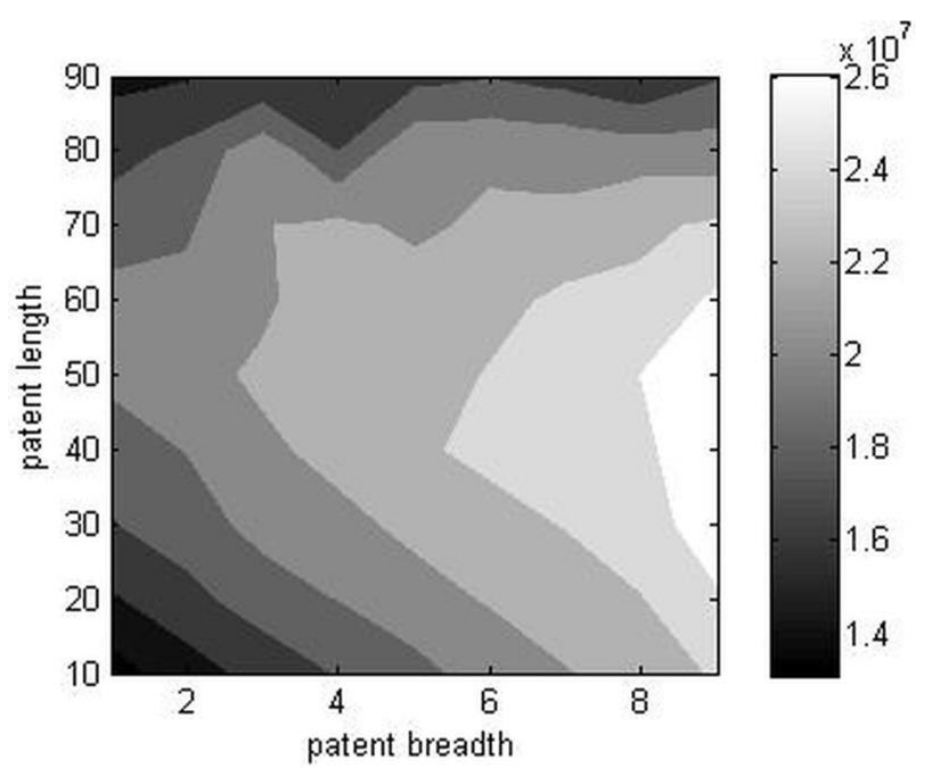

Figure 4.13. Total welfare as a function of patent breadth and length

\subsection{Conclusion}

This chapter is meant to analyze the interaction between R\&D activities of firms and heterogeneous consumer preferences in structuring the evolution of an industry and the effects of patent length and breadth on market outcomes. The proposed methodology is to develop an evolutionary, multiagent based, sector-level innovation model addressing the supply and demand side of the market simultaneously with the coevolution of heterogeneous consumer preferences, heterogeneous firm knowledge bases and technology levels at the micro level. A simultaneous consideration of technological progress and market dynamics with the help of ABM techniques allowed us to analyze such a multi-faceted phenomenon.

Using an agent-based model brought about a few important advantages over other modelling techniques in the relevant literature. The first is that it enabled studying a dynamic search process with sequential innovation rather than a single, isolated innovation. Secondly, ABM allowed us to have heterogeneous consumers rather than employing a representative agent on 
the demand side. Lastly, rather than single-product firms, the market is populated with multi-product firms which can serve to different niches of consumers concurrently. In sum, ABM provided the essential dynamics with heterogeneous agents, which is an essential foundation for a sector level innovation model and which is a better representation of the reality.

There are different mechanisms in place behind the effects of patent length and patent breadth on the main variables of interest in the model. The effect of patent length manifests itself in a continuous manner whereas patent breadth should be broad enough to cover a whole new class of technologies to have its effect felt by the market participants. So, there is discontinuity in the way market outcomes are conditioned by patent breadth. As a policy implication, the optimum patent policy is found to be granting broad patents for a limited period of time. In parallel with several empirical and theoretical studies referred to in the literature review, the results suggest that the patent policy should not be too weak or too strong to achieve the desired policy results. A 'mild' patent policy appears to be the optimum one to maximize technological progress and total welfare by striking a balance between giving the adequate incentives to do R\&D and avoiding an overly oligopolistic market structure when innovation is sequential.

A possible extension to this study would be repeating this simulation exercise for a complex product in a multi-dimensional technology space rather than in a one-dimensional one as in this study. Agent-based simulation modeling technique also allows for the inclusion of multiple competing product lines instead of a single one adopted in our analysis. These model choices rule out the possibility of dimensional interrelatedness and possible network externalities, which could be operationalized within a complex product space and/or multiple product lines and this may have implications for the model results and hence for policy advice. However, one should weigh these more realistic representations against a more complex model structure with a higher number of parameters.

The current analysis leaves out a few relevant issues such as research joint ventures, the effect of patent fees, the extension of patent terms, crosslicensing, pooling and, in general, the issue of markets for technologies. These 
issues have potential implications for competition and innovation structure (Shapiro, 2000).

It also remains to see what happens when a structural market characteristic (e.g. market size) or a behavioural rule (e.g. R\&D intensity, utility function) is changed. Another possible extension will be letting firms switching between being an innovator or imitator in time due to varying market and technological conditions rather than an exogenous imposition of strategies right from the beginning. Such a formulation would be a much more realistic representation of firms and let us study firm specific and aggregate factors leading to adoption of and shift from/to different strategies. 



\section{Chapter 5}

\section{Research Joint Ventures in an R\&D Driven Market with}

\section{Evolving Consumer Preferences}

\subsection{Introduction}

Firms heavily depend on improved products to survive in competitive markets. A continuous introduction of new products necessitates both specialized and diverse types of knowledge, which is almost often beyond the limits of the accumulated knowledge within the boundaries of a single firm (Cowan et al., 2006). Hence, firms turn to the market to find what they look for, but due to its tacitness, knowledge is hard to acquire in the market. Tacitness, of course, inhibits imitation - which preserves innovation incentives - but it also prevents a deliberate and intentional market based transferring of knowledge (Mowery et al., 1998). That is why firms collaborate in R\&D partnerships with on a reciprocal basis to share knowledge (Morone and Taylor, 2012). R\&D partnerships are part of a relatively large and diverse group of inter-firm relationships that one finds in between standard market transactions of unrelated companies and full integration by means of mergers and acquisitions (Hagedoorn, 2002). 
Alongside monetary funding, the contribution of an individual firm to an R\&D partnership involves sharing of human capital, accumulated knowledge embedded in firm-specific factors, and access to information and activities within its own R\&D division. Firms are not merely technological entities but are rather complex conglomerations of human capital and knowledge accumulated through past learning. Learning and R\&D activities are historically path-dependent and they generate firm-specific human capital, knowledge, and R\&D resources which create divergence in knowledge and expertise of different firms, which are often likely to be complementary. Firms form alliances to share these resources and to boost their R\&D productivity with the help of knowledge complementarities. In these alliances, technological overlap as a basis of a common technological understanding, reciprocity as a prerequisite for knowledge exchange, and the expected value of a research cooperation are the major determinants (Cantner and Meder, 2006).

This study explores three research questions frequently studied in research joint venture (RJV) literature. The first question is whether R\&D collaborators command a higher market share than non-collaborators. The second question is what kind of a relationship there is between competition level and the market share of R\&D collaborators. The last research question is whether higher capability heterogeneity among firms means higher market share of collaborators motivated by knowledge sharing. To answer these questions, an evolutionary, multi-agent based, sector-level innovation model is designed to simulate the dynamics of an R\&D driven sector. First, this model will be used to analyze the interaction between $R \& D$ activities of firms and differentiated consumer preferences in structuring the evolution of an industry. Then, we will explore our research questions regarding $R \& D$ collaborations within this context and the reader will observe that how one differentiates between collaborators and non-collaborators has a significant effect on the answers.

An apparent advantage of a simulation analysis in comparison to an empirical one in the context of this study is that one can effortlessly keep track of all variables of interest and observe whether a firm showing the characteristic of being a collaborator is actually collaborating at a given point 
in time. As will be clear in the following, this discrepancy may have significant consequences for the research results. Hence, we observe that the empirical findings in the relevant literature may be driven by the way a firm is defined as an R\&D collaborator. Another advantage of a simulation analysis over empirical studies in the context of this line of research is the opportunity to conduct controlled experiments to answer research questions like, ceteris paribus, how competition level and capability heterogeneity affects the market share of R\&D collaborators and knowledge sharing R\&D collaborators, respectively. This and many other uses of ABM in overcoming the constraints of empirical methods are explicitly discussed in Garcia (2005). It also helps us to understand the underlying mechanisms that explain why certain results occur the way they do. There are also a few advantages of this evolutionary model over the alternative ones in the relevant literature. To begin with, it is one of the few models studying RJVs with different motives (cost sharing vs. knowledge sharing) from an agent-based perspective. Secondly, whereas most evolutionary models focus on process innovation, this one exclusively models product innovation, i.e. technical progress is embodied in products. The third is that firms compete both in the R\&D process and goods market rather than in any one of them. Lastly, rather than single-product firms, the market is populated with multi-product firms which can serve to different niches of consumers concurrently. With the continuous introduction of new innovations, products transform from undiscovered to discovered and then from cutting edge product to obsolete. As the product space steadily shifts, the consumers are compelled to redefine their product choices within the given product range.

The rest of the chapter is organized as follows: Section 2 is a literature review where the research questions are also discussed. This part opens with the incentives to engage in RJVs and continues with the effect of competition on collaborators' market share and knowledge sharing incentives in R\&D collaborations. Section 3 details the simulation model. In section 4 , the results of the simulation analyses are discussed. Section 5 concludes. 


\subsection{Literature Survey and Research Questions}

\subsubsection{Incentives to engage in RJVs}

R\&D is considered by many observers as one of the, until recently, least expected activities that companies would be willing to share with others as it constitutes one of their core competencies and can lead to undesirable knowledge spillovers (Hagedoorn, 2002; Belderbos et al., 2018; MolinaMorales et al., 2011). Even so inter-firm collaboration has exploded during the past couple of decades, in parallel to the intensification of international competition, changing the nature of collaboration from peripheral interests to the very core functions of the corporation, and from equity to non-equity forms of collaboration. Importantly, cooperation focusing on the generation, exchange, and/or adaptation of new technologies has risen at very fast rates (Calogirou et al., 2003). These two facts explain why R\&D partnering has attracted so much attention during the recent years, both in the academic and in the popular press (Hagedoorn, 2002).

Two major strands of theoretical literature can be distinguished in this field. The industrial organization literature has extensively examined the incentives and welfare effects of R\&D cooperation among competing firms and focused on the role of R\&D investments and R\&D spillovers. Theoretical contributions in the management literature have stressed that $R \& D$ collaboration aims at minimizing transaction costs and exploiting complementary know-how between partner firms (Belderbos et al., 2004).

Cooperative $R \& D$ as an arrangement among a group of firms to share the costs and results of an R\&D project also helps to correct market failures which prevent firms from conducting the socially optimum level of R\&D. Firms refraining from investing in $R \& D$ because of the threat of free-riding on the end results are more motivated to innovate if they can find a partner with whom to share risks and costs. RJVs can increase the efficiency of the R\&D process through economies of scale, elimination of duplication of effort, dissemination of knowledge, and utilization of synergies among firms. RJVs also allow firms to undertake costly R\&D projects that none would undertake 
alone (Sinha and Cusumano, 1991). Ahuja (2000) asserted that each single partner can potentially obtain a greater amount of knowledge than would be the case from a comparable research investment made individually (Arvanitis, 2012). Collaboration with competitors can also help resolve common technological issues in the development of industry standards (Gnyawali and Park, 2011). Cooperative R\&D can be executed in many forms, including R\&D contracts, R\&D consortia, and RJVs (Sakakibara, 1997).

According to Sakakibara (1997), in the economic literature, firms' motives for participating in cooperative R\&D can be divided into two major classes: reasons related to $R \& D$, and reasons unrelated to $R \& D$. The two major R\&Drelated reasons are enhancing R\&D productivity through cooperation on R\&D inputs and changing the appropriability conditions of R\&D outputs (Katz, 1995; Geroski, 1993). Reasons unrelated to R\&D include improved market access through partners and the collection of government subsidies. An extensive survey of incentives, strategies, and outcomes of RJVs by Caloghirou and Vonortas (2000) revealed the following major objectives of firms to join such RJVs:

* Establishment of new relationships

* Access to complementary resources and skills

* Technological learning

* Keeping up with major technological developments

With all their benefits, partnerships have the negative potential to block competition and create various kinds of static and dynamic monopolies in existing and future markets, respectively (Hagedoorn et al., 2000). The threat of anti-competitive behavior increases significantly when repeated $R \& D$ collaboration occurs between firms that also meet in many product markets (Vonortas, 2000). White (1985) suggested that RJVs could reduce the probability of success of $R \& D$ by reducing the number of research paths explored toward a solution. RJVs can also slow down the rate of R\&D (Katz, 1986) and delay the realization of an innovation (Ordover and Willig, 1985).

\subsubsection{The effect of being in a RJV on market share}

Sarkar et al. (2001) suggested that the propensity to R\&D cooperation ('alliance proactiveness') will lead to higher levels of economic performance 
in terms of sale growth, market share and product development and that alliances between partners of unequal size mostly provide larger firms access to the tacit knowledge of small firms, which in turn benefit from the financial and marketing resources of the larger ones (Arvanitis, 2012). Belderbos et al. (2004) found that competitor cooperation positively affects growth in sales per employee of products and services new to the market and using a combination of objective and subjective measures, Link and Bauer (1989) have shown a positive correlation between cooperative R\&D conducted by a firm, the firm's market share, and the productivity of the firm's in-house R\&D. Overall, previous empirical work appears to suggest a positive impact of R\&D cooperation on firm performance (Belderbos et al., 2006). Hence our first research question is whether collaborators command a higher market share than non-collaborators.

\subsubsection{The effect of competition on RJV}

Firms' proactiveness in R\&D collaboration is dependent on the level of market competition. If the level of competition is low, they have less incentive to collaborate, since potential gains may be offset by the costs and risks involved. Hence, they rely on their internal resources in their R\&D activities. At a high level of competition, R\&D collaboration incentives are impeded by the environmental complexity as there is little to be gained from collaboration. Firms facing moderate levels of competition are more inclined to cooperate than firms facing low competition as they have more to gain from collaboration and they are more attractive partners than firms working in a highly competitive environment. Thus, markets with moderate competition may be the ones where collaboration is most likely. That is why some empirical studies predict an inverted U-shaped relationship for the impact of competitive intensity on the likelihood of forming an R\&D alliance (Ang, 2008; Wu, 2012; Wu and Pangarkar, 2010). Therefore, our next question is what kind of a relationship there is between competition level and the market share of collaborators. 


\subsubsection{Skills Sharing}

According to Hamel (1991), firms use alliances as an opportunity to internalize the skills or competencies of its partner to create next-generation competencies. By means of collaboration, firms can create synergistic combinations of assets, knowledge, and/or capabilities that may contribute to lowering the costs and/or increasing the perceived value of their offerings (Belderbos, et al., 2012). Such learning-based arguments imply that a key objective of cooperative R\&D is complementary knowledge or skill-sharing among participants (Miotti and Scahwald, 2003). Complementary knowledge here is defined as knowledge that, in combination, yields better R\&D results by increasing innovative productivity (Teece, 1992). Kodama (1992) asserted that 'technology fusion' or the combining of existing technologies into hybrid technologies becomes increasingly important for innovation. Cooperative $R \& D$ is a way to internalize and combine complementary resources and knowledge (Sakakibara, 1997). Analyzing over 7000 co-operative agreements worldwide, Hagedoorn and Schakenraad (1990) reported that complementarity is one of the primary motives for the formation of joint ventures and research corporations in information technologies, biotechnology, and new materials.

The resource-based view suggests that the degree of heterogeneity in participating firms' capabilities is an important determinant of the success of cooperative R\&D. Capability heterogeneity is defined here as the breadth or diversity of technological capabilities of firms. Today's highly sophisticated innovations often depend upon work across several areas of science and technology (Hagedoorn, 1993). Few firms have the breadth of knowledge required for such undertakings (Randor, 1991), and so a new combination of core competencies is necessary to build core competencies (Hagedoorn, 1995; Tyler and Steensma, 1995). Partnerships in which firms have high compatibility in organizational processes and partner-specific absorptive capacity allowing for effective transfer of know-how tend to outperform partnerships in which overlapping knowledge is narrow (Dyer and Singh, 1998; Mora-Valentin et al., 2004). Anbarci et al. (2002) also stressed the importance of complementarity between cooperating firms' R\&D processes and R\&D inputs in RJVs (Belderbos et al., 2006). 
There are two conditions that have to be fulfilled for these RJVs to succeed: first, the partners require some level of technological overlap to facilitate knowhow exchange (Baum et al., 2010). Second, their knowledge bases have to be different - otherwise nothing can be learnt (Mowery et al., 1998). Hence, optimal learning entails a trade-off between the advantage of increased cognitive distance for establishing new linkages and for the emergence of innovations and the disadvantage of less mutual understanding (Cohen and Levinthal, 1990). If the value of learning is the mathematical product of novelty value and understandability, it has an inverse U-shaped relation with cognitive distance, with an optimum level that yields maximal value of learning (Wuyts et al., 2005; Nooteboom, et al., 2007). Because firms motivated by knowledge sharing pick their partners according to this criterion, our last research question will be whether higher capability heterogeneity among firms will mean higher market share of collaborators motivated by knowledge sharing.

As a final point, technological overlap among alliance partners may increase over the course of collaboration, as a result of organizational learning and technology transfer within the venture (Mowery et al., 1998). Partner firms start to resemble each other regarding their product portfolio and R\&D routines after having RJVs experiences together (Noteboom, 2004). Whether this common history contributes to their prospective joint R\&D projects' success and hence to their tendency to work together in the following periods depends on their dynamic cognitive distance.

\subsection{The Model}

The simulation analysis in this chapter is based on the agent-based model developed in Chapter 3. Within this section, the peculiarities of the model used in this chapter will be explained including the determination of the R\&D productivity and partnering heuristic. 


\subsubsection{Innovation Strategies}

A firm is either an innovator or imitator from the beginning and stays as such throughout the simulation. Every firm engages in one R\&D project at a time and in picking R\&D projects, they pursue a technology-push strategy. They select R\&D projects starting from the highest technology base they possess to come up with cutting edge technology possible. Every period a constant number of firms enter the market as an exact copy of an already existing firm, except for its innovation strategy. It is equally likely that the newcomer is an $R \& D$ collaborator or a non-collaborator and an innovator or an imitator. If the new firm is a collaborator, it is again equally likely that it is a knowledgesharing or a cost-sharing collaborator.

\subsubsection{Partnering}

Partnerships are only formed for the sake of technology development projects and whether a firm collaborates or not depends on its strategy. Firms do not change their strategies throughout the simulation. There are collaborator and non-collaborator firms and whereas non-collaborators make R\&D in isolation, collaborators always find a partner if they can. Any given collaborator firm partners with only one firm at a time and two firms should have the same strategy to go into a partnership (e.g. knowledge sharing innovators only collaborate with knowledge sharing innovators and cost sharing imitators only collaborate with cost sharing imitators). Two firms should be planning to invest in the same of class of technology to go into a partnership. This way the firms high on the technology ladder are prevented from being exploited by the firms working with comparatively inferior technologies. The RJVs are formed for a single R\&D project and dissolved once the project is over.

Collaborators are divided into two groups according to their motivation for partnering and hence the way they choose their partners. Following the stream of evolutionary economists (e.g. Nelson and Winter, 1982; Dosi et al., 1988) the choice of the cooperation partner is based on the participating firms' assets of routines and resources developing over time (Cantner and Meder, 2006). The firms motivated with knowledge sharing partner with firms which 
are at optimum distance from them in technique space in order to maximize their R\&D productivity. The firms motivated by cost sharing partner with firms with the largest possible R\&D budget. Because technique and R\&D budget is a symmetric measure (they do not differ according to the perspectives of different firms), a partnership carries the same weight for both sides and hence, all partnership offers are accepted. For knowledge motivated firms, in technique space, if firm $\mathrm{A}$ is at optimum distance from firm B so is firm B from firm A. In a parallel vein among cost motivated collaborators, firm A offers partnership to firm B which has the highest R\&D budget after firm $\mathrm{A}$ and this offer is accepted, because firm B cannot get a better offer from another firm.

As a final point, firms move toward each other in the one-dimensional technique space when they engage in a RJV. Working on the same product development project make firms resemble each other in the way they perform R\&D. Depending on their relative positions in the technique space before the project, this step towards each other either increases or decreases the possibility that two knowledge sharing firms collaborate in the following rounds. After several R\&D projects together, it will be highly unlikely for these two firms to go into a partnership, since there will not be much left to learn from each other. This tendency will drive knowledge sharing incumbent firms to partner with new entrants in the long term.

\subsubsection{R\&D Productivity}

This study defines R\&D productivity as the efficiency at which R\&D budget is exploited for product development projects (parameters $\partial$ and $\beta$ in equations 4.6 and 4.9 in Chapter 3 , respectively). For non-collaborators, this efficiency is the same and constant for all firms. For collaborators, it is limited between a maximum and minimum level and its exact value is a function of the difference in techniques between partners. For this model, technique can be interpreted as the way of doing R\&D. Each firm is assigned a random value in one-dimensional technique space when it enters the market. There is an inverted U-shape relationship between difference in techniques and R\&D productivity of the joint R\&D project (Figure 5.1) (Nooteboom et al., 2007). 


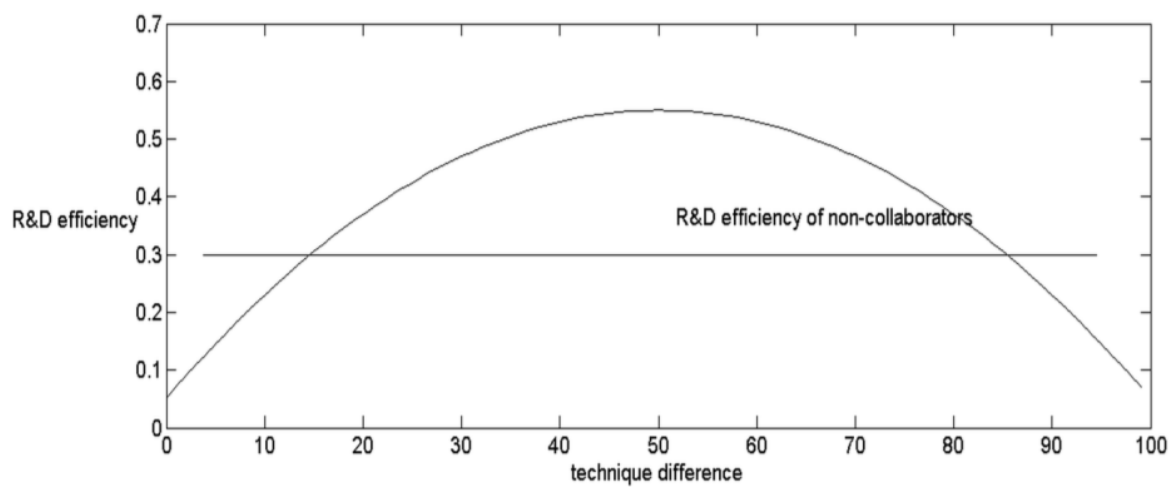

Figure 5.1. R\&D efficiency of a RJV as a function of the difference in techniques between firms

This kind of a relationship derives from the effect of knowledge complementarities on research success. If two firms are very similar in the way they perform $R \& D$, then there is not much to gain from this partnership. There is not much point in tapping into the knowledge base of your partner as it mostly overlaps with yours. If there is a radical difference in their R\&D techniques, potential knowledge complementarities are overshadowed by communication problems. The firms are too different to learn from each other (Cowan et al., 2006). In both cases, R\&D productivity can be lower than what it would be if these firms chose not to collaborate. The best of both worlds lies somewhere in between: when firms differ enough so that there is something to learn from each other, but still they are similar enough so that they can share their accumulated knowledge to exploit knowledge complementarities. Therefore R\&D productivity reaches its peak at a moderate level of difference in techniques.

\subsubsection{The Pseudo-Code of the Model}

At the initialization period, market is populated with $\mathrm{N}$ firms each endowed with an R\&D strategy (50/50 probability of being an innovator or an imitator, a collaborator or a non-collaborator and a knowledge-sharing or cost-sharing collaborator), a random R\&D technique and a product portfolio. Also, each consumer is assigned to an ideal product profile. The routine for the rest of the simulation is implemented as follows: 
1. Firms set a price for each product as a function of profits from that product in the previous periods.

2. Firms make marketing expenses for each product as a function of the quality of that product.

3. Each consumer determines her ideal product.

4. Consumers sample a few random products, structure their memory sets and purchase the best product within this set.

5. Products with an average market share below a threshold level are deleted from the market. Firms with no products to sell leave the market. New firms with random strategies enter.

6. In accordance with their R\&D strategies, firms either choose to perform R\&D on their own or form RJVs.

7. Each firm and RJV either innovates or imitates.

\subsection{Simulation Analysis}

\subsubsection{Model Dynamics}

In the following we will present the results of the simulation analysis. The data for the analysis is produced as an average over 100 simulation runs of 1000 steps using the base model configuration. The only thing that changes from one simulation to the other is the seed value which is a number used to initialize the pseudorandom generation process. This seed value governs all the stochastic processes within the model and two simulations with the same seed value always give the very same results. We start with introducing the evolution of the main variables of interest to show how R\&D activities of firms and heterogeneous consumer preferences interact in structuring the evolution of an industry.

Figure 5.2 reports inverse Herfindahl index. Figure 5.2 signifies a severe shake-out of firms from the beginning of the simulation run until the figure reaches its lowest value when the market concentration is at its maximum. This is followed by dispersion where a higher number of firms share the 


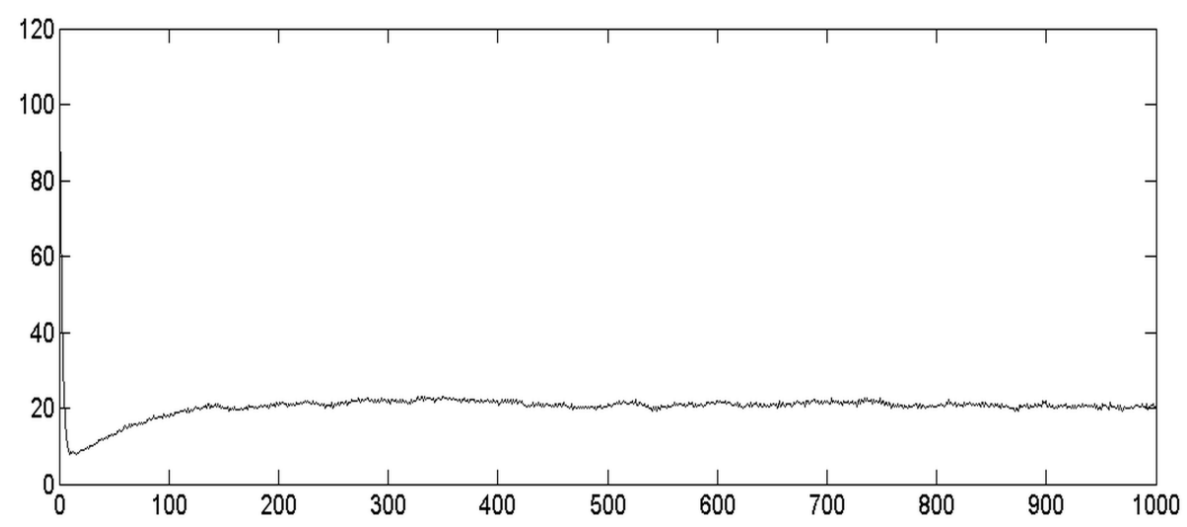

Figure 5.2. Inverse Herfindahl Index

market creating a more competitive environment and stabilization for the following periods. The model is initialized with a population of firms and those which cannot successfully serve to heterogeneous consumer needs are eliminated from the market in the early periods stabilizing the concentration rate for the following terms.

Figure 5.3 traces the time-path of the market shares of the groups of firms following one of six different strategies: non-collaborator innovators, noncollaborator imitators, knowledge-sharing collaborator innovators, knowledge-sharing collaborator imitators, cost-sharing collaborator innovators, and cost-sharing collaborator imitators. The figure shows that heterogeneity in firms' innovation strategies is sustainable; every strategy enjoys a positive market share throughout the simulation run. Figure 5.3 also signifies a shake-out of the market shares in the initial periods followed by a dispersion and stabilization for the following terms.

Figure 5.4 allows us to observe the maximum (upper series) and the minimum (lower series) level of product qualities available in the market. Whereas the maximum quality level is mainly determined by the R\&D activities of the firms and the minimum level mainly by the competitive forces and heterogeneous consumer tastes, the interaction between demand and supply dynamics affects these levels both. The continuous introduction of new products by innovation raises the maximum quality and renders low quality products obsolete by shifting consumer preferences towards hightech products. Technological change is the engine of economic growth in this 


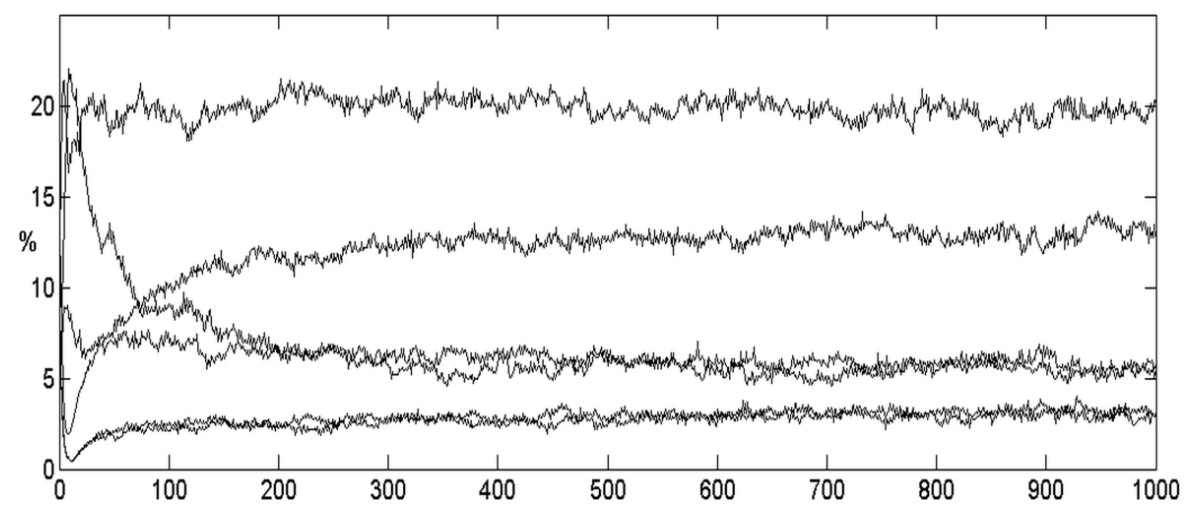

Figure 5.3. Market shares (\%) of firm groups following different R\&D strategies

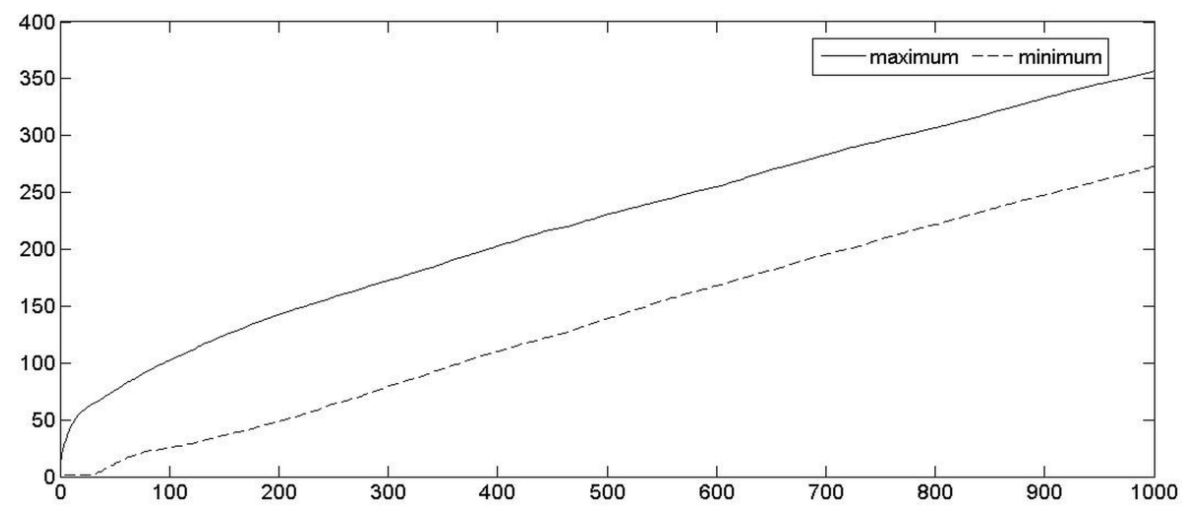

Figure 5.4 Maximum and minimum quality levels available

model. If for some reason technology creation comes to a halt (e.g. imitators conquer innovators dominating the whole market and leaving innovators with no financial resources to innovate), the economic growth also stagnates. Therefore, both consumers and imitator firms depend upon innovator firms to prosper.

Going into an R\&D partnership requires firms to have the same $R \& D$ strategy and to invest in similar technologies. Even if these criteria are met, a possible partner might already be in an R\&D collaboration. This means at a given time, only some of the potential collaborator firms are actually in a RJV. A similar differentiation between potential and realized collaborators can be 
found in Zhong and Ozdemir (2010). Figure 5.5 shows this ratio of the number of active collaborators to potential collaborators. The ratio is very high in the initial periods when the firms are quite homogeneous in their product portfolios. As product range increases together with technological progress, it swiftly decreases and then levels off for the following periods. There are two alternative explanations for the fact that not all prospective collaborators are in collaboration at every period. Either some of them (roughly 65\% for the second half of the simulation run) are continuously collaborating whereas others are generally unable to find a partner or most of the firms are in collaboration during some part of their life and in isolation for the rest. A closer examination of the simulation results shows that the latter is the case. An average potential collaborator spends some of its time in $R \& D$ collaborations and some for individual projects. Then the question arises as to when a firm should be regarded as a collaborator especially in collecting macro data. At a given period should a prospective collaborator's market share add to the total market share of collaborators irrespective of whether it is actually in a partnership or not at that specific period or should only active collaborators' market share count? This study shows that the answer to this question determines the outcomes of our research questions.

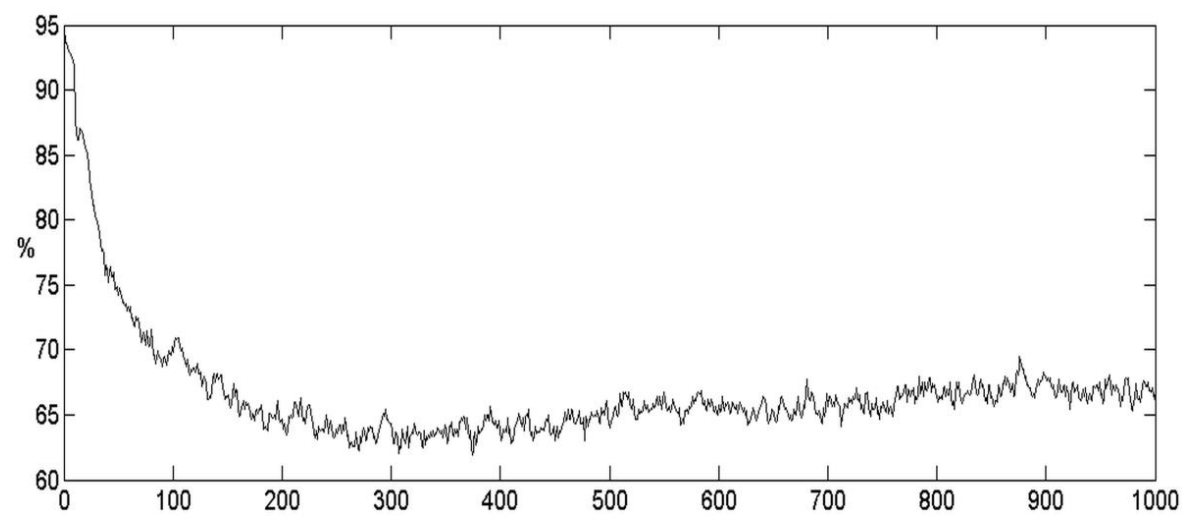

Figure 5.5 The ratio (\%) of active collaborators to potential collaborators

An interesting follow-up question is how this ratio of active to potential collaborators is affected by a behavioural rule (R\&D intensity) and a structural market characteristic (market size). A simulation analysis enables 
one to ask such "what-if" questions that are not possible for an empirical study. These effects can be observed in Figure 5.6 for R\&D intensity and in Figure 5.7 for market size. The higher the level of R\&D intensity and the bigger the market size, the lower this ratio. The explanation for this lies in the evolution of product ranges of the firms. A higher R\&D intensity or a bigger market allows a firm to have an increased product range, which makes it less likely for a potential $R \& D$ collaborator to find a partner planning to invest in a similar product.

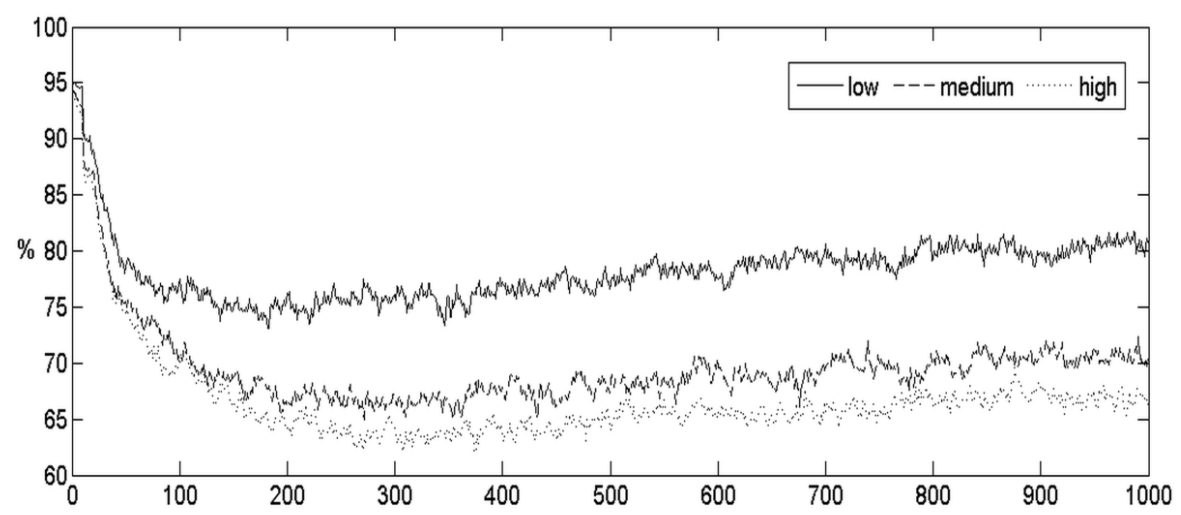

Figure 5.6. The ratio (\%) of active collaborators to potential collaborators when R\&D intensity is low, medium and high

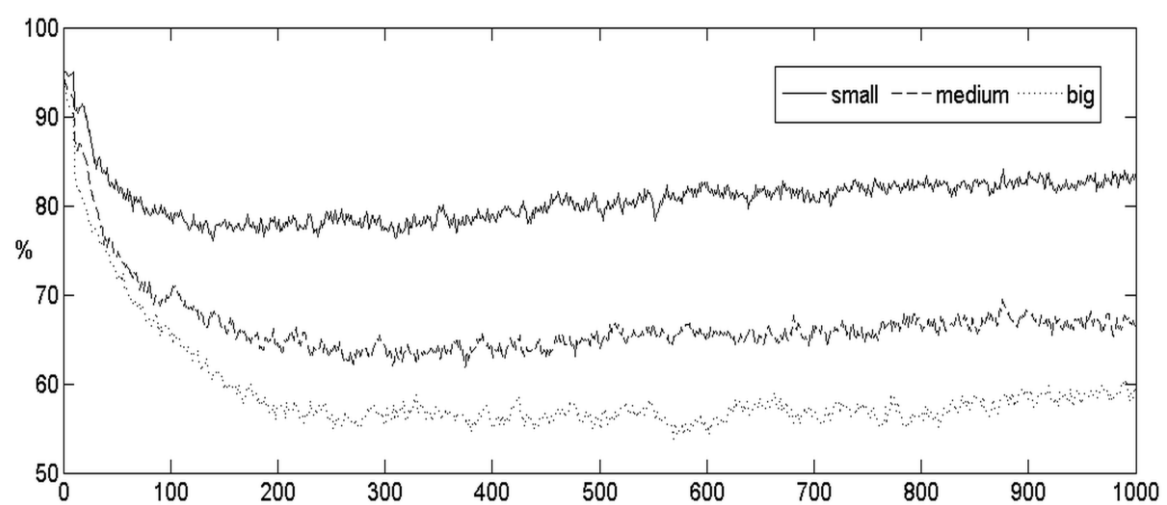

Figure 5.7. The ratio (\%) of active collaborators to potential collaborators when market size is small, medium and high 


\subsubsection{Simulation Experiments}

This subsection includes the results of a series of simple simulation experiments designed to answer our research questions. ${ }^{8}$ The analysis in this section is based on the end of simulation values of variables for 100 simulation runs each with a different seed value. At this point the reader should be reminded that there are six exclusive strategies: non-collaborator innovators, non-collaborator imitators, cost-sharing collaborator innovators, knowledge-sharing collaborator innovators, cost-sharing collaborator imitators, and knowledge-sharing collaborator imitators.

We start with our first question whether collaborators command a higher market share than non-collaborators. Being in collaboration involves a tradeoff. The R\&D efficiency of joint R\&D projects can be higher (especially for firms motivated by technology sharing) than that of firms working in isolation due to knowledge complementarities. Besides, collaborators pool their $R \& D$ resources to succeed in $R \& D$ projects that no other firm can do in isolation. The downside of being in collaboration is that they need to share the end result of the R\&D projects, which makes the partners compete against each other in the same product markets and R\&D race. The distribution of the end of simulation value of the market share of collaborator firms is drawn as a box plot in Figure 5.8 with two different calculation methods for the very same simulation run. In the first case (active collaborators) a firm is regarded to be a collaborator at a given period only if it is in collaboration at that specific period. In the second case (potential collaborators) a firm is always regarded as a collaborator if it shows the characteristic of being a collaborator by trying to collaborate with a partner every period. Therefore, potential collaborators include all active collaborators together with the firms who failed in partnering although they tried. The mean values for active and potential ones are $34 \%$ and $56 \%$, respectively. To test our research question, one needs to observe if the average market share of collaborator firms is significantly higher than $50 \%$ and since the average market share for active collaborators is way lower than this value, this analysis will be performed

\footnotetext{
${ }^{8}$ The results of the sensitivity analysis confirm that simulation experiment results are robust to changes in market size and R\&D intensity.
} 


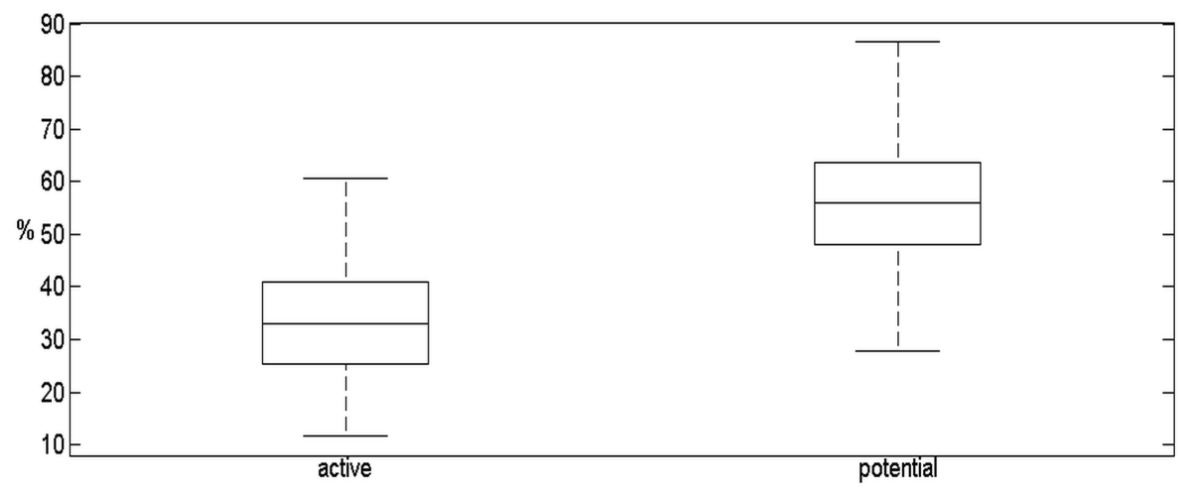

Figure 5.8. The market share (\%) of active and potential collaborator firms

only for potential collaborators using a one-sided t-test. However, the t-test requires the sample follow a normal distribution. To test for the normality of this sample, the Jarque-Bera test is performed. The test result shows that the null hypothesis that the sample comes from a normal distribution cannot be rejected. ${ }^{9}$ Now that it can be safely assumed that our sample comes from a normal distribution, a one-sided t-test can be performed. The null hypothesis that the mean is not bigger than 50 is rejected. Hence, we can argue that on average collaborators command a higher market share than noncollaborators. This simulation exercise makes it possible to collect data both on potential and active collaborators and exemplifies how the way one differentiates between collaborators and non-collaborators produces opposite results to the very same research question. In empirical studies researchers do generally not have a chance to make such a distinction.

Our second question was what kind of a relationship there is between competition level and market share of collaborators. Figure 5.9 shows how the market share of active collaborators is conditioned by the level of competition which is proxied with the number of new entrants every period. A closer examination of the simulation data reveals that there is a strong positive and linear relationship between the number of entries and the level of competition which is measured by the Herfindahl index. The box plot for

${ }^{9}$ All statistical tests in this section are performed at $5 \%$ significance level. 


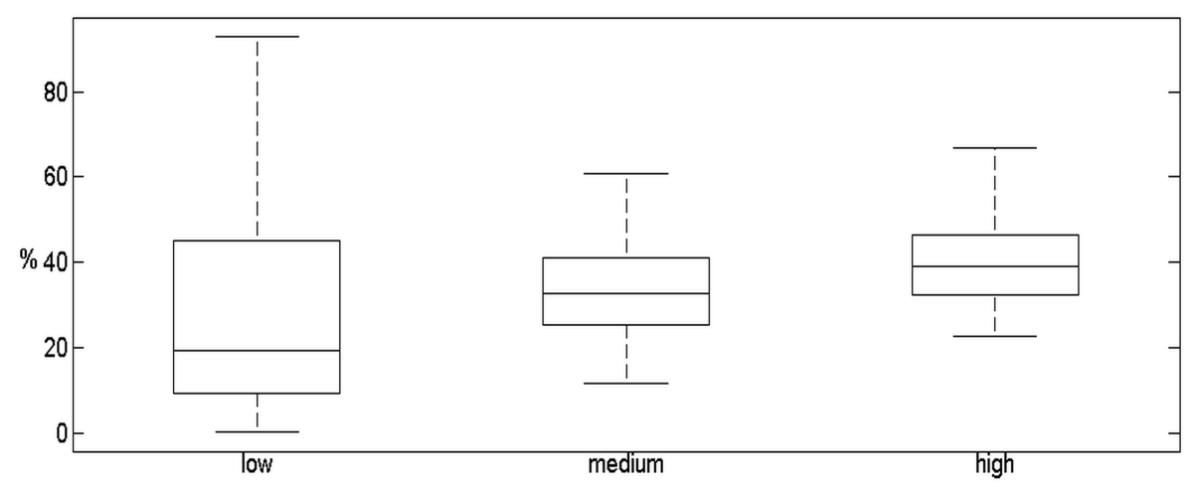

Figure 5.9. The market share (\%) of active collaborator firms when the level of competition is low, medium and high

the distribution of the end of simulation value of the market share of collaborators is drawn for the cases when the level of competition is low, medium and large with median values of $19 \%, 33 \%$ and $39 \%$, respectively. This figure is a vivid example of how competition can increase the efficiency of R\&D collaborations through economies of scale and elimination of duplication of efforts. Sharing costs and pooling knowledge made it possible for the collaborators to undertake costly $R \& D$ projects that none would undertake alone in a highly competitive environment. A hypothesis test can be performed to support this graphical analysis with a statistical one. The normality of the sample distributions should be checked first to determine the type of the hypothesis test. The Jarque-Bera test results show that only when the level of competition is low, the sample does not follow a normal distribution. Therefore, Wilcoxon rank sum and t-test test will be used to test the null hypothesis that competition does not positively affect the market share of active collaborators. The hypothesis test results complement our graphical analysis; the mean value when competition is high is statistically significantly higher than the mean value when it is medium and the median value when it is medium is statistically significantly higher than the median value when it is low. Therefore, our hypothesis is rejected.

Repeating this simulation analysis with an alternative approach to collecting data on the market share of collaborator firms leads to strikingly diverse results. At this point it should be stated that in the previous case at a 
given moment a firm is regarded as a collaborator only if it participates in a RJV at that specific moment. Alternatively, Figure 5.10 depicts the distribution of the end of simulation value of the market share of collaborators when a firm is counted always as a collaborator if it engages in R\&D partnership activities independent of the outcome which might be a success or failure in finding a partner. This is the only difference between these two cases. Competition this time negatively affects collaborator firms. A possible explanation might be the negative effect of having to share the fruits of RJVs -turning a research partner directly into a competitor- which is emphasized especially when competition is already high due to a high number of new entrants every period. The median values are $80 \%, 56 \%$ and $53 \%$ when competition is low, medium and high, respectively. The normality test again shows that only when the level of competition is low, the sample does not follow a normal distribution which requires one to use nonparametric Wilcoxon rank sum and t-test test to investigate the null hypothesis that competition level does not negatively affect the market share of potential R\&D collaborators. The test results conclude that the median value when competition is low is statistically significantly higher than the median value when competition is moderate and the mean value when competition is moderate is higher than the mean value when competition is high. Therefore, the research hypothesis is rejected also using this alternative approach, but this time the direction of the relationship between competition and the market share of collaborators is opposite to the previous case and this relationship is again statistically significant. This discrepancy in the analysis results necessitates a deeper examination and the simulation model provides us the required simulation data for this next step. A possible explanation may lie in how the ratio of the number of active collaborators to the number of potential ones is conditioned by the level of competition. Figure 5.11 gives this collaboration ratio in time for three different levels of competition and it confirms our expectation. The ratio is higher when competition is high than when it is medium and it is much higher when it is medium than when it is low. This is because the level of competition is positively related with the number of new entrants each period. When there is a larger pool of potential partners, it is more likely for a firm to collaborate with another following the 


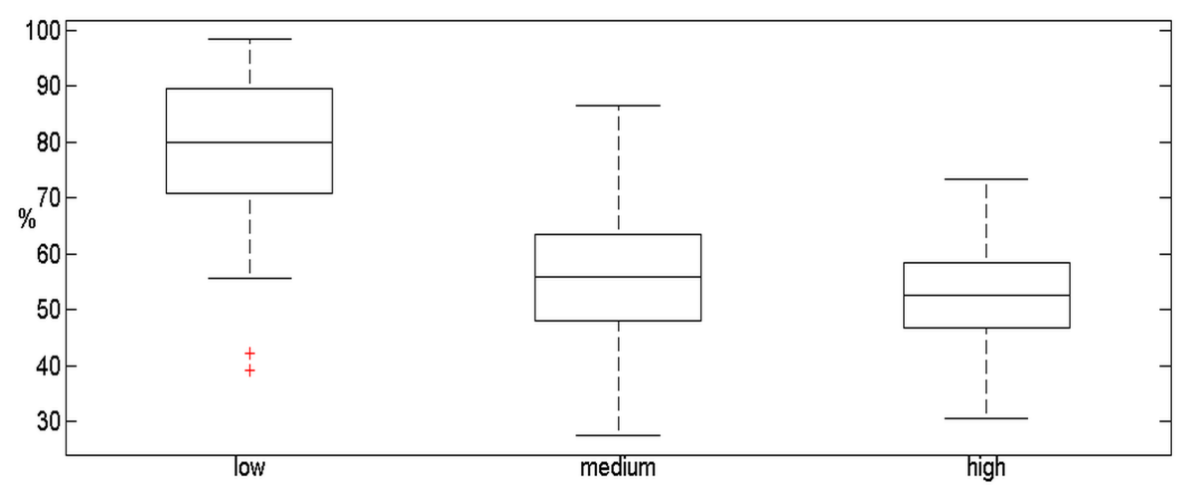

Figure 5.10. The market share (\%) of potential collaborator firms when the level of competition is low, medium and high

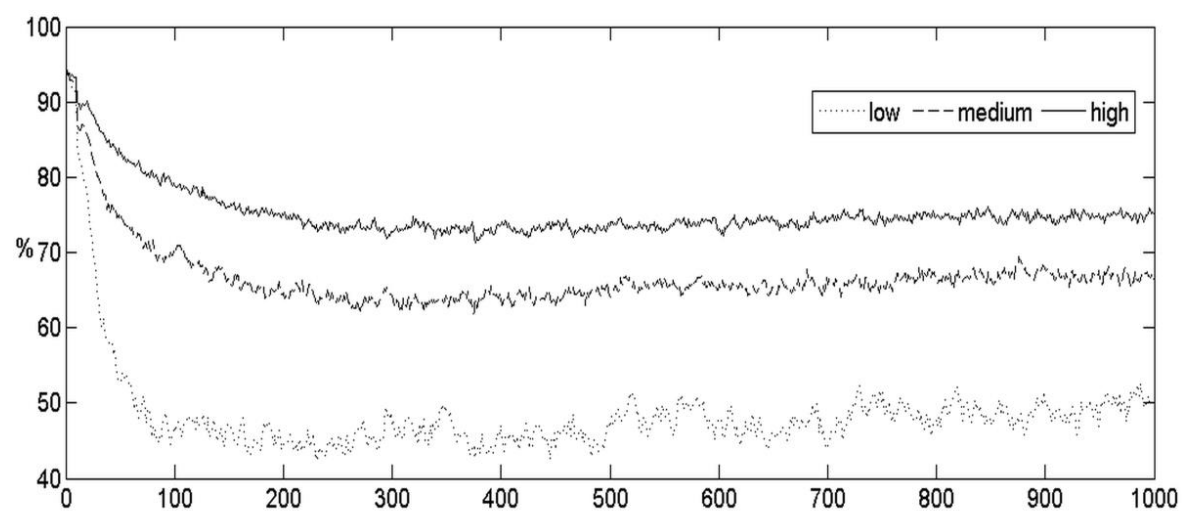

Figure 5.11. Collaboration ratio (\%) when competition is low, medium and high

same R\&D strategy and planning to invest in a similar technology. That collaboration ratio increases in competition explains how potential collaborators can lose their market share whereas active collaborators increase theirs as competition intensifies. Hence with the help of our simulation model we conclude that the underlying mechanism behind diverse results regarding the effect of competition on the market share of collaborators in two different cases is how collaboration ratio is determined by the level of competition. 
In the literature survey it was claimed that the relative importance of the skillsharing motive in R\&D consortia increases with heterogeneous capabilities (Sakakibara, 1997). Heterogeneous capabilities increase the possibility that two firms joining for an R\&D process possess complementary knowledge enhancing their innovative productivity. Capability heterogeneity is defined here as the breadth or diversity of technological capabilities that firms command. Furthermore, Anbarci et al. (2002) claimed that if complementarity is extremely low, RJVs can further lead to lower profits and social welfare as well. Figure 5.12 is drawn to explore these claims and shows how the market share of technology motivated active collaborators is affected by the overall capability heterogeneity in the firm population. The distributions for the end of simulation value of the market share of collaborators motivated with technology sharing are given as a box plot when knowledge heterogeneity is low, medium, and high with median values of $1 \%, 14 \%$, and $16 \%$, respectively. As suggested by Anbarci et al. (2002), when capability heterogeneity and hence technology complementarity is too low, the market is dominated by the non-collaborators. Starting from this highly disadvantageous point for the collaborators, they increase their market share with an increase in capability heterogeneity. As stated before, this is because a higher level of heterogeneity makes it more likely for a firm to partner another firm which is at optimum distance from itself in the technique space and this boosts knowledge complementarity and hence R\&D productivity of this alliance over that of a firm doing R\&D in isolation. Further increases in knowledge heterogeneity do not bring about a higher market share for technology collaborators. The reason is that population knowledge heterogeneity levels beyond an optimum point do not boost the possibility that any two firms in optimum distance from each other in technique space form an alliance. Therefore, beyond an optimum value, further increases in knowledge heterogeneity do not increase average R\&D productivity. This graphical analysis should be supplemented with a statistical one. Using Jarque-Bera test, it is concluded that the samples do not come from normal distributions. Hence, Wilcoxon rank sum test is performed to see whether the market share of knowledge-sharing active collaborators increases with knowledge heterogeneity. The test results show that the median value for a 


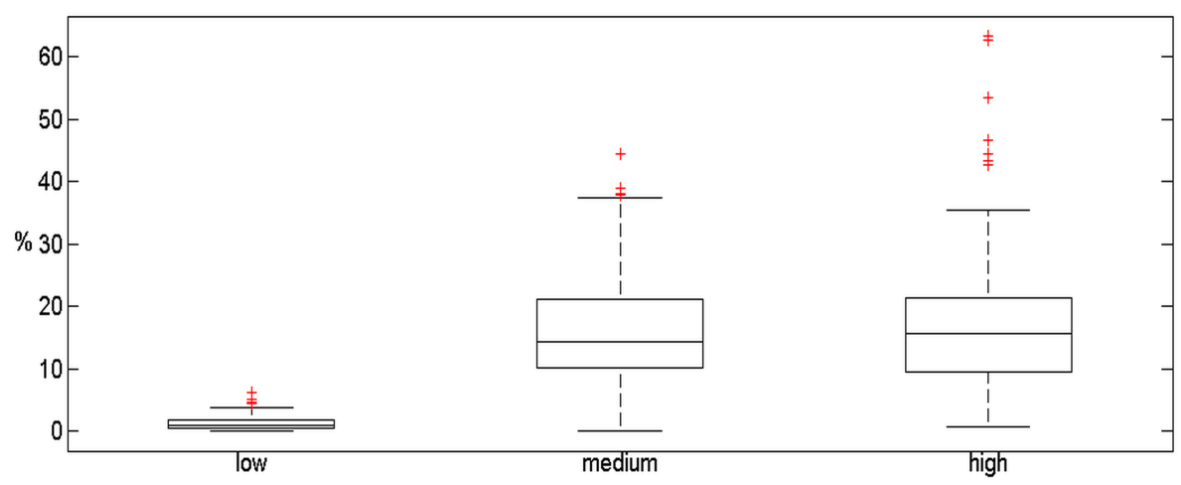

Figure 5.12. The market share (\%) of knowledge-sharing active collaborators when knowledge heterogeneity is low, medium or high

low level of knowledge heterogeneity is significantly lower than the median value for a medium level, which in turn is not statistically significantly different than it is when the knowledge heterogeneity is high. These results perfectly support the graphical analysis.

The effect of knowledge heterogeneity can also be tested for knowledgesharing potential collaborators. A box plot for the distribution of the end of simulation value of the market share of knowledge-sharing potential collaborators for different level of knowledge heterogeneity can be observed in Figure 5.13. It is very similar to Figure 5.12 supporting the argument that knowledge heterogeneity does its job on knowledge-sharing active collaborators through its effect on knowledge-sharing potential collaborators. This graphical explanation can be confirmed with a statistical test. JarqueBera test shows that only when heterogeneity is low, the sample does not come from a normal distribution. To test whether there is a statistically significant difference between the median values and means of the samples, Wilcoxon rank sum and t-test is used. The median value for a low level of knowledge heterogeneity is significantly lower than the median value for a medium level and the mean value for a medium level is significantly lower than it is when the knowledge heterogeneity is high. Hence the graphical explanation is statistically confirmed.

For a complete analysis one should also explore collaboration ratio within knowledge-sharing potential collaborators as a function of knowledge 


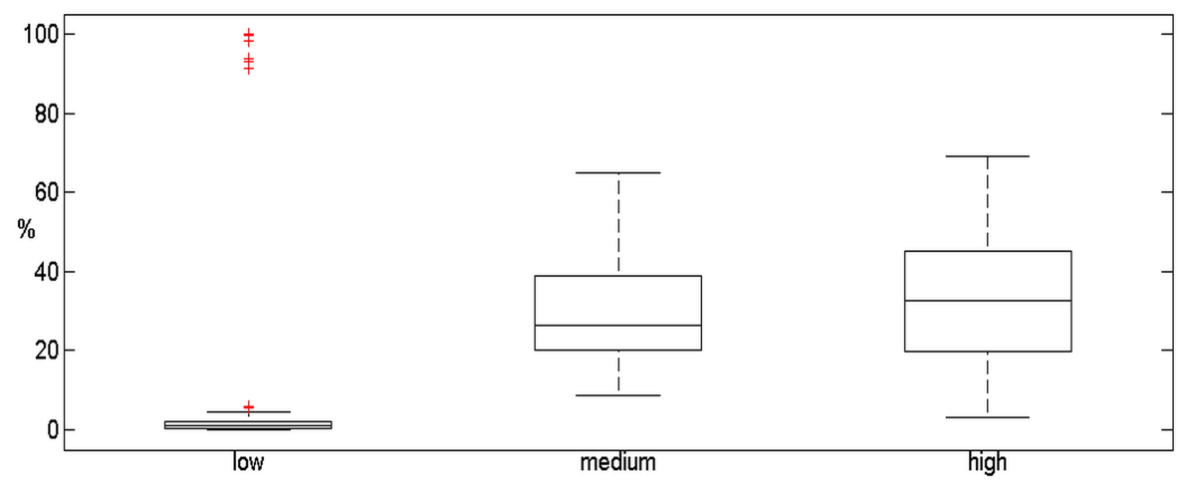

Figure 5.13. The market share (\%) of knowledge-sharing potential collaborators when knowledge complementarity is low, medium or high

heterogeneity. Figure 5.14 is drawn for this purpose. Collaboration ratios take on very similar values for medium and high levels of knowledge heterogeneity, which is in congruence with the fact that the market shares of knowledge-sharing collaborators are very close at these knowledge heterogeneity levels. However, a comparatively higher collaboration ratio does not go along with low market shares of knowledge-sharing collaborators when knowledge heterogeneity is low. Limited knowledge heterogeneity suppresses technological progress and hence product diversification among RJVs increasing the likelihood for a potential R\&D collaborator to find a partner planning to invest in a similar product. Hence the simulation model enables us to observe that the reason for the low market share of knowledge-sharing active collaborators in this case is the low market share of knowledge-sharing potential collaborators.

\subsection{Conclusion}

Although R\&D partnership is the least expected form of collaboration since knowledge creation is a core competence of a firm, we have observed acceleration in the number of such partnerships in the past few decades. This 


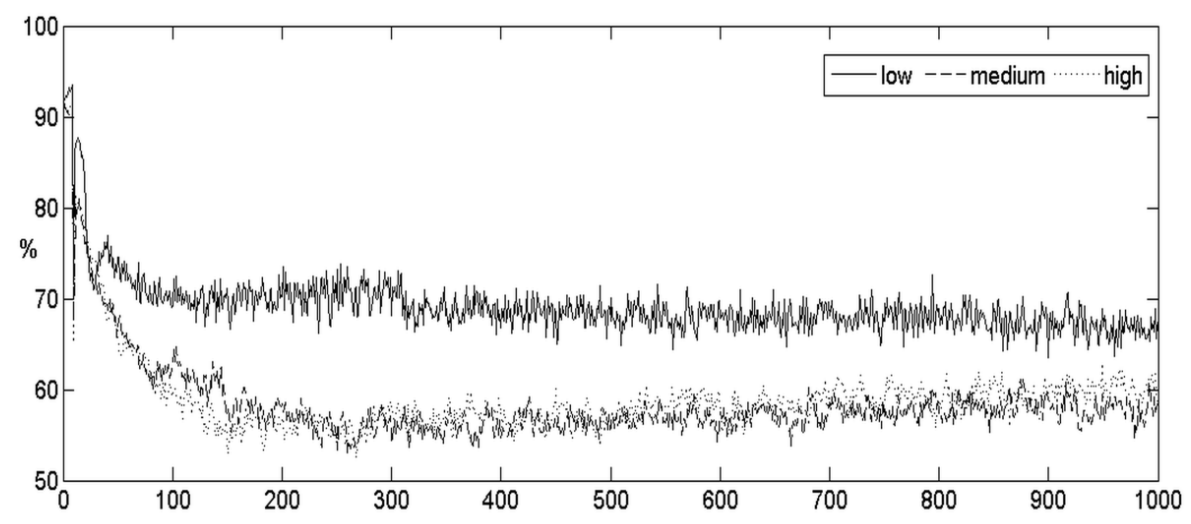

Figure 5.14. Collaboration ratio (\%) within knowledge-sharing potential collaborators when knowledge complementarity is low, medium or high

phenomenon has motivated economists to study the incentives of firms to collaborate in R\&D and the effects of these collaborations on firms with different incentives. This study is a contribution to the discussion of the frequently encountered research questions in this literature and to furthering the understanding of the reasons behind the research results with the help of an agent-based model.

The agent-based model simulates the working of an R\&D driven market with both supply and demand side. Firms compete both in goods market and R\&D process and consumers act to maximize their utility with their product choices that fit their preferences best. The interaction between supply and demand results in technological progress that continuously renews technology portfolios of firms and product choices of consumers. Firms achieve technological progress either via innovation or imitation and either in a RJV or in isolation.

The simulation model used in this study allowed us to draw a distinction between active and potential collaborators, which is harder to make in empirical studies. A firm is an active collaborator only if it succeeds in forging an alliance whereas it is sufficient to search for a partner to be counted as a potential collaborator. The first conclusion of this chapter is that active R\&D collaborators command a lower market share than non-collaborators. In other words, the disadvantage of creating your own competitor in the goods 
market and $R \& D$ race by sharing the end results of the $R \& D$ projects outweighs the advantages of pooling R\&D budgets and knowledge complementarities on the part of collaborators. An alternative look into this research question reveals that the market share of potential collaborators is higher than that of non-collaborators. Active collaborators command less than half of the market, because not all potential RJVs are realized. Such a distinction between active and potential collaborators is possible with the use of a simulation model.

The second research question was about the effect of competition on the market share of collaborators. Competition increases active collaborators' market share. Working on pooled R\&D budgets and exploiting knowledge complementarities creates economies of scale and enable collaborators to succeed in huge R\&D projects that no firm can undertake alone in a highly competitive environment. As opposed to active collaborators, potential collaborators are found to lose their market share as competition intensifies. A possible explanation is the negative effect of the resemblance of the product portfolios of the firms in a RJV, which gets even worse with sharpening competition. These opposite results stem from the fact that competition which is driven by the number of new entries every period has a positive effect on the ratio of active to potential collaborator firms by increasing the likelihood of participating in a RJV. The simulation model keeps track of collaboration ratio which explains why potential collaborators can lose their market share whereas active collaborators increase theirs as competition intensifies.

Lastly, technology complementarity boosts the market share of active collaborators motivated by knowledge sharing. The level of knowledge complementarity is a function of the overall heterogeneity in the knowledge pool of firms and there is an optimum level for this heterogeneity beyond which further increases do not bring about any increases in the R\&D productivity of alliances. This result stems from the fact that what determines the success of knowledge complementarities is the possibility that two firms at optimum distance from each other in the technique space form an alliance and this possibility is conditioned by the level of knowledge heterogeneity in the firm population. Knowledge heterogeneity has a very similar effect on 
potential collaborators and the simulation results showed us that collaboration ratio within potential collaborators helps to explain the market share of active collaborators specifically when knowledge heterogeneity is moderate or high.

The simulation analysis in this study enabled us to use two alternative methods to measure market share of collaborator firms. The outcomes of the simulation tests are driven by the chosen method. A clear inference based on these outcomes is that the research results of the empirical studies on RJVs should be interpreted with some caution regarding the preferred method of defining collaborator firms.

In this model, firms are endowed with an R\&D strategy when they enter the market which they are not allowed to change. A possible extension would be the endogenisation of these strategies by letting firms freely choose and possibly change them according to varying market and technological conditions (e.g. ceasing to go into R\&D partnerships once market leadership is gained). However, one should keep in mind that such a realistic move will increase the complexity of the model making the interpretation of the study results even harder. One other avenue for improvement is that the onedimensional technology space of the model can be substituted with a multidimensional one. This will have implications for knowledge complementarities and hence for R\&D collaborations. It also remains to see what happens when a structural market characteristic (e.g. market size) or a behavioural rule (e.g. R\&D intensity, utility function) is changed. 



\section{Chapter 6}

\section{Concluding Remarks}

The purpose of this concluding chapter is to summarize the main results of the study, outline some of its limitations, and suggest some avenues for further research.

This thesis study consists of essays on innovation strategies in the tradition of evolutionary economics. The chapters address the research topics: taxonomy of innovation strategies, sustainability of heterogeneity in innovation strategies, the effects of patent policy on market outcomes and research joint ventures. For the empirical part of the dissertation, latent class analysis is used to categorize firms into clusters with distinct innovation strategies using Community Innovation Survey 4 data. For the theoretical part, an evolutionary multi-agent based sector-level innovation model platform is created addressing supply and demand side of the market simultaneously with the coevolution of heterogeneous consumer preferences, heterogeneous firm knowledge bases and technology levels at the micro level.

We hope to have developed a reasonably realistic simulation model of innovation at sectoral level in a structured way giving due consideration to its multi-dimensionality. The dynamic formation of capabilities and resources and the search routine into technology space are represented within this simulation model. This simulation platform helped us to ask and 
answer several "what if" questions that would not be possible in an empirical study mostly due to data constraints. The stage for this theoretical model is set with a preceding taxonomic study of innovation patterns shedding light onto the major features of the innovative processes.

\subsection{Summary of the main findings}

Chapter 2 is an empirical taxonomic study over innovation modes drawing upon on firm-level survey data on innovation indicators from 16 countries participated CIS 4. An original contribution of this study is to show how a cluster of firms following a specific innovation strategy is linked to other groups within models of different number of clusters. Latent class analysis of the sample data concludes that a newly formed cluster takes in a significant share of the firms of more than a single existing cluster. A hybrid formation of a new cluster of two already existing clusters is a frequent occurrence. This finding indicates that the empirical identification of innovation modes using a variety of statistical techniques is strictly contingent on model choice. An innovation strategy defined in a given clustering model can be lost and/or a new innovation mode undefined in the previous steps can be identified with an increase in the number of clusters. Finally, based on interpretability and compatibility with previous taxonomic studies of innovation modes, a 4cluster model is selected for an in-depth analysis of innovation strategies. The results of this chapter hopefully inform policy makers to identify firm groups with distinct innovation strategies for a more efficient innovation and technology policy.

The aims of the third chapter are twofold. The first is to analyze the interaction between $R \& D$ activities of firms and heterogeneous consumer preferences in structuring the evolution of an industry. The second is to explore the heterogeneity in firms' innovation strategies: is heterogeneity sustainable in the long term and what happens to the market shares of firms having different innovation strategies when a structural market characteristic (market size) or a behavioural rule (R\&D intensity) is changed. The simulation analysis concludes that coexistence of a variety firms with distinct 
innovation strategies is viable even in the long run. This heterogeneity emerges as a dynamic equilibrium with continuous technological change and firm entry/exit. It is also concluded that market sharing between these firm groups is determined by market size and $R \& D$ intensity. A larger market favors imitators against innovators, demand-pull firms against technologypush ones and diversified firms against focused firms. In a similar vein, adopting a higher R\&D intensity at the industry level increases the market shares of imitator, demand-pull and diversified firms. The pace of technological progress is affected by this very market sharing between different strategies throughout the simulation run. A larger market or a higher R\&D intensity does not directly translate into a faster technological change, since it is also a function of the innovators' market share. If an increase in the size of the market or in R\&D intensity cannot compensate for the loss of market share by innovators, one can even observe a slowdown in technological change.

Chapter 4 explores the effect of patent policy on market outcomes and opens with introducing the evolution of the main variables of interest to explore model dynamics and continues with the results of a series of simulation experiments designed to analyze how these variables of interest are conditioned by patent length and breadth. The effect of patent length manifests itself in a continuous manner whereas patent breadth should be broad enough to cover a whole new class of technologies to have its effect felt by the market participants. So, there is discontinuity in the way market outcomes are conditioned by patent breadth. The simulation analysis concludes that the optimum patent policy is granting broad patents for a limited time period.

Chapter 5 brings an alternative approach to R\&D collaborations with an evolutionary, multi-agent based, sector-level R\&D model. The model simulates the evolution of an R\&D driven market composed of profit-driven firms and boundedly rational consumers and is used to answer some frequently discussed research hypotheses in the relevant empirical literature. This chapter extends beyond a basic confirmation/rejection of these hypotheses by showing that the way a firm is defined as an R\&D collaborator has significant effects on research results. The simulation results show that 
$R \& D$ collaborators command either a higher or lower market share than noncollaborators and competition either increases or decreases collaborators' market share depending on the method of measurement, technology complementarity boosts the market share of collaborators motivated by knowledge sharing and there is an optimum level for knowledge heterogeneity beyond which further increases do not bring about any increases in the market share of alliances. Based on these outcomes it is recommended that the research results of the empirical studies on research joint ventures should be interpreted with some caution regarding the chosen method of defining collaborator firms.

The very nature of agent-based simulation models requires a very explicit modelling of every module within the system (innovation mechanism, pricing heuristic, firm interaction, consumer purchase, etc.). In general, this specificity of the simulation exercise permitted an increased understanding of an industry-level innovation system through controlled computational experiments. The model demonstrated how firm level heterogeneity in innovation strategies evolved and persisted as a dynamic equilibrium with continuous technological change and firm entry and exit. It also functioned as a laboratory increasing our normative understanding for the discovery of good designs: the optimum patent length and breadth for the sake of fastest technological change and highest wealth creation. Last but not least, the distinctive capability of this modeling technique in tracking the status and behaviour of each and every individual agent in real time (e.g. being in an $R \& D$ collaboration or not at a specific point in time) enabled us to observe how micro-level interactions lead to macro outcomes.

\subsection{Limitations of the study and avenues for further research}

Using an agent-based model brought about a few important advantages over other modelling techniques in the relevant literature. The first is that it enabled studying a dynamic search process with sequential innovation rather than a single, isolated innovation. Secondly, ABM allowed us to have 
heterogeneous consumers rather than employing a representative agent on the demand side. Lastly, rather than single-product firms, the market is populated with multi-product firms which can serve to different niches of consumers concurrently. In sum, ABM provided the essential dynamics with heterogeneous agents, which is an essential foundation for a sector level innovation model and which is a better representation of the reality.

In the utilized model, firms are endowed with an innovation strategy and they do not change it throughout the simulation. A radical extension to this study will be the endogenization of the innovation strategies by letting firms freely choose and possibly change them in time due to varying market and technological conditions. Firms can even adopt different strategies simultaneously in different product development projects. Such a formulation would be a much more realistic representation of firms and let us study firm specific and aggregate factors leading to adoption of and shift from/to different strategies.

A possible extension to the model would be repeating this simulation exercise for a complex product in a multi-dimensional technology space rather than in a one-dimensional one as in this study. Agent-based simulation modeling technique also allows for the inclusion of multiple competing product lines instead of a single one adopted in our analysis. These model choices rule out the possibility of dimensional interrelatedness and possible network externalities, which could be operationalized within a complex product space and/or multiple product lines and this may have implications for the model results and hence for policy advice. However, one should weigh these more realistic representations against a more complex model structure with a higher number of parameters. 



\section{Bibliography}

Aghion, P., \& Howitt, P. (1992). A model of growth through creative destruction. Econometrica, 60(2), 323-351.

Agresti, A., \& Yang, M. (1986). An empirical investigation of some effects of sparseness in contingency tables. Computational Statistics and Data Analysis, 5, 9-21.

Ahuja, G. (2000). Collaboration, networks, structural holes, and innovation: A longitudinal study. Administratuve Science Quarterly, 45, 425-455.

Akcigit, U. (2009). Firm size, innovation dynamics and growth. Retrieved from https://www.economicdynamics.org/meetpapers/2009/paper_1267.pdf

Anbarci, N., Lemke, R., \& Santanu R. (2002). Inter-firm complementarities in R\&D: A re-examination of the relative performance of joint ventures. International Journal of Industrial Organization, 20, 191-213.

Ang, S. H. (2008). Competitive intensity and collaboration: Impact of firm growth across technological environments. Strategic Management Journal, 29(10), 1057-1075.

Archibugi, D., Cesaratto, S., \& Sirilli, G. (1991). Sources of innovative activities and industrial organization in Italy. Research Policy, 20(4), 299 313.

Arundel, A., \& Hollanders, H. (2005, March). EXIS: An exploratory approach to innovation Scoreboards. Retrieved from http://digitalarchive.maastrichtuniversity.nl/fedora/get/guid:25cbd28fefcf-4850-a43c-ab25393fcca7/ASSET1 
Arundel, A., Lorenz, E., Lundvall, B.-A., \& Valeyre, A. (2007). How Europe's economies learn: A comparison of work organization and innovation mode for the EU-15. Industrial and Corporate Change, 16(6), 1175-1210.

Arvanitis, S. (2012). How do different motives for R\&D cooperation affect firm performance? - An analysis based on Swiss micro data. Journal of Evolutionary Economics, 22, 981-1007.

Asikainen, A. L. (2015). Innovation modes and strategies in knowledge intensive business services. Service Business, 9, 77-95.

Barney, J. B. (1991). Firm resources and sustained competitive advantage. Journal of Management, 17, 99-120.

Baum, J. A. C., Cowan, R., \& Jonard, N. (2010). Network-independent alliance selection and innovation networks. Management Science, 56(11), 2094-2110.

Belderbos, R., Carree, M., \& Lokshin, B. (2004). Cooperative R\&D and firm performance. Research Policy, 33, 1477-1492.

Belderbos, R., Carree, M., \& Lokshin, B. (2006). Complementarity in R\&D cooperation strategies. Review of Industrial Organization, 28, 401-426.

Belderbos, R., Gilsing, V., \& Lokshin, B. (2012). Persistence of, and interrelation between horizontal and vertical technology alliances. Journal of Management, 38(6), 1788-1811.

Belderbos, R., Gilsing, V., Lokshin, B., Carree, M., \& Sastre, J. F. (2018). The antecedents of new R\&D collaborations with different partner types: On the dynamics of past R\&D collaboration and innovative performance. Long Range Planning, 51(2), 285-302.

Bergmann, R., \& Friedl, G. (2008). Controlling innovative projects with moral hazard and asymmetric information. Research Policy, 37, 1504-1514.

Bergstrom, C. T., \& Godfrey-Smith, P. (1998). On the evolution of behavioral heterogeneity in individuals and populations. Biology and Philosophy, 13, 205-231.

Bessen, J., \& Hunt, R. M. (2007). An empirical look at software patents. Journal of Economics and Management Strategy, 16(1), 157-189. 
Bessen, J., \& Maskin, E. (2009). Sequential innovation, patents and imitation. RAND Journal of Economics, 40(4), 611-635.

Biernacki, C., \& Govaert, G. (1999). Choosing models in model-based clustering and discriminant analysis. Journal of Statistical Computation and Simulation, 64, 49-71.

Boulding, K. E. (1991). What is evolutionary economics? Journal of Evolutionary Economics, 1, 9-17.

Breschi, S., Malerba, F., \& Orsenigo, L. (2000). Technological regimes and Schumpeterian patterns of innovation. The Economic Journal, 110(463), 388410.

Caloghirou, Y., \& Vonortas N. S. (2000). Science and technology policies towards research joint ventures. Final Report, Project SOE1-CT97-1075, TSER, European Commission, DG XII.

Calogirou, Y., Ioannides, S., \& Vonortas, N. S. (2003). Research joint ventures: A critical survey of the theoretical and empirical literature. Journal of Economic Surveys, 17(4), 541-570.

Cantner, U., \& Meder, A. (2006). Determinants influencing the choice of a cooperation partner (Jenaer Schriften zur Wirtschaftswissenschaft No. 20/2006, Jena). Retrieved from https://www.researchgate.net/publication/5140855_Determinants_influe ncing_the_choice_of_a_cooperation_partner

Carley, K. M., \& Gasser, L. (1999). Computational organization theory. In G. Weiss (Ed.), Multiagent systems: A modern approach to distributed artificial intelligence (pp. 299-330). Cambridge, MA: MIT Press.

Chang, H. (1995). Patent scope, antitrust policy, and cumulative innovation. RAND Journal of Economics, 26, 34-57.

Christensen, J. F. (2002). Corporate strategy and the management of innovation and technology. Industrial and Corporate Change, 11, 263-288. 
Clausen, T., Pohjola, M., Sapprasert, K., \& Verspagen, B. (2011). Innovation strategies as a source of persistent innovation. Industrial and Corporate Change, 21(3), 553-585.

Cohen, M., Burkhart, R., Dosi, G., Egidi, M., Marengo, L., Warglien, M., \& Winter, S. (1996). Routines and other recurring action patterns of organizations: Contemporary research issue. Industrial and Corporate Change, 5(3), 653-699.

Cohen, W. M., Nelson R. R., \& Walsh, J. P. (2000). Protecting their intellectual assets: Appropriability conditions and why U.S. manufacturing firms patent (or not). (NBER Working Paper Series Working Paper 7552). Retrieved from http://www.nber.org/papers/w7552.pdf

Cohen, W., \& Levinthal, D. (1990). Absorptive capacity: A new perspective on learning and innovation. Administrative Science Quarterly, 35(1), 128 152.

Cooper, B. (2000). Modelling research and development: How do firms solve design problems? Journal of Evolutionary Economics, 10, 395-423.

Cowan, R., Jonard, N., \& Zimmermann, J. -B. (2006). Evolving networks of inventors. Journal of Evolutionary Economics, 16, 155-174.

Cyert, R., \& March, J. (1963). A behavioral theory of the firm. Englewood Cliffs, NJ: Prentice-Hall.

David, P. A. (1985). Clio and the Economics of QWERTY. American Economic Review, 75(2), 332-337.

Dawid, H. (2006). Agent-based models of innovation and technological change. In L. Tesfatsion and K. L. Judd (Eds.), Handbook of Computational Economics, Volume 2: Agent-Based Computational Economics (pp. 1235-1272). North-Holland: Elsevier B.V.

de Jong, J. P. J., \& Marsili, O. (2006). The fruit flies of innovations: A taxonomy of innovative small firms. Research Policy, 35, 213-229. 
de WIT, G. (2005). Firm size distributions: An overview of steady-state distributions resulting from firm dynamics models. International Journal of Industrial Organization, 23, 423-450.

Dosi, G., Freeman, C., Nelson, R., Silverberg, G., \& Soete, L. (1988). Technical change and economic theory. London and New York: Pinter Publisher.

Dosi, G., Marengo, L., \& Pasquali, C. (2006). How much should society fuel the greed of innovators? On the relations between appropriability, opportunities and rates of innovation. Research Policy, 35, 1110-1121.

Dosi, G., Marsili, O., Orsenigo, L., \& Salvatore, R. (1995). Learning, market selection and the evolution of industrial structures. Small Business Economics, 7, 411-436.

Dosi, G., Napoletano, M., Roventini, A., Stiglitz, J. E., Treibich, T. (2017). Rational heuristics? Expectations and behaviors in evolving economies with heterogeneous interacting agents. (LEM Working Paper Series, No. 2017/31, Scuola Superiore Sant'Anna, Laboratory of Economics and Management (LEM), Pisa). Retrieved from https://www.econstor.eu/bitstream/10419/174581/1/2017-31.pdf

Drejer, I., \& Vinding, A. L. (2006). Organisation, 'anchoring' of knowledge, and innovative activity in construction. Construction Management and Economics, 24, 921-931.

Dunne, T., Roberts, M. J., \& Samuelson, L. (1988). Patterns of firm entry and exit in U.S. manufacturing industries. Rand Journal of Economics, 19(4), 495515.

Durand, R. (2001). Firm selection: An integrative perspective. Organization Studies, 22, 393-417.

Duysters, G., \& Lokshin, B. (2011). Determinants of alliance portfolio complexity and its effect on innovative performance of companies. Journal of Product Innovation Management, 28 (4), 570-585.

Dyer, J., \& Singh, H. (1998). The relational view: Cooperative strategy and sources of interorganizational competitive advantage. Academy of Management Review, 23, 660-679. 
Edmondson, A. C., \& Nembhard, I. M. (2009). Product development and learning in project teams: The challenges are the benefits. Journal of Product Innovation Management, 26, 123-138.

Encaoua, D., Dominique, G., \& Catalina, M. (2006). Patent systems for encouraging innovation: Lessons from economic analysis. Research Policy, 35, 1423-1440.

Eswaran, M., \& Gallini, N. (1996). Patent policy and the direction of technical change. RAND Journal of Economics, 27(4), 722-746.

Eurostat (2007). The CIS 3 Anonymised Microdata Sets. Eurostat: Luxembourg.

Evangelista, R. (2000). Sectoral patterns of technological change in services. Economics of Innovation and New Technology, 9, 183-221.

Everitt, B. S. (1993). Cluster Analysis. London: Oxford University Press.

Falvey, R., Foster, N., \& Greenaway, D. (2006). Intellectual property rights and economic growth. Review of Development Economics, 10(4), 700-719.

Filippetti, A. (2011). Innovation modes and design as a source of innovation: A firm-level analysis. European Journal of Innovation Management, 14(1), 526.

Fleming, L., \& Sorenson, O. (2004). Science as a map in technological search. Strategic Management Journal, 25, 909-928.

Foster, N. (2014). Intellectual property rights and the margins of international trade. The Journal of International Trade \& Economic Development, 23(1), 130 .

Frenz, M., \& Lambert, R. (2012). Mixed modes of innovation: An empiric approach to capturing firms' innovation behaviour. (OECD Science, Technology and Industry Working Papers, 2012/06, OECD Publishing). Retrieved from https://www.oecd-ilibrary.org/docserver/5k8x610bp3bpen.pdf?expires $=1549558075 \&$ id=id\&accname=guest\&checksum=F599CA8 1CC2777D93CA3FDC4AB63D08B 
Friedman, M. (1953). Essays in positive economics. Chicago: The University of Chicago Press.

Gallini, N. T. (1992). Patent policy and costly imitation. RAND Journal of Economics, 23, 52-63.

Gallini, N. T. (2002). The economics of patents: Lessons from recent U.S. patent reform. Journal of Economic Perspectives, 16, 131-154.

Garcia, R. (2005). Uses of agent-based modeling in innovation/new product development. Journal of Product Innovation Management, 22(5), 380-398

Geroski, P. A. (1993). Antitrust policy towards co-operative R\&D ventures. Oxford Review of Economic Policy, 9(2), 58-71.

Gilbert R., \& Shapiro, C. (1990). Optimal patent length and breadth. RAND Journal of Economics, 21(1), 106-112.

Gilbert, N., Pyka, A., \& Ahrweiler, P. (2001). Innovation networks-A simulation approach. Journal of Artificial Societies and Social Simulation, 4(3). Retrieved from http://jasss.soc.surrey.ac.uk/4/3/8.html

Gnyawali, D. R., \& Park, B. J. (2011). Co-opetition between giants: Collaboration with competitors for technological innovation. Research Policy, 40, 650-663.

Grebel, T., \& Pyka, A. (2003). Agent-based modelling - A methodology for the analysis of qualitative development processes. (Universitaet Augsburg Institute for Economics Discussion Paper Series, 251). Retrieved from http://www.wiwi.uni-augsburg.de/vwl/institut/paper/251.pdf

Grebel, T., \& Pyka, A. (2006). Agent-based modelling - A methodology for the analysis of qualitative development processes. In C. F. C. Billari, T. Fent, A. Prskawetz, \& J. Scheffran (Eds.), Agent-based computational modelling - Applications in demography, social, economic and environmental sciences (pp 17-37). Heidelberg: Physica-Verlag.

Green, J., \& Scotchmer, S. (1995). On the division of profit in sequential innovation. RAND Journal of Economics, 26, 20-33. 
Grossman, G. M., \& Helpman, E. (1991a). Quality ladders in the theory of growth. Review of Economic Studies, 58, 43-61.

Grossman, G. M., \& Helpman, E. (1991b). Quality ladders and product cycles. Quarterly Journal of Economics, 106, 557-586.

Hagedoorn, J. (1993). Understanding the rationale of strategic technology partnering: Interorganizational modes of cooperation and sectoral differences. Strategic Management Journal, 14(5), 371-385.

Hagedoorn, J. (1995). A note on international market leaders and networks of strategic technology partnering. Strategic Management Journal, 16(3), 241250.

Hagedoorn, J. (2002). Inter-firm R\&D partnership: An Overview of major trends and patterns since 1960. Research Policy, 31(4), 477-492.

Hagedoorn, J., Link, A. N., \& Vonortas, N. S. (2000). Research partnerships. Research Policy, 29(4-5), 567-586.

Hagenaars, J. A., \& McCutcheon, A. L. (Eds.) (2003). Applied Latent Class Analysis. Cambridge: Cambridge University Press.

Hair, J. F., Anderson, R. E., Tatham, R. L., \& Black W. C. (1998). Multivariate Data Analysis, Fifth ed. Englewood Cliffs, NJ.: Prentice Hall.

Hamel, G. (1991). Competition for competence and inter-partner learning within international strategic alliances. Strategic Management Journal, Summer Special Issue, 12, 83-103.

Heinen, T. (1996). Latent Class and Discrete Latent Trait Models: Similarities and Differences. Thousand Oaks, CA: Sage Publications.

Helfat, C. E. (1994a). Evolutionary trajectories in petroleum firm R\&D. Management Science, 40(12), 1720-1747.

Helfat, C. E. (1994b). Firm-specificity in corporate applied R\&D. Organization Science, 5(2), 173-184.

Heller, M. A., \& Eisenberg, R. S. (1998). Can patents deter innovation? The anticommons in biomedical research. Science, 280(5364), 698-701. 
Hollenstein, H. (1996). A composite indicator of a firm's innovativeness: An empirical analysis based on survey data for Swiss manufacturing. Research Policy, 25, 633-645.

Hollenstein, H. (2003). Innovation modes in the Swiss service sector: A cluster analysis based on firm-level data. Research Policy, 32, 845-863.

Hunt, R. M. (2004). Patentability, industry structure, and innovation. The Journal of Industrial Economics, 52(3), 401-425.

Jensen, M. B., Johnson, B., Lorenz, E., \& Lundvall, B. Å. (2007). Forms of knowledge and modes of innovation. Research Policy, 36, 680-693.

Jewkes, J., Sawers, D., \& Stillerman, R. (1969). The sources of invention. London: MacMillan.

Kash, D. E., \& Kingston, W. (2001). Patents in a world of complex technologies. Science and Public Policy, 28(1), 11-22.

Katz, M. L. (1986). An analysis of cooperative research \& development. Rand Journal of Economics, 17, 527-543.

Katz, M. L. (1995). Joint ventures as a means of assembling complementary inputs. Group Decision and Negotiation, 4(5), 383-400.

Kauffman, S. A. (1993). The Origins of Order. Oxford: Oxford University Press.

Kimura, M. (1983). The Neutral Theory of Molecular Evolution. Cambridge: Cambridge University Press.

Kitch, E. W. (1997). The nature and function of the patent system. Journal of Law and Economics, 20, 265-290.

Klemperer, P. (1990). How broad should the scope of patent protection be? RAND Journal of Economics, 21(1), 113-130.

Klepper, S., \& Thompson, P. (2006). Submarkets and the evolution of market structure, RAND Journal of Economics, 37, 861-886.

Kodama, F. (1992). Technology fusion and the new R\&D. Harvard Business Review, 70(4), 70-78. 
Kogut, B., \& Zander, U. (1992). Knowledge of the Firm, Combinative Capabilities, and the Replication of Technology. Organization Science, 3(3), 383-397.

Koo, B., \& Wright, B. D. (2003). Economics of patenting an input essential to further research. In O. Granstrand (Ed.), Economics, law and intellectual property-seeking strategies for research and teaching in a developing field. The Netherlands: Kluwer Academic Publishers.

Leiponen, A., \& Drejer, I. (2007). What exactly are technological regimes?: Intraindustry heterogeneity in the organization of innovation activities. Research Policy, 36, 1221-1238.

Lerner, J. (2002). 150 years of patent protection. American Economic Review, 92(2), 221-225.

Levin, R. C., Klevorick, A. K., Nelson, R. R., \& Winter, S. G. (1987). Appropriating the returns from industrial research and development. Brookings Papers on Economic Activity, 3, 783-820.

Link, A. N., \& Bauer, L. L. (1989). Cooperative Research in U.S. Manufacturing: Assessing Policy Initiatives and Corporate Strategies. Lexington, MA: Lexington Books.

Lundvall, B-Å. (1992). National systems of innovation: Towards a theory of innovation and interactive learning. London: Pinter Publishers.

Magidson J., \& Vermunt J. K. (2004). Latent Class Models. In D. Kaplan (Ed.), The Sage Handbook of Quantitative Methodology for the Social Sciences (pp. 175-198). Thousand Oaks: Sage Publications.

Malerba, F. (2004). Sectoral systems of innovation: Basic concepts. In F. Malerba (Ed.), Sectoral Systems of Innovation (pp. 9-41). Cambridge: Cambridge University Press.

Malerba, F., \& Orsenigo, L. (1996). Schumpeterian patterns of innovation are technology specific. Research Policy, 25, 451-478. 
Malerba, F., Nelson, R., Orsenigo, L., \& Winter, S. (1999). 'History-friendly' models of industry evolution: the computer industry. Industrial and Corporate Change, 8(1), 3-40.

Marengo, L. (1992). Coordination and organizational learning in the firm. Journal of Evolutionary Economics, 2, 313-326.

Marengo, L., \& Valente, M. (2010). Industry dynamics in complex product spaces: An evolutionary model. Structural Change and Economic Dynamics, $21,5-16$.

Marengo, L., Pasquali, P. C., Valente, M., \& Dosi, G. (2012). Appropriability, patents, and rates of innovation in complex products industries. Economics of Innovation and New Technology, 21, 753-773.

Massini, S., Lewin, A. Y., \& Greve, H. R. (2005). Innovators and imitators: Organizational reference groups and adoption of organizational routines. Research Policy, 34, 1550-1569.

Maynard-Smith, J. (1982). Evolution and the Theory of Games. Cambridge: Cambridge University Press.

Mazzoleni, R., \& Nelson, R. R. (1998). The benefits and costs of strong patent protection: A contribution to the current debate. Research Policy, 27, 273284.

Merges, R., \& Nelson, R. R. (1990). On the complex economics of patent scope. Columbia Law Review, 90, 839-916.

Merges, R., \& Nelson, R. R. (1994). On limiting or encouraging rivalry in technical progress: The effects of patent scope decisions. Journal of Economic Behavior and Organization, 25, 1-24.

Metcalfe, S. (1998). Evolutionary Economics and Creative Destruction. London: Routledge.

Minniti, A., Parello, C., \& Segerstrom, P. S. (2013). A Schumpeterian growth model with random quality improvements. Economic Theory, 52(2), 755791. 
Miotti, L., \& Sachwald, F. (2003). Co-operative R\&D: Why and with whom? An integrated framework of analysis. Research Policy, 32, 1481-1499.

Molina-Morales, X., Martinez-Fernandez, T., \& Torlo, V. (2011). The dark side of trust: the benefits, costs and optimal levels of trust for innovation performance. Long Range Planning, 44, 118-133.

Mora-Valentin, E., Montoro-Sanchez, A., \& Guerras-Martin, L. (2004). Determining factors in the success of $R \& D$ cooperative agreements between firms and research organizations. Research Policy, 33, 17-40.

Morone, P., \& Taylor, R. (2012). Proximity, knowledge integration and innovation: An agenda for agent-based studies. Journal of Evolutionary Economics, 22, 19-47.

Mowery, D. C. (2009). Plus ca change: Industrial R\&D in the third industrial revolution. Industrial and Corporate Change, 18(1), 1-50.

Mowery, D., Oxley, J., \& Silverman, B. (1998). Technological overlap and interfirm cooperation: Implications for the resource-based view of the firm. Research Policy, 27, 507-523.

Mueller, D. C. (2004). Models of man: Neoclassical, behavioral, and evolutionary. Politics, Philosophy, Economics, 3, 59-76.

Nelson, R. R. (1982). The role of knowledge in R\&D efficiency. Quarterly Journal of Economics, 97(3), 453-470.

Nelson, R. R. (1991). Why do firms differ, and how does it matter? Strategic Management Journal, 12, 61-74.

Nelson, R. R. (1993): National innovation systems: A comparative analysis. New York, NY: Oxford University Press.

Nelson, R. R., \& Winter, S. G. (1982): An Evolutionary Theory of Economic Change. Cambridge, MA. and London, England: The Belknap Press of Harvard University Press.

Nooteboom, B. (2004). Learning and governance in inter-firm relations. Revue d'Economie Politique, 114(1), 55-76. 
Nordhaus, W. (1969). Innovation, growth, and welfare. Cambridge, MA: MIT Press.

O'Donoghue, T. A. (1998). Patentability requirement for sequential innovations. RAND Journal of Economics, 29, 654-679.

O'Donoghue, T. A., Scotchmer, S., \& Thisse, J. F. (1998). Patent breadth, patent life, and the pace of technological progress. Journal of Economics \& Management Strategy, 7(1), 1-32.

OECD (1992). Oslo Manual: OECD Proposed Guidelines for Collecting and Interpreting Innovation Data, 1st edition. Paris: OECD.

OECD/Eurostat (1997). Proposed Guidelines for Collecting and Interpreting Technological Innovation Data, $2^{\text {nd }}$ edition. Paris: OECD.

OECD (2006). Community innovation statistics. From today's Community Innovation Surveys to better surveys tomorrow. Retrieved from http://www.oecd.org/science/inno/37489901.pdf

Ordover, J. A., \& Willig, R. D. (1985). Antitrust for high-technology industries: Assessing research joint ventures and mergers. Journal of Law and Economics, 28, 311-333.

Ortega-Argilés, R., \& Brandsma, A. (2010). EU-US differences in the size of R\&D intensive firms: Do they explain the overall R\&D intensity gap. Science and Public Policy, 37(6), 429-441.

Pavitt, K. (1984). Sectoral patterns of technical change: Towards a taxonomy and a theory. Research Policy, 13(6), 343-373.

Peneder, M. (2002). Intangible investment and human resources. Journal of Evolutionary Economics, 12, 107-134.

Peneder, M. (2010). Technological regimes and the variety of innovation behaviour: Creating integrated taxonomies of firms and sectors. Research Policy, 39, 323-334.

Randor, M. (1991). Technological acquisition strategies and processes: A reconsideration of the make versus buy decision. International Journal of Technology Management, 6, 113-135. 
Romer, P. M. (1990). Endogenous technological change. Journal of Political Economy, 98(5), 71-102.

Rumelt, R. (1987). Theory, strategy, and entrepreneurship. In D. J. Teece (Ed.), The competitive challenge: Strategies for industrial innovation and renewal (pp. 137-158). Cambridge, MA: Blackwell.

Sakakibara, M. (1997). Heterogeneity of firm capabilities and cooperative research and development: An empirical examination of motives. Strategic Management Journal, 18 (Summer Special Issue), 143-164.

Sarkar M. B., Echambadi, R. A. J., \& Harrison, J. S. (2001). Alliance entrepreneurship and firm market performance. Strategic Management Journal, 22, 701-711.

Saviotti, P. P., \& Mani G. S. (1998). Technological evolution, self-organization and knowledge. The Journal of High Technology Management Research, 9(2), 255-270.

Shapiro, C. (2000). Navigating the patent thicket: Cross licenses, patent pools and standard setting. In A. Jaffe, J. Lerner, \& S. Stern (Eds.), Innovation policy and the economy, Vol. 1. Cambridge, MA: NBER and MIT Press.

Silva, S. T., \& Teixeira, A. A. C. (2008). On the divergence of evolutionary research paths in the past 50 years: A comprehensive bibliometric account. Journal of Evolutionary Economics, 19, 605-642.

Simon, H. (1955). A behavioral model of rational choice. Quarterly Journal of Economics, 69, 99-188.

Sinha, D. K., \& Cusumano, M. A. (1991). Complementary resources and cooperative research: A model of research joint ventures among competitors. Management Science, 37(9), 1091-1106.

Srholec, M., \& Verspagen, B. (2012). The voyage of the beagle into innovation: Explorations on heterogeneity, selection, and sectors. Industrial and Corporate Change, 21(5), 1221-1253. 
Stančík, J., \& Biagi, F. (2012). Characterizing the evolution of the EU-US RED intensity gap using data from top RED performers. Retrieved from http://xivrem.ujaen.es/wp-content/uploads/2011/11/89-R-127M709.pdf

Stein, J. C. (1997). Waves of creative destruction: Firm-specific learning-bydoing and the dynamics of innovation. Review of Economic Studies, 64, 265288.

Tandon, P. (1982). Optimal patents with compulsory licensing. Journal of Political Economy, 90, 470-486.

Teece, D. (1986). Profiting from technological innovation: Implications for integration, collaboration, licensing and public policy. Research Policy, 15, 285-305.

Teece, D. J. (1992). Competition, cooperation and innovation: Organizational arrangements for regimes of rapid technological progress. Journal of Economic Behavior \& Organization, 18, 1-25.

Teece, D., Pisano, G., \& Shuen, A. (1997) Dynamic capabilities and strategic management. Strategic Management Journal, 18(7), 509-533.

Teitelbaum, D., \& Dowlatabadi, H. (2000). A computational model of technological innovation at the firm level. Computational $\mathcal{E}$ Mathematical Organization Theory, 6(39), 227-247.

Tether, B. S., \& Tajar, A. (2008). The organisational-cooperation mode of innovation and its prominence amongst European service firms. Research Policy, 37, 720-739.

Trigo (2013). The nature of innovation in $R \& D$ and non-R\&D-intensive service firms: Evidence from firm-level latent class analysis. Industry and Innovation, 20(1), 48-68.

Tyler, B. B., \& Steensma, H. K. (1995). Evaluating technological collaborative opportunities: A cognitive modeling perspective. Strategic Management Journal, 16, 44-70. 
Valente, M. (2008). Laboratory for Simulation Development - LSD. (Discussion Paper 2008/12, LEM). Pisa: LEM. Retrieved from http://www.lem.sssup.it/WPLem/files/2008-12.pdf

Vallée, T., \& Yildizoglu, M. (2006). Social and technological efficiency of patent systems. Journal of Evolutionary Economics, 16, 189-206.

Vermunt J. K., \& Magidson, J. (2002). Latent class cluster analysis. In J. A. Hagenaars, \& A. L. McCutcheon (Eds.), Applied latent class analysis (pp. 89106). Cambridge, UK: Cambridge University Press.

Vermunt, J. K., \& Magidson, J. (2005). Latent GOLD 4.0 User's Guide. Belmont, Massachusetts: Statistical Innovations Inc. Retrieved from http://statisticalinnovations.com/technicalsupport/LGusersguide.pdf

Vonortas, N. S. (2000). Multimarket contact and inter-firm cooperation in R\&D. Journal of Evolutionary Economics, 10(1-2), 243-271.

Wernerfelt, B. (1984). The resource-based view of the firm. Strategic Management Journal, 5(2), 171-180.

White, L. J. (1985). Clearing the legal path to cooperative research. Technology Review, 88(5), 39-44.

Windrum, P. (2004). Neo-Schumpeterian simulation models. (MERITInfonomics Research Memorandum Series no: 2004-0020). Retrieved from file://C:/Users/63096sce/Downloads/Neo-

Schumpeterian_Simulation_Models.pdf

Windrum, P. (2007). Neo-Schumpeterian simulation models. In H. Hanusch \& A. Pyka (Eds.), Elgar companion to Schumpeterian economics (pp. 405-439). Cheltenham, UK and Northampton, MA: Edward Elgar.

Winter, S. (1993). Patents and welfare in an evolutionary model. Industrial and Corporate Change, 2, 211-231.

Wu, J. (2012). Technological collaboration in product innovation: The role of market competition and sectoral technological intensity. Research Policy, 41, 489-496. 
Wu, J., \& Pangarkar, N. (2010). The bidirectional relationship between competitive intensity and collaboration: Evidence from China. Asia Pacific Journal of Management, 27(3), 503-522.

Wuyts, S., Colombo, M., Dutta, S., \& Nooteboom, B. (2005). Empirical tests of optimal cognitive distance. Journal of Economic Behavior and Organization, $58,277-302$.

Yildizoglu, M. (2001). Connecting adaptive behavior and expectations in models of innovation: The potential role of artificial neural networks. European Journal of Economic and Social Systems, 15(3), 203-220.

Yildizoglu, M. (2002). Competing R\&D strategies in an evolutionary industry model. Computational Economics, 19, 51-65.

Zhong, X., \& Ozdemir, S. Z. (2010). Structure, learning, and the speed of innovating: a two-phase model of collective innovation using agent based modeling. Industrial and Corporate Change, 19(5), 1459-1492. 



\section{Valorization}

This thesis study consists of essays on innovation strategies in the tradition of evolutionary economics. The chapters address the research topics: taxonomy of innovation strategies, sustainability of heterogeneity in innovation strategies, the effects of patent policy on market outcomes and research joint ventures. For the empirical part of the dissertation, latent class analysis is used to categorize firms into clusters with distinct innovation strategies using Community Innovation Survey 4 data. For the theoretical part, an evolutionary multi-agent based sector-level innovation model platform is created addressing supply and demand side of the market simultaneously with the coevolution of heterogeneous consumer preferences, heterogeneous firm knowledge bases and technology levels at the micro level.

Chapter 2 is a taxonomic exercise over innovation modes. It relies on firmlevel survey data on innovation indicators from 16 countries participated CIS 4. An original contribution of this study is to show how a cluster of firms following a specific innovation strategy is linked to other groups within models of different number of clusters using latent class analysis. Then a 4cluster model (science-based, market-based, external-based and low-profile innovators) is selected for an in-depth analysis of innovation strategies. It is concluded that policy makers should be well-informed about the extent of heterogeneity in innovation modes within and between sectors to conduct efficient innovation policies.

The aims of the third chapter are twofold. The first is to analyze the interaction between research and development (R\&D) activities of firms and heterogeneous consumer preferences in structuring the evolution of an 
industry. The second is to explore the heterogeneity in firms' innovation strategies: is heterogeneity sustainable in the long term and what happens to the market shares of firms having different innovation strategies when a structural market characteristic (market size) or a behavioural rule (R\&D intensity) is changed. To answer these research questions, an evolutionary, multi-agent based, sector-level innovation model is designed. The model addresses supply and demand side of the market simultaneously with the coevolution of heterogeneous consumer preferences, heterogeneous firm knowledge bases and technology levels at the micro level. The simulation analysis concludes that coexistence of a variety firms with distinct innovation strategies is viable even in the long run and market sharing between these firm groups is determined by market size and $R \& D$ intensity. The pace of technological progress is affected by this very market sharing between different strategies throughout the simulation run.

Chapter 4 explores the effect of patent policy on market outcomes and opens with introducing the evolution of the main variables of interest to explore model dynamics and continues with the results of a series of simulation experiments designed to analyze how these variables of interest are conditioned by patent length and breadth. The effect of patent length manifests itself in a continuous manner whereas patent breadth should be broad enough to cover a whole new class of technologies to have its effect felt by the market participants. So, there is discontinuity in the way market outcomes are conditioned by patent breadth. The simulation analysis concludes that the optimum patent policy is granting broad patents for a limited time period.

Chapter 5 presents an alternative approach to R\&D collaborations with an evolutionary, multi-agent based and sector-level R\&D model. The model is firstly used to simulate the evolution of an R\&D driven market composed of profit-driven firms and boundedly rational consumers. Next, frequently discussed research questions in the relevant empirical literature are explored. This modeling exercise extends beyond a basic confirmation/rejection of these research questions by showing that the way a firm is defined as an R\&D collaborator has significant effects on research results. A clear inference based on these outcomes is that the research results of the empirical studies on 
research joint ventures should be interpreted with some caution in regard to the chosen method of defining collaborator firms.

$\mathrm{ABM}$ requires a very explicit modelling of every module within the system (innovation mechanism, pricing heuristic, firm interaction, consumer purchase, etc.). In general, this specificity of the simulation exercise permitted an increased understanding of an industry-level innovation system through controlled computational experiments. The model demonstrated how firm level heterogeneity in innovation strategies evolved and persisted as a dynamic equilibrium with continuous technological change and firm entry and exit. It also functioned as a laboratory increasing our normative understanding for the discovery of good designs: the optimum patent length and breadth for the sake of fastest technological change and highest wealth creation. Last but not least, the distinctive capability of this modeling technique in tracking the status and behaviour of each and every individual agent in real time (e.g. being in an R\&D collaboration or not at a specific point in time) enabled us to observe how micro-level interactions lead to macro outcomes.

We hope to have developed a reasonably realistic simulation model of innovation at sectoral level in a structured way giving due consideration to its multi-dimensionality. This simulation platform helped us to ask and answer several "what if" questions that would not be possible in an empirical study mostly due to data constraints. 



\section{Biography}

Salih Çevikarslan was born in Izmit, Turkey in 1980. He completed his secondary education in Kocaeli College in 1998. He received his BSc degree in Mechanical Engineering at the Middle East Technical University in 2003 and his MA degree in Economics at Istanbul Technical University (ITU) in 2006. After working for three years as a research assistant at ITU, he joined UNU-MERIT PhD programme and was appointed as a teaching assistant (AiO) at the Department of Economics, Maastricht University. He worked as a post-doc researcher at the Department of Design, Production and Management, University of Twente and he is a lecturer in Economics at Erasmus University College. 



\section{UNU-MERIT/MGSoG Dissertation Series}

2019

Wondimagegn Mesfin Tesfaye

Essays on the Impacts of Climate-

Smart Agricultural Innovations on

Household Welfare

UNU-MERIT/MGSoG Dissertation

Series № 219

\section{Tatevik Poghosyan}

How Board Networks Affect Firm

Performance and Innovation Incentives

in Transition Economies: The Case of

Armenia

UNU-MERIT/MGSoG Dissertation

Series № 218

\section{Arip Muttaqien}

Essays on Inequality and Polirization:

Empirical Studies in Developing Asia

UNU-MERIT/MGSoG Dissertation

Series № 217

2018

\section{Katrin Marchand}

Essays on Forced Migration and

Labour Market Participation in

Developing Countries

UNU-MERIT/MGSoG Dissertation

Series № 216

\section{Ortrun Merkle}

The Myth of Gender Neutral Power:

Corruption and Gender Norms

UNU-MERIT/MGSoG Dissertation

Series № 215

\section{Biljana Meshkovska}

Life after Trafficking:

(re)integration processes of women that have been trafficked for the purpose of sexual exploitation in Europe

UNU-MERIT/MGSoG Dissertation

Series № 214

\section{Vincenzo Vinci}

The Relevance of Institutions and

People's Preferences for Social

Protection

UNU-MERIT/MGSoG Dissertation

Series № 213

\section{Silke Heuser}

The Effectiveness of Environmental

Policies on Reducing Deforestation in

the Brazilian Amazon

UNU-MERIT/MGSoG Dissertation

Series № 212

\section{Jennifer Waidler}

Social Assistance and Remittances and Their Role in the Fight Against

Poverty

UNU-MERIT/MGSoG Dissertation

Series № 211 


\section{Choolwe Muzyamba}

The role of community mobilization in the promotion of maternal health of women living with HIV in Zambia UNU-MERIT/MGSoG Dissertation Series № 210

Juan Carlos A. Castillo Sánchez

Assessing the Role of the Export Sector in Mexican Economic

Development,1965-2014

UNU-MERIT/MGSoG Dissertation

Series № 209

\section{Tareq Abuelhaj}

Food Security Policy Impact Analysis:

The Econometrics of Cash and Food

Assistance Cost Effectiveness

UNU-MERIT/MGSoG Dissertation

Series № 208

Marta Férnandez de Arroyabe Arranz

Essays on MEAS and Innovation

UNU-MERIT/MGSoG Dissertation Series № 207

\section{Clotilde Mahé}

Essays on Migration and Occupational Choice

UNU-MERIT/MGSoG Dissertation Series № 206

\section{Simone Sasso}

Talent on the move. Essays on Human Capital, Graduate Mobility and Economic Development UNU-MERIT/MGSoG Dissertation Series № 205
Khaled Walid Rajab

Strategic Planning under Fragility UNU-MERIT/MGSoG Dissertation Series № 204

\section{Mutinta Hambayi Nseluke}

A Tall Order: Improving Child Linear Growth

UNU-MERIT/MGSoG Dissertation Series № 203

\section{Elvis Korku Avenyo}

Innovations and Firm Performance in sub-Saharan Africa: Empirical Analyses

UNU-MERIT/MGSoG Dissertation Series № 202

\section{Ni Zhen}

Employment Dynamics, Firm

Performance and Innovation

Persistence in the Context of Differentiated Innovation Types:

Evidence from Luxembourg UNU-MERIT/MGSoG Dissertation Series № 201

\section{Caroline Wehner}

Too Scared to Achieve: The Relation

Between Neuroticism, Conscientiousness and Socioeconomic Outcomes UNU-MERIT/MGSoG Dissertation Series № 200

\section{Stefania Innocenti}

On Institutional Persistence UNU-MERIT/MGSoG Dissertation Series № 199 


\section{Hassen Abda Wako}

Economic Globalization, Institutions

and Development: Essays on Aid,

Foreign Direct Investment and Trade

UNU-MERIT/MGSoG Dissertation

Series № 198

2017

\section{Hans-Erik Edsand}

Winds of Change

UNU-MERIT/MGSoG Dissertation

Series № 197

\section{Ana Patricia Silva Vara}

Redressing the Gender Gap

UNU-MERIT/MGSoG Dissertation

Series № 196

\section{Andrés Iván Mideros Mora}

Essays on the Economic Effects of Noncontributory Social Protection

UNU-MERIT/MGSoG Dissertation

Series № 195

Tobias Broich

New Actors in the Global Economy

UNU-MERIT/MGSoG Dissertation

Series № 194

\section{Bernard Nikaj}

From No-government to E-government UNU-MERIT/MGSoG Dissertation

Series № 193

\section{Ali Safarnejad}

Prioritizing the HIV Response

UNU-MERIT/MGSoG Dissertation

Series № 192

\section{Clovis Freire}

Diversification and Structural

Economic Dynamics

UNU-MERIT/MGSoG Dissertation

Series № 191

\section{Michael Verba}

Innovation and Knowledge Dynamics:

Essays on the Knowledge Economy

UNU-MERIT/MGSoG Dissertation

Series № 190

\section{Pui Hang Wong}

The Hearts and Minds in Conflict and Peace: The Economics of

Counterinsurgency and the Psychology of Reconstruction

UNU-MERIT/MGSoG Dissertation

Series № 189

\section{Brenda Yamba}

Schooling Despite All Odds: Evidence from Lesotho on Female Child Carers who Stayed in School UNU-MERIT/MGSoG Dissertation Series № 188

\section{Sheng Zhong}

Moving towards An Energy Efficient Future: Essays on Energy Efficiency, Technology and Development UNU-MERIT/MGSoG Dissertation Series № 187 


\section{Julieta Marotta}

Access to Justice and Legal

Empowerment of Victims of Domestic

Violence through Legal Organizations

in the City of Buenos Aires: A

Qualitative Empirical Legal Study

UNU-MERIT/MGSoG Dissertation

Series, № 186

\section{Andrea Franco-Correa}

On the Measurement of

Multidimensional Poverty as a Policy

Tool: Empirical Applications to Chile,

Colombia, Ecuador and Peru

UNU-MERIT/MGSoG Dissertation

Series, № 185

2016

\section{Yesuf Awel}

Insurance for Growth: Empirical

Essays on Insurance Demand and

Impacts in Africa

UNU-MERIT Dissertation Series,

№ 108

\section{Tigist Mekonnen Melesse}

Grow More Food using Fewer

Resources: Agricultural Technology

Adoption and Innovation Practices for

Inclusive and Sustainable

Development

UNU-MERIT Dissertation Series, № 107

\section{Eleni Yitbarek}

Getting Ahead or left Behind? Essays

on Poverty Dynamics and Social

Mobility in Africa

UNU-MERIT Dissertation Series,

№ 106

\section{Thuy Dieu Nguyen}

Firm-Level Theory and Evidence of

Corruption

UNU-MERIT Dissertation Series, № 105

\section{Raquel Tsukada Lehman}

Essays on Household Production with

Labor-Saving Technology

UNU-MERIT Dissertation Series,

№ 104

\section{Eva Barteková}

Multi-Problem Challenges for a

Renewable Future: Empirical Studies

on Competitive Disadvantages from

Electricity Price Differentials and

Mineral Supply Risk in an Open

Economy

UNU-MERIT Dissertation Series, № 103

\section{Jocelyn Olivari}

Entrepreneurial Traits and Innovation:

Evidence from Chile

UNU-MERIT Dissertation Series,

№ 102

\section{Muhammad Shafique}

Essays on the role of knowledge, RED, and Technology-based Firms in the Evolution of Socio-techno-economic System

UNU-MERIT Dissertation Series, № 101 


\section{Serdar Türkeli}

Governance of Innovation Policy:

Empirical Studies on Applied Political

Economy by Multi-Methods Analysis

UNU-MERIT Dissertation Series,

№ 100

\section{Ayokunu Adedokun}

Pathways to Sustainable Peace

building in Divided Societies: Lessons

and Experiences from Mozambique

MGSoG Dissertation Series, № 75

\section{Luiz Rothier Bautzer}

Organizing Concurrent Engineering

through ICT Platforms

Blueprinting Product Lifecycle

Management Platforms across

Disciplinary Agencies

MGSoG Dissertation Series, № 74

\section{Natalia Popova}

Migration in the Periphery of the

European Union:

Determinants of Successful and

Sustainable Labour Market Integration of Return Migrants in Albania, Egypt, Moldova and Tunisia

MGSoG Dissertations Series, № 73

\section{Richard A. Martina}

Uncertainty and Resource Constraint in the Small Island Developing States: Essays in Entrepreneurial Cognition MGSoG Dissertations Series, № 72

\section{Cécile Cherrier}

The Expansion of Basic Social

Protection in Low-income Countries:

An Analysis of Foreign Aid Actors'

Role in the Emergence of Social

Transfers in Sub-Saharan Africa

MGSoG Dissertations series, № 71

\section{Paul Caldron}

The Tacit Bargain in Short-Term

Medical Missions: Why U.S.

physicians go and what it costs

MGSoG Dissertation Series, № 70

\section{Mahmut Kobal}

Customs \& Excellence: A Comparative Approach on Administrative and Regulatory Compliance Perspectives of the EU-Turkey Customs Union

MGSoG Dissertation Series, № 69

\section{Craig Loschmann}

Essays on Conflict-related Migration and Development in the Case of

Afghanistan

MGSoG Dissertations Series, № 68

\section{Andrea Milan}

Rural Livelihoods, Location and

Vulnerable Environments: Approaches to Migration in Mountain areas of

Latin America

MGSoG Dissertation Series, № 67

\section{Farida Lada}

On Guarding the Welfare of Clinical

Trial Subjects While Promoting Novel

Drug Innovation

A Game Theoretical Approach

MGSoG Dissertation Series, № 66 


\section{Hibret Belete Maemir}

Dissecting Aggregate Productivity:

International Integration and Growth

with Heterogeneous Firms

UNU-MERIT Dissertation Series, № 96

\section{Giorgio Triulzi}

Looking for the Right Path: Technology

Dynamics, Inventive Strategies and

Catching-up in the Semiconductor

Industry

UNU-MERIT Dissertation Series, № 95

\section{Abdul Baseer Qazi}

Knowledge flows and networks in the ICT sector: The case of Pakistan UNU-MERIT Dissertation Series, № 94

\section{Ajay Thutupalli}

Technology Paradigm Shifts in Agriculture: Drivers of Sustainability and Catch up

UNU-MERIT Dissertation Series, № 93

\section{Eduardo Urias}

Improving access to HIVIAIDS

treatment in Brazil: When are

Compulsory Licenses effective in Price Negotiations?

UNU-MERIT Dissertation Series, № 92
Why have so few Countries

Industrialised?

UNU-MERIT Dissertation Series, № 91

\section{Daniel Opolot}

The Evolution of Beliefs and Strategic

Behaviour

UNU-MERIT Dissertation Series, № 90

\section{Alejandro Lavopa \\ Structural Transformation and \\ Economic Development: Can \\ Development Traps be Avoided \\ UNU-MERIT Dissertation Series, № 89}

\section{Jinjin Zhao}

Urban water management reform: The Case of China

UNU-MERIT Dissertation Series, № 88

\section{Simona Vezzoli}

Borders, Independence and Postcolonial Ties: the Role of the State in Caribbean Migration

MGSoG Dissertation Series, № 65

\section{Silvia Consuelo Gómez Soler}

Civil Conflict and Education: How

Does Exposure to Civil Conflict Affect

Human Capital Accumulation?

Evidence from Standardized Exit

Exams in Colombia

MGSoG Dissertation Series, № 64 


\section{Paula Nagler}

Occupational Choice in the Developing

World

MGSoG Dissertation Series, № 63

\section{Jasmin Kientzel}

Determinants of Professional

Commitment to Environmental

Sustainability

MGSoG Dissertation Series, № 62

\section{Mehmet Güney Celbiş}

Regional Policies: Convergence, Trade, and the Allocation of Public Capital

MGSoG Dissertation Series, № 61

\section{Florian Henning}

Living Up to Standard:

Interoperability Governance and

Standards Adoption in Government

Information Networks

MGSoG Dissertation Series, № 60

\section{Niels P. Groen}

The Never-Ending Project

Understanding E-Government Project

Escalation

MGSoG Dissertation Series, № 59

\section{Derek Copp}

Teacher-Based Reactivity to Provincial Large-scale Assessment in Canada MGSoG Dissertation Series, № 58

\section{Michaella Vanore}

Family-Member Migration and the Psychosocial Health Outcomes of Children in Moldova and Georgia MGSoG Dissertation Series, № 57

\section{Sonja Fransen}

The Economic and Social Effects of Remittances and Return Migration in Conflict-Affected Areas: The Case of Burundi

MGSoG Dissertation Series, № 56

\section{Ibrahim Khalil Conteh}

The Impact of Floods on Primary

School Education in Zambia

MGSoG Dissertation Series, № 55

\section{Richard Bluhm}

Growth Dynamics and Development Essays in Applied Econometrics and Political Economy

MGSoG Dissertation Series, № 54

\section{Nevena P. Zhelyazkova}

Work-Family Reconciliation and Use of Parental Leave in Luxembourg:

Empirical Analysis of Administrative Records

MGSoG Dissertation Series, № 53

\section{4}

\section{Dirk Crass}

The Impact of Brands on Innovation and Firm Performance: Empirical Evidence from Germany

UNU-MERIT Dissertation Series, № 87

\section{Samyukta Bhupatiraju}

The Geographic Dimensions of Growth and Development

UNU-MERIT Dissertation Series, № 86 


\section{François Lafond}

TheEvolution of Knowledge Systems

UNU-MERIT Dissertation Series, № 85

\section{Annalisa Primi}

Promoting Innovation in Latin

America: What Countries Have

Learned (and What They Have Not) in

Designing and Implementing

Innovation and Intellectual Property

Policies

UNU-MERIT Dissertation Series,

№ 84

\section{Fatoumata Lamarana Diallo}

Evaluation of Meal and Deworming

Programs for Primary Schools in Rural

Senegal

UNU-MERIT Dissertation Series, № 83

\section{Sachin Kumar Badkas}

Metachoice and Metadata: Innovating with Environmental Policy Analysis in Europe

MGSoG Dissertation Series, № 52

\section{Irina S. Burlacu}

An Evaluation of Tax-Benefit Systems

Impact on the Welfare of Frontier

Worker:

The Case of Luxembourg and Belgium

MGSoG Dissertation Series, № 51

\section{Özge Bilgili}

Simultaneity in Transnational

Migration Research: Links Between

Migrants' Host and Home Country

Orientation

MGSoG Dissertation Series, № 50

\section{Yulia Privalova Krieger}

Reshaping the Big Agenda:

Transnational Politics and Domestic ResistanceFinancial crisis and social protection reform in Bosnia and Herzegovina

MGSoG Dissertation Series, № 49

\section{Marieke van Houte}

Moving Back or Moving Forward?

Return migration after Conflict

MGSoG Dissertation Series, № 48

\section{Oxana Slobozhan}

Global Governance in the Management of Natural Resources: The Case of the Extractive Industries Transparency Initiative (EITI)

MGSoG Dissertation Series, № 47

\section{Luis Bernardo Mejia Guinand}

The Changing Role of the Central

Planning Offices in Latin America: A

Comparative Historical Analysis

Perspective (1950-2013)

MGSoG Dissertation Series, № 46

\section{Cheng Boon Ong}

Ethnic Segregation in Housing,

Schools and Neighbourhoods in the

Netherlands

MGSoG Dissertation Series, № 45

\section{Luciana V. Cingolani}

Bureaucracies for Development:

Oxymoron or Reality? Studies on State

Capacity in Challenging Governance

Contexts

MGSoG Dissertation Series, № 44 


\section{Carlos Cadena Gaitán}

Green Politics in Latin American

Cities - Sustainable Transport Agendas

MGSoG Dissertation Series, № 43

\section{Katie Kuschminder}

Female Return Migration and

Reintegration Strategies in Ethiopia

MGSoG Dissertation Series, № 42

\section{Metka Hercog}

Highly-Skilled Migration and New

Destination Countries

MGSoG Dissertation Series, № 41

\section{Margaret Agaba Rugadya}

Can Remittances Influence the Tenure and Quality of Housing in Uganda?

MGSoG Dissertation Series, № 40

\section{Ilire Agimi}

New Governance Under Limited

Statehood: The Case of Local

Government Reform in Kosovo

MGSoG Dissertation Series, № 39

2013

\section{Anant Kamath}

Information Sharing through Informal

Interaction in Low-Tech Clusters

UNU-MERIT Dissertation Series, № 82

\section{Flavia Pereira de Carvalho}

What we talk about when we talk about Brazilian Multinationals: An Investigation on Brazilian FDI, Economic Structure, Innovation and the Relationship between them UNU-MERIT Dissertation Series, № 81

\section{Jun Hou}

Complementarity in Innovation and Development: A Cross-country

Comparison

UNU-MERIT Dissertation Series, № 80

\section{Rufin Baghana}

Impacts of Government Incentives to $R \mathcal{E} D$, Innovation and Productivity: A Microeconometric Analysis of the Québec Case UNU-MERIT Dissertation Series, № 79

\section{Lilia I. Stubrin}

High-Tech Activities in Emerging Countries: A Network perspective on the Argentinean Biotech Activity UNU-MERIT/MGSoG Dissertation Series, № 78

\section{Kristine Farla}

Empirical Studies on Institutions, Policies and Economic Development MGSoG Dissertation Series, № 38 
Marina Petrovic

Social Assistance and Activation in the Pursuit of Happiness: Shedding New

Light on Old Policy Solutions to Social Exclusion

MGSoG Dissertation Series, № 37

\section{Laura Torvinen}

Assessing Governance Assessments:

The Case of Mozambique: Governance

Assessments in the Context of Aid

Effectiveness Discourse

MGSoG Dissertation Series, № 36

\section{Biniam Egu Bedasso}

Institutional Change in the Long

Shadow of Elite: Essays on

Institutions, Human Capital and

Ethnicity in Developing Countries

MGSoG Dissertation Series, № 35

\section{Sepideh Yousefzadeh Faal}

Deghati

Childhoods Embargoed: Constructing

and Reconstructing Multidimensional

Child Poverty in Iran 1984-2009

MGSoG Dissertation Series, № 34

\section{Robert Bauchmüller}

Investing in Early Childhood Care and Education: The Impact of Quality on Inequality

MGSoG Dissertation Series, № 33

\section{Martin Rehm}

Unified Yet Separated: Empirical

Study on the Impact of Hierarchical

Positions within Communities of

Learning

MGSoG Dissertation Series, № 32
2012

\author{
Abdul Waheed \\ Innovation Determinants and \\ Innovation as a Determinant: Evidence \\ from Developing Countries \\ UNU-MERIT Dissertation Series, \\ № 77
}

\section{Bilal Mirza}

Energy Poverty and Rural Energy

Markets in Pakistan

UNU-MERIT Dissertation Series, № 76

\section{Benjamin Engelstätter}

Enterprise Software and Video Games:

An Empirical Analysis

UNU-MERIT Dissertation Series, № 75

\section{Fulvia Farinelli}

Natural Resources, Innovation and

Export Growth: The Wine Industry in

Chili and Argentina

UNU-MERIT Dissertation Series

\section{Rodolfo Lauterbach}

Innovation in Manufacturing: From

Product Variety and Labor

Productivity Growth to Economic

Development in Chile

UNU-MERIT Dissertation Series

\section{Kirsten Wiebe}

Quantitative Assessment of

Sustainable Development and Growth in Sub-Saharan Africa

UNU-MERIT Dissertation Series, № 74 


\section{Julio Miguel Rosa}

Organizational Strategies, Firms'

Performance and Spatial Spillovers:

The Canadian Case in Research and

Development.

UNU-MERIT Dissertation Series, № 73

Johannes Wilhelmus Marie Boels

Joseph Schumpeter, Honderd Jaar

Economische Ontwikkeling: Een

Historisch-theoretische Beschouwing.

UNU-MERIT Dissertation Series

\section{Dorcas Mbuvi}

Utility Reforms and Performance of the

Urban Water Sector in Africa

MGSoG Dissertation Series, № 31

\section{Lina Salanauskaite}

Distributional Impacts of Public

Policies: Essays in Ex-Ante and Ex-

Post Evaluation

MGSoG Dissertation Series, № 30

\section{Esther Schüring}

To Condition or not - is that the

Question?

An Analysis of the Effectiveness of ExAnte and Ex-Post Conditionality in

Social Cash Transfer Programs

MGSoG Dissertation Series, № 29

\section{Joe Abah}

Strong Organisations in Weak States:

Atypical Public Sector Performance in

Dysfunctional Environments

MGSoG Dissertation Series, № 28

\section{Zina Samih Nimeh}

Social Citizenship Rights: Inequality

and Exclusion

MGSoG Dissertation Series, № 27

2011

\section{Daniel Vertesy}

Interrupted Innovation: Emerging

Economies in the Structure of the

Global Aerospace Industry

UNU-MERIT Dissertation Series, № 72

\section{Tina Saebi}

Successfully Managing Alliance

Portfolios: AnAlliance Capability View UNU-MERIT Dissertation Series, № 71

\section{Nora Engel}

Tuberculosis in India: A Case of Innovation and Control

UNU-MERIT/MGSoG Dissertation

Series, № 70

\section{Evans Mupela}

Connectivity and growth in Sub-

Saharan Africa: The Role of

Communication Satellites

UNU-MERIT Dissertation Series,

№ 69

\section{Nantawan Kwanjai}

Cross Cultural Intelligence amid

Intricate Cultural Webs: A Tale of the

UnDutchables in the Land of 1002

Smiles

UNU-MERIT Dissertation Series, № 68 


\section{Lina Sonne}

Innovation in Finance to Finance

Innovation: Supporting Pro-poor

Entrepreneur-based Innovation

UNU-MERIT Dissertation Series, № 67

\section{Lenka Eisenhamerová}

Legitimacy of 'Humanitarian Military

Intervention'

MGSoG Dissertation Series, № 26

\section{Sonila Tomini}

Informal Payments for Health Care

Services in Albania

MGSoG Dissertation Series, № 25

\section{Jinjing Li}

Dynamic Microsimulation in Public

Policy Evaluation

MGSoG Dissertation Series, № 24

\section{Aziz Atamanov}

Rural Nonfarm Employment and

International Migration as

Alternatives to Agricultural

Employment: The Case of Kyrgyzstan

MGSoG Dissertation Series, № 23

\section{Frieda Vandeninden}

Poverty Alleviation: Aid and Social

Pensions

MGSoG Dissertation Series, № 22

\section{Juliana Nyasha Tirivayi}

The Welfare Effects of Integrating

AIDS Treatment with Food Transfers:

Evidence from Zambia

MGSoG Dissertation Series, № 21

\section{Agnieska Ewa Sowa}

Who's Left Behind? Social Dimensions

of Health Transition and Utilization of

Medical Care in Poland

MGSoG Dissertation Series, № 20

\section{Emmanaouil Sfakianakis}

The Role of Private Actors in the

Provision of Public Goods with

Applications to Infrastructure and

Financial Stability

MGSoG Dissertation Series, № 19

\section{Siu Hing Lo}

White Collars Green Sleeves: An Interorganizational Comparison of

Determinants of Energy-Related

Behaviors among Office Workers

MGSoG Dissertation Series, № 18

\section{Treena Wu}

Constraints to Human Capital

Investment in Developing Countries:

Using the Asian Financial Crisis in

Indonesia as a Natural Experiment

MGSoG Dissertation Series, № 17

\section{Henry Espinoza Peña}

Impact Evaluation of a Job-Training

Programme for Disadvantaged Youths:

The Case of Projoven

MGSoG Dissertation Series, № 16 
Fernando Santiago

Human Resources Management

Practices and Learning for Innovation

in Developing Countries:

Pharmaceutical Firms in Mexico

UNU-MERIT Dissertation Series, № 66

\section{Zakaria Babutsidze}

Essays on Economies with

Heterogeneous Interacting Consumers

UNU-MERIT Dissertation Series, № 65

\section{Bertha Vallejo}

Learning and Innovation Under

Changing Market Conditions: The

Auto Parts Industry in Mexico

UNU-MERIT Dissertation Series, № 64

\section{Donatus Ayitey}

Technical Change, Competitiveness

and Poverty Reduction: A Study of the

Ghanaian Apparel Industry

UNU-MERIT Dissertation Series, № 63

\section{Sergey Filippov}

Multinational Subsidiary Evolution:

Corporate Change in New EU Member States

UNU-MERIT Dissertation Series, № 62

\section{Asel Doranova}

Technology Transfer and Learning under the Kyoto Regime: Exploring the Technological Impact of CDM Projects in Developing Countries

UNU-MERIT Dissertation Series, № 61

\section{Florian Tomini}

Between Family and Friend:

Understanding the Interdependency of Private Transfers

MGSoG Dissertation Series, № 15

\section{Michał Polalowski}

The Institutional Transformation of

Social Policy in East Central Europe:

Poland and Hungary in Comparative and Historical Perspective

MGSoG Dissertation Series, № 14

\section{Maha Ahmed}

Defining, Measuring and Addressing

Vulnerability: The Case of Post

Conflict Environments

MGSoG Dissertation Series, № 13

\section{Pascal Beckers}

Local Space and Economic Success:

The Role of Spatial Segregation of Migrants in the Netherlands

MGSoG Dissertation Series, № 12

\section{Victor Cebotari}

Conflicting Demands in Ethnically

Diverse Societies: Ethno political

Contention and Identity Values in

Europe

MGSoG Dissertation Series, № 11 
Dennis Gyllensporre

Competing and Complementary

Perspectives on the EU as a Crisis

Management Actor:

An Examination of the Common

Security and Defence Policy through

the Lenses of Idealism and Realism

MGSoG Dissertation Series, № 10

Judit Vall Castello

Business Cycle and Policy Effects on Labour Market Transitions of Older and Disabled Workers in Spain

MGSoG Dissertation Series, № 9

\section{Keetie Roelen}

False Positives or Hidden Dimensions:

The Definition and Measurement of

Child Poverty

MGSoG Dissertation Series, № 8

Denisa Maria Sologon

Earning Dynamics in Europe

MGSoG Dissertation Series, № 7

\section{Melissa Siegel}

Money and Mobility: Migration and

Remittances

MGSoG Dissertation Series, № 6

Jessica S. Hagen-Zanker

Modest Expectations: Causes and

Effects of Migration on Migrant

Households inSource Countries

MGSoG Dissertation Series, № 5
2009

\begin{abstract}
Alexis Habiyaremye
From Primary Commodity Dependence to Diversification and Growth:

Absorptive Capacity and Technological Catch Up in Botswana and Mauritius.

UNU-MERIT Dissertation Series,

№ 60
\end{abstract}

\section{Yoseph Getachew}

The Role of Public Capital in Economic Development

UNU-MERIT Dissertation Series, № 59

\section{Sandra Leitner}

Embodied Technological Change and

Patterns of Investment in Austrian

Manufacturing

UNU-MERIT Dissertation Series,

№ 58

\section{Semih Akçomak}

The Impact of Social Capital on

Economic and Social Outcomes

UNU-MERIT Dissertation Series, № 57

\section{Abraham Garcia \\ The Role of Demand in Technical \\ Change \\ UNU-MERIT Dissertation Series, № 56}

\section{Saurabh Arora}

Coherence in Socio-technical Systems:

A Network Perspective on the Innovation Process

UNU-MERIT Dissertation Series, № 55 


\section{Mirtha R. Muniz Castillo}

Human Development and Autonomy

in Project Aid: Experiences from four

bilateral projects in Nicaragua and $E l$

Salvador

MGSoG Dissertation Series, № 4

\section{Christiane Arndt}

Governance Indicators

MGSoG Dissertation Series, № 3

\section{Britta Augsburg}

Microfinance: Greater Good or Lesser

Evil?

MGSoG Dissertation Series, № 2

2008

\section{Rutger Daems}

Medicines for the Developing World

UNU-MERIT Dissertation Series, № 54

\section{Johannes Hanel}

Assessing Induced Technology:

Sombart's Understanding of Technical

Change in the History of Economics

UNU-MERIT Dissertation Series,

№ 53

\section{Rifka Weehuizen}

Mental Capital: the Economic

Significance of Mental Health

UNU-MERIT Dissertation Series,

№ 52

\section{Danielle Cloodt}

The Relationship between RED

Partnership Formation, Social

Embeddedness and Innovative

Performance

UNU-MERIT Dissertation Series, № 51

\section{Sabine Fuss}

Sustainable Energy Development

under Uncertainty

UNU-MERIT Dissertation Series,

№ 50

\section{Geranda Notten}

Measuring and Managing Poverty

Risks

MGSoG Dissertation Series, № 1

2007

\section{Tobias Kronenberg}

Reconciling Environmental

Conservation with Economic

Prosperity: The Feasibility of Double

Dividends in the Short and Long Run

UNU-MERIT Dissertation Series,

№ 49

\section{Viktoria Kravtsova}

Assessing the Impact of Foreign Direct Investment in Transition Economies UNU-MERIT Dissertation Series, № 48 


\section{Suhail Sultan}

The Competitive Advantage of Small and Medium Sized Enterprises: The Case of Jordan's Natural Stone Industry

UNU-MERIT Dissertation Series, № 47

2006

\section{Bulat Sanditov}

Essays on Social Learning and Imitation

UNU-MERIT Dissertation Series, № 46

\section{Mamata Parhi}

Dynamics of New Technology Diffusion: A Study of the Indian Automotive Industry

UNU-MERIT Dissertation Series, № 45

\section{Andreas Reinstaller}

Social Structures and the Innovation Process: Their Role in the Demand of Firms and Consumers

UNU-MERIT Dissertation Series, № 44

\section{Rose Kiggundu}

Innovation systems and Development:

The Journey of a Beleaguered Nile

Perch Fishery in Uganda

UNU-MERIT Dissertation Series, № 43

\section{Thomas Pogue}

The Evolution of Research

Collaboration in South African Gold Mining: 1886-1933

UNU-MERIT Dissertation Series, № 42

\section{Geoffrey Gachino}

Foreign Direct Investment, Spillovers and Innovation: The Case of Kenyan Manufacturing Industry UNU-MERIT Dissertation Series, № 41

\section{Önder Nomaler}

Technological Change, International Trade and Growth: An Evolutionary, Multi-Agents-Based Modeling

Approach

UNU-MERIT Dissertation Series, № 40

2005

Samia Satti Osman Mohamed-

Nour

Change and Skill Development in the Arab Gulf Countries

UNU-MERIT Dissertation Series, № 39

\section{Elad Harison}

Intellectual Property Rights:

Economics and Policy Analysis UNU-MERIT Dissertation Series, № 38 


\section{Daniel Dalohoun}

Learning to innovate: agricultural innovation and entrepreneurship: the case of Songhai farmers in Benin

UNU-MERIT Dissertation Series, № 37

\section{Müge Ozman}

Networks, Organizations and

Knowledge

UNU-MERIT Dissertation Series, № 36

\section{Bas Straathof}

Product Variety and Economic

Growth: The Counteracting Effects of

Scale and Idiosyncrasy

UNU-MERIT Dissertation Series, № 35

\section{Wilfred Schoenmakers}

Knowledge Flows between

Multinational Companies: A Patent

Data Analysis

UNU-MERIT Dissertation Series, № 34

\section{Myriam Cloodt}

Mergers and Acquisitions ( $M$ and As) in High-Tech Industries: Measuring the Post-M and A Innovative

Performance of Companies UNU-MERIT Dissertation Series, № 33
2004

\section{Paola Criscuolo}

RED Internationalisation and

Knowledge Transfer: Impact on MNEs and their Home Countries

UNU-MERIT Dissertation Series, № 32

\section{Maarten Verkerk}

Trust and Power on the Shop Floor UNU-MERIT Dissertation Series, № 31

\section{Gottfried Leibbrandt}

Adoption, Harmonization and Succession of Network Technologies across Countries

UNU-MERIT Dissertation Series, № 30

\section{Mark Sanders}

Skill Biased Technical change: Its Origins, the Interaction with the Labour Market and Policy Implications UNU-MERIT Dissertation Series, № 29

2003

\section{Nadine Roijakkers}

Inter-firm Cooperation in High-tech Industries: a Study of RED

Partnerships in Pharmaceutical Biotechnology

UNU-MERIT Dissertation Series, № 28 
Viki Sonntag

Speed, Scale and Sustainability

UNU-MERIT Dissertation Series, № 27

\section{Masaru Yarime}

From End-of-Pipe Technology to Clean

Technology

UNU-MERIT Dissertation Series,

№ 26

\section{Stéphane Malo}

The Combinatorial Chemistry

Revolution: Sustaining a Superior

Performance Position through

Technological Learning

UNU-MERIT Dissertation Series,

№ 25

\section{2}

\section{Annelies Hogenbirk}

Determinants of Inward Foreign

Direct Investment: the Case of the

Netherlands

UNU-MERIT Dissertation Series, № 24

\section{Bastiaan Johan terWeel}

The Computerization of the Labour Market

UNU-MERIT Dissertation Series
2001

\section{John Adeoti}

Technology Investment in Pollution Control in Sub-Saharan Africa: The Case of the Nigerian Manufacturing Industry

UNU-MERIT Dissertation Series, № 23

\section{Edward Huizenga}

Innovation Management: How

Frontrunners Stay Ahead: An

Empirical Study on Key Success

Factors in the ICT sector

UNU-MERIT Dissertation Series, № 22

\section{0}

\section{Machiel van Dijk}

Technological Change and the Dynamics of Industries: Theoretical Issues and Empirical evidence from Dutch Manufacturing UNU-MERIT Dissertation Series, № 21

\section{9}

\section{Jan Cobbenhagen}

Managing Innovation at the Company Level: A Study on Non-Sector-Specific Success Factors UNU-MERIT Dissertation Series, № 20 
Marjolein Caniëls

Regional Growth Differentials: The

Impact of Locally Bounded Knowledge

Spillovers

UNU-MERIT Dissertation Series, № 19

1998

\begin{abstract}
Aldo Geuna
Resource Allocation and Knowledge production: Studies in the Economics of University Research UNU-MERIT Dissertation Series, № 18
\end{abstract}

1996

\section{Reinoud Joosten}

Dynamics, Equilibria, and Values UNU-MERIT Dissertation Series, № 17

\section{Hugo Kruiniger}

Investment, $R \mathcal{E} D$, and the Financing

Decisions of the Firm

UNU-MERIT Dissertation Series, № 16

\section{5}

\section{Hans van Meij1}

Endogenous Technological Change:

The Case of Information Technology,

Theoretical Considerations and

Empirical Results

UNU-MERIT Dissertation Series, № 15

\section{René Kemp}

Environmental Policy and Technical

Change: A Comparison of the

Technological Impact of Policy

Instruments

UNU-MERIT Dissertation Series, № 14

\section{Rohini Acharya}

The Impact of New Technologies on Economic Growth and Trade: A Case Study of Biotechnology

UNU-MERIT Dissertation Series, № 13

\section{Geert Duysters}

The Evolution of Complex Industrial Systems: The Dynamics of Major IT Sectors

UNU-MERIT Dissertation Series, № 12

\section{Marjan Groen}

Technology, Work and Organisation: A Study of the Nursing Process in Intensive Care Units

UNU-MERIT Dissertation Series, № 11

\section{4}

\section{Huub Meijers}

On the Diffusion of Technologies in a Vintage Framework: Theoretical Considerations and Empirical Results UNU-MERIT Dissertation Series, № 10 
Theon van Dijk

The Limits of Patent Protection: Essays on the Economics of Intellectual

Property Rights

UNU-MERIT Dissertation Series, № 9

\section{Hans Voordijk}

Naar Integrale Logistiek in

Bedrijfsketens: Ontwikkelingen in de Bouw

UNU-MERIT Dissertation Series, № 8

1993

\section{Paul Diederen}

Technological Progress in Enterprises and Diffusion of Innovation:

Theoretical Reflections and Empirical

Evidence

UNU-MERIT Dissertation Series, № 7

\section{Ben Dankbaar}

Economic Crisis and Institutional Change: The Crisis of Fordism from the Perspective of the Automobile Industry UNU-MERIT Dissertation Series, № 6

\section{Hanno Roberts}

Accountability and Responsibility: The Influence of Organisation Design on Management Accounting UNU-MERIT Dissertation Series, № 5
1992

\section{Bart Verspagen}

Uneven Growth between

Interdependent Economies: An

Evolutionary View on Technology

Gaps, Trade and Growth

UNU-MERIT Dissertation Series,

№ 4

\section{Sjoerd Romme}

A Self-organization Perspective on

Strategy Formation

UNU-MERIT Dissertation Series, № 3

\section{9}

\section{John Spangenberg}

Economies of Scale, and Atmosphere in Research Organisations UNU-MERIT Dissertation Series, № 2

1988

\section{John Hagedoorn}

Evolutionary and Heterodox Innovation Analysis: A Study of Industrial and Technological Development in Process Control and Information Technology

UNU-MERIT Dissertation Series, № 1 